\title{
KNOWLEDGE ECONOMY AS AN INITIATOR OF SUSTAINABLE URBANISM IN EMERGING METROPOLISES: THE CASE OF DOHA, QATAR
}

\author{
Ashraf M. Salama, ${ }^{*}$ Florian Wiedmann, ${ }^{*}$ Alain Thierstein, ${ }^{* *}$ \\ Sven Conventz, ${ }^{* *}$ and Wafa Al Ghatam** \\ *Department of Architecture, University of Strathclyde, 75 Montrose Street, \\ Glasgow G1 1XJ, United Kingdom \\ ${ }^{* *}$ Department of Architecture, Technische Universität München, Arcisstrasse 21, \\ 80333 Munich, Germany
}

*Corresponding Authors' email address: / florian.wiedmann@strath.ac.uk / ashraf.salama@strath.ac.uk /

\begin{abstract}
This paper is a comprehensive coverage of a research project of the National Priority Research Program of the Qatar National Research Fund, entitled 'Investigating the Qualities of the Urban Environment in Emerging Regional Metropolises', and carried out between 2011 and 2014 through the joint collaboration of Qatar University and Technische Universität München. Through the shift of global economic forces Gulf cities, such as Qatar's capital Doha, are developed as central hubs between developed economies in the West and the rising economies of Asia. In the context of international competition between cities new challenges are emerging where cities need to find ways to sustain and extend their position in a globalizing world. Therefore the research process placed emphasis on the complex interrelationship of knowledge economies and spatial developments in the Gulf region. The work is premised on the assumption that non-physical economic aspects and the qualities of the urban environment are interdependent. It analyses the qualities of the urban environment of Doha as an important regional metropolis through a comprehensive investigation utilizing a set of interdisciplinary research methods that include analysis of historic documents, Delphi interview series, company network analysis, GIS analysis, cognitive mapping, behavioural studies, media surveys, attitude surveys, and space syntax analysis. The outcomes promise important results regarding urban qualities in the city of Doha culminating into various recommendations aimed at potential beneficiaries including public sector organizations, private sector and real estate development companies, and academia.
\end{abstract}

Keywords: Urbanism, knowledge economies, urban qualities, spatial transformation, sustainability, identity, Qatar

\section{INTRODUCTION}

\section{Background}

Since the 1970s cities worldwide have been competing to become international service centres within growing global networks. These 'global cities' (Sassen, 1991) have become the main drivers of the world economy and junctions through which flow transactions of people, goods and information ('space flows', Castells, 1989 and 2004 and Appadurai, 1996). This phenomenon was made possible by the introduction of new infrastructural technologies such as aviation, fibre optic wires and satellites (Alderson and Beckfield, 2007; Friedmann, 1986; Friedmann and Wolff, 1982). Thus, for any new player to be successful in entering the global network it must invest in the establishment of infrastructure that will enable it to access foreign markets and international producers. To be a truly key hub within this global network however the emerging city must attract the business of international and transnational firms and ideally their 
headquarters in order to diversify its economy toward independence from heavy industries and the export of natural resources (Beaverstock, Smith and Taylor, 2000). This kind of innovative evolution in a city's economy is highly dependent on and is driven by the presence of a population equipped with the knowledge and ambition to create and sustain new and diverse sectors and services. In turn, this kind of knowledge-based innovation and creativity, at the same time as sustaining a city's self-existence, is highly attractive to the type of international firms needed to make an emerging city a contender on the global playing field. Today, cities worldwide are facing a fierce competition to attract globally connected service sectors in order to secure economic growth (Savitch, 2002; Simmie, 2001; Simon, 1995).

One of the key challenges that particularly emerging cities in the Global South face in this competition is that many sectors of the knowledge economy, especially the advanced producer service sector, are centralized in and monopolized by the existing global cities that already possess the advantages described above. Consequently, emerging cities are engaged in intense competition for international investors to accelerate and generate the urban growth required to become the kind of agglomerations that would attract the relocation or establishment of international companies (Malecki, 2000). In this respect, tourism is a commonly used strategy to initiate urban growth and is a regarded as a marketing tool to attract investment. This is often referred to as 'city branding'. This strategy includes investment in multi-mode transport systems, cultural facilities and the development of services and amenities. In addition, the expansion of transportation capacities is needed to transform cities into global and regional trading hubs (Witlox and Derudder, 2007).

One major challenge emerging cities face is to develop an urban environment that integrates liveability parameters that would draw long-term investment. This high-quality built environment is, in contrast to the previous industrial urbanization, crucial to a city's development toward becoming an international service centre because of the expectations relevant to the liveability of cities of the high-income and qualified workforce that the city would need to attract and retain for its knowledge economies (Stillerman, 2006). Without a large body of qualified workforce successful economic diversification is not possible in contrast to other economic sectors, companies in knowledge economies are highly dependent on the long-term employment of qualified staff and thus a highly attractive urban environment (Cohen, 1981). A particular challenge in establishing these attractive environments is a rather diverse multiculturalism due to vast migration in a short period of time and the resulting complexity of various needs and perceptions (Sanderock, 1998; Salama and Wiedmann, 2013d).

In the Gulf region the initial success of Dubai's development model for establishing a regional hub by liberalizing local markets during the 1990s had a huge impact on the entire region and seemed to introduce a fast track as to how to diversify Gulf economies and enter global networks (Wiedmann, 2012). One of Dubai's early competitors was Qatar and its capital Doha, the rulers of which were keen to diversify by building on a limited but key number of elements in contrast to Dubai's less discriminating approach. While Dubai has pursued development in almost all its economic sectors in parallel, Doha has focused on specializing in its main sectors only and developing its future economic role in the global network (Adham, 2008). In this respect, exclusivity defines its economic development strategy rather than undefined expansion. Today international sports events and investment in cultural projects have been attracting regional and worldwide attention (Salama and Wiedmann, 2013a \& b).

One unique aspect of contemporary urbanism in the Gulf is the generation of cities in the desert supplied with state-of-the-art infrastructure intended to attract global immigration and transform these newly built shells into vibrant business centres (Fox, Mourtada-Sabbah and AlMutawa, 2006). The possibility of applying this approach to the development of cities from scratch is enabled not only by the remaining wealth of oil resources but also by the potential of the Gulf's geopolitical location close to rising markets in Asia, which is of great interest to regional and 
international speculation. While in global cities urban governance has reacted to expanding knowledge economies by accommodating their specific needs, leading to a morphological transformation of cities, urban governance in the Gulf has itself been the initiator of space for evolving knowledge economies. This can be seen in the recent public investment in the development of infrastructure and the introduction of marketing strategies to attract international attention (Salama, Wiedmann and Thierstein, 2013).

Over the years as the number of immigrants has increased, an 'airport society' with an everexchanging population has evolved. In this context policy makers and planners must draw plans and construct visions for entire cities that should foster urban consolidation. However, the urban population that should be served by these plans is as yet unknown while architects who must design buildings for this undefined society are left with little orientation other than generic forms and traditional decoration in a commercially driven urban environment. A successful diversification process relies on the integration of all the complex needs of knowledge economies in all layers of urban development. The successful establishment of knowledge economies in emerging cities such as Doha relies on a highly diverse and efficient urban environment with a certain degree of unique identity (Salama, 2012; 2013; 2014). Thus, there is an increasing need to analyse contemporary urbanism in the Gulf region in order to detect the factors that contribute to urban qualities as well as consequences for the successful establishment of knowledge economies (Wiedmann et al., 2014). Today, Knowledge based economies have been identified as the key driver for spatial and urban development processes. They include services, high tech industries, and higher education institutions, and are characterized by strong international presence and transnational practices. Yet, how exactly can cities balance the pressure of rapid urban growth and the increasing need for urban qualities to become attractive hubs for the international elite of companies and their employees is at the core of this investigation.

\section{Key objectives of the research project}

This research project aims to deliver in-depth insights into the various mechanisms of urbanism in an emerging city, whose development is mainly driven by public investments in establishing new knowledge economies to gain independence reliance on oil resources. Due to the very particular roots of Doha as one of the most recently emerging cities in the Gulf region, four key objectives can be pursued. They are envisaged as a series of questions to provide a multi-dimensional view on the interdependencies between economic and urban and spatial transformation processes:

1) How urban governance evolved historically and how it is structured today: Urban governance has a direct impact on urban transformation processes by introducing new public investment strategies as well as a new development vision and subsequent physical planning. The project aims to analyse the various forms of how urban governance is rooted in Qatar and how it is transforming to accommodate the new challenge to establish a diversified economy including the introduction of new master planning processes.

2) How companies establish networks within their local surroundings, the region, and worldwide: The new knowledge economies have led to a complex network of multi-branch companies, which have established their offices in Doha. In order to understand the local, regional and global connectivity of the new economic sectors, the various networks should to be analysed. Based on these network analyses the various degrees of connectivity can be explored, which is a main indicator for the current state of economic transformation in Qatar and its capital city.

3) How the emerging 'creative class' uses and perceives their urban surroundings: Due to the investment into establishing new economic sectors in addition to the subsequent construction boom a large number of highly educated migrants have moved to Doha. This 
new socioeconomic class, often referred to as 'creative class' (Florida, 2002), is decisive to redefine urbanism in an emerging city. The project thus aims to examine how this new social group is living in Doha and how individuals perceive their new surroundings depending on their cultural and socio-economic backgrounds. Moreover, the project aims to understand how public spaces are used by this expanding migrant groups.

4) How spatial structures have been transformed to accommodate the needs of companies and inhabitants as well as the high urban growth rate itself: In addition to the various factors defining urban development, the project aims to deliver insights into the spatial dimension of urban growth as well as the very particular redefinition of new urban centres and their spatial accessibility in order to adjust to new economies and their spatial practice.

\section{METHODOLOGICAL APPROACH}

\section{Research framework based on Henri Lefebvre's theory of space production}

The first research stage involved the implementation of a research framework, which would enable the interdisciplinary research of the complex interrelationship between spatial developments and the dynamics of emerging knowledge economies. The framework was developed on the basis of an extensive literature review regarding the theory of space production in emerging cities. After a first review Henri Lefebvre's theory of space production has been detected as a main basis for a framework that combines analyses of all the various factors that impact urban growth and development. Lefebvre expressed his idea of the production of space using a triad that amalgamates three types of spaces: the conceived, the perceived and the lived.

Firstly, Lefebvre defined 'conceived space' as the space conceptualized by scientists, planners, social engineers, etc., also known as 'representations of space'. These representations are abstract as they are rooted in the principles, beliefs and visions held by such practitioners, decision makers and others who are in a position to impose their personal notion of 'order' on the concrete world and so create a practical impact on space within social and political practice (Lefebvre, 1991, p. 41). 'Perceived space' is the space of 'spatial practice', which Lefebvre defined as the space where movement and interaction take place, where networks develop and materialise. Thus, it includes both daily routines on an individual level and urban realities such as the networks that link places designated for work, leisure and 'private' life (Lefebvre, 1991, p. 38). Lastly, 'lived space' is understood by Lefebvre as the unconscious, non-verbal direct relation between humans and space. Also known as 'representational space', it is directly lived through associated images and symbols (Lefebvre, 1991, p. 39). Products of representational space are often symbolic works such as art, design and aesthetic trends (Lefebvre, 1991, p. 42).

Based on Lefebvre's ideas, the production of urban space can be analysed by investigating each factor in this process using the perceived-conceived-lived triad (Figure 1). Thus, all the factors that affect the nature and structure of the urban fabric in the production of space in emerging cities such as Doha can be sought for and examined with a special focus on understanding the role of knowledge economies and their impact. Thus, a framework has been developed in which all aspects are analysed utilizing various methodologies in order to investigate the development of urban qualities in direct relation to factors that weaken or strengthen them. 


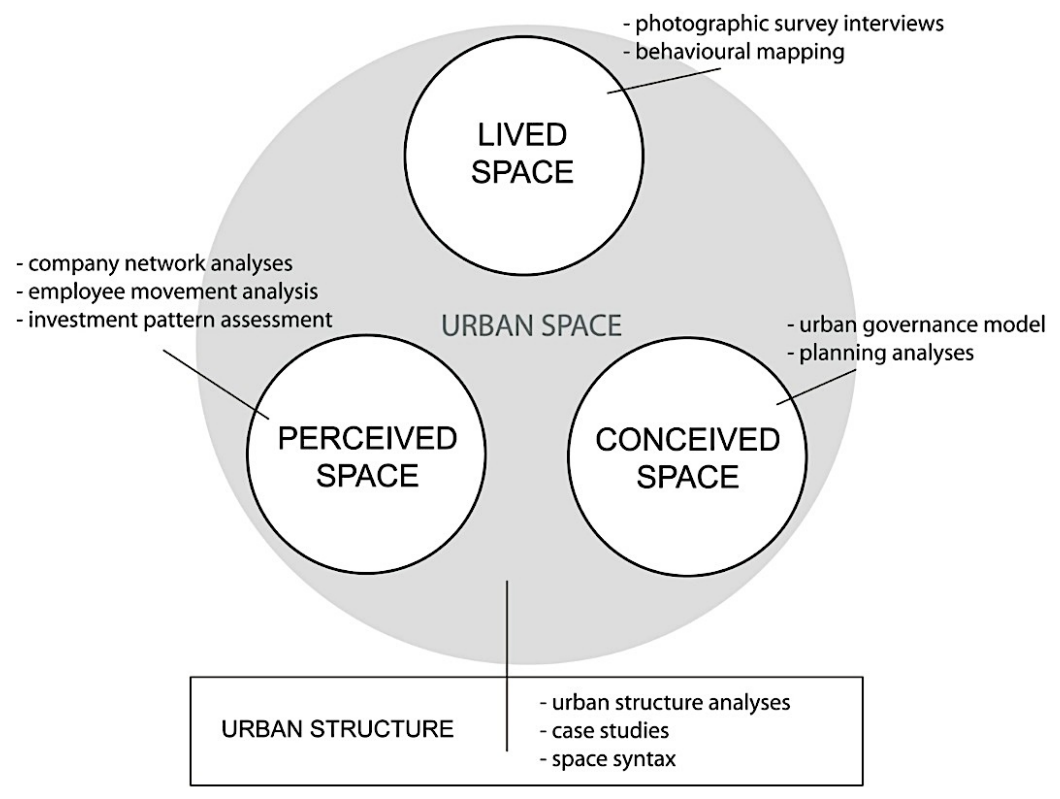

Figure 1. Framework model (Source: Authors).

\section{Research tools and techniques}

The framework involves comprehensive analyses of urban planning decision making processes as well as in-depth investigation that applies interlocking network models to examine how urban space is currently used by companies and knowledge intensive economic sectors. Taking into account the importance of the role played by the employees working in these companies and their perception of contemporary urban space in the city, the framework employs empirical research approaches that involve survey studies, focused interviews, observation, and behavioural mapping. In addition to investigating the various factors driving spatial transformation, the evolutionary aspects of the city's urban structure are traced and analysed using GIS data and space syntax studies. The framework is based on three main hypotheses:

- Urban space is a product of conscious decision making within the public sector.

- Urban space is a product of the collective spatial practice of all users.

- Urban space is a product of accumulated subjective attachment and identification.

Based on these three main factors producing urban spaces and thus urban qualities, the research team developed a unique set of four main research modules to explore the emerging and newly urbanised areas of Doha:

- The analysis of past and present urban governance.

- The investigation of how the urban environment is used by companies, inhabitants and developers.

- The exploration of how the existing urban environment is perceived by inhabitants.

- The examination of the resulting spatial configuration and current development tendencies.

The nature of the preceding questions, objectives, and hypothesis required the development of a trans-disciplinary approach. More than nine different methodologies were envisaged:

a) Evaluation of Historic Documents: In order to understand current urban development dynamics and the urban structure itself the historic development of Doha was explored by evaluating historic maps and statistics as well as reports. Key data were gathered from the Ministry of Municipality and Urban Planning (MMUP), which provided the project team 
with GIS data and high-resolution aerial photography of Doha from 1947, 1959, 1971, 1977 and 1988.

b) Delphi Interview Series: An interview series with ten urban planning officials was implemented on the principles of the Delphi interview methodology. The Delphi method is a frequently used communication technique, originally developed as a systematic, interactive forecasting method, which relies on a panel of experts. In the case of this project ten experts responded to questions in two rounds. After the first round the experts were informed about the evaluated first interview results as well as the reasons they provided for their judgments. Thus, all planning officials could revise their earlier answers in light of the replies of other members of their panel. During this process the range of the answers decreased and the group converged towards certain responses. Finally, the process was stopped and the mean or median scores of the final round determined the results.

c) Company Network Analysis: The main objective of this analysis was to clarify global and local connectivity of multi-branch companies within international and regional company networks. After the selection of 160 multi-branch companies within advanced producer service and high tech sectors by using company data networks, such as the regional data base Zawya, the company network analysis was implemented. It encompassed three main methodologies:

- Interlocking network analysis: The interlocking network analysis estimates the connectivity of cities from the intra-firm office networks of multi-branch multi-location enterprises. It is based on the methodology of the Globalization and World Cities Study Group (GaWC). The primary output of this analysis is a model of network connectivity; a measure that estimates how well connected a location is within the overall intra-firm network.

- Value chain analysis: Knowledge exchange and business activities do not only arise through intra-firm branch office networks, but primarily from the division of labour between companies in one city. By means of a web survey that combines relational data on firm locations with the degree and importance of working interrelationships along individual firms' chain of value light was shed on the value added process of companies.

- Face-to-face interviews with business practitioners: In addition to the interlocking network analysis and the value chain analysis, the company network analysis included a series of in-depth face-to-face interviews with senior business practitioners and organizations.

d) GIS Analyses: Based on GIS data from 2003, 2006, 2009 and 2012 the land use development and urban growth rate were investigated by using the software application ArcGIS. Basic GIS data were provided by the Ministry of Municipality and Urban Planning. The data set included the contemporary state of urban development. In order to investigate previous development stages the project team reduced the GIS data from 2012 manually by comparing the data to high-resolution satellite images. Subsequently all data were extracted and evaluated. In addition to the calculation of settlement growth and land use distribution the project team calculated the distances between residences and main weekly activities of employees engaged in high service sectors. Therefore, the locations of residences, working places, preferred grocery stores and leisure spaces were assessed based on 130 questionnaire respondents and integrated within the GIS model of Doha. Subsequently the average distances were calculated and evaluated depending on the various locations of inhabitants.

e) Cognitive Mapping: Cognitive mapping was utilized, which is composed of a series of psychological transformations by which individuals acquire, code, store, recall, and 
decode information about the relative locations and attributes in their everyday spatial environment. In order to examine the experience of the city's inhabitants in terms of movement and their comprehension of the city in terms of where they live, work, entertain, and what travel routes they use, a survey questionnaire was developed with two objectives in mind. The first aim was to gather data for interpretations of how the city is experienced based on the inhabitants' reactions to certain parameters, rather than utilizing the more standard practice of reading and interpreting the city based on analyses of reports by specialized professionals or observers. The second objective was to investigate the way in which inhabitants perceive movement in the city in relation to the geographical locations most important to them such as living areas, work areas, and the public places they frequent.

f) Behavioural Studies: The investigation of human behaviour within urban environments is a key to understand the various qualities as well as shortcomings of certain spatial configurations (Rapoport, 1990 and 2005). In order to implement a wider analysis of behavioural patterns and trajectories the project team envisioned mapping the movement and activity within 12 key urban open spaces by systematically recording them at different times of the day and week. The 12 key spaces were selected according to a preliminary evaluation of questionnaires regarding most frequently visited urban spaces. The observation records provided the project team with data representing the dynamic use of the selected spaces and facilitated comparison between different spaces in terms of broad similarities and differences in use and user types. This methodology of behavioural observation added an important quantitative perspective on the subject of how the urban environment is being used by inhabitants.

g) Media Survey: Printed media also has a significant impact on the impressions the readers develop and the mental images they acquire as a result of their reading (Salama, 2013). Such an impact is based on a number of factors, namely, the credibility of the media and the way in which their content is presented, understood, and interpreted. In essence, printed media plays a key role in building an image in the minds of readers, especially when targeting specific groups. In answering the question of how Qatar wants to portray itself and its capital Doha to the global community in the printed media, an examination of the influence of printed media was conducted. Two important monthly magazines were selected: Oryx, the official in-flight magazine of Qatar Airways, and Edge magazine, which represents itself as Qatar's catalyst for business.

h) Attitude Surveys and Questionnaires: 350 Employees of 30 different companies participated in an attitude survey regarding the quality of urban life in Doha. Questionnaire forms were distributed after an official agreement has been met between the project team and the company managements. The questionnaire placed emphasis on the assessment of the individual perception of Doha regarding the quality of urban life. Participants received multiple-choice questions regarding mobility, housing, working environments, services and leisure spaces. They were also asked to provide the project team with their general information, such as age group, country of origin and how many years they have stayed in Doha. The final section of the questionnaire included a short photographic survey of key urban spaces in Doha in order to examine how attractive or alienating certain urban spaces are perceived by a majority of participants. In addition to the quantitative evaluation of questionnaires, questionnaires were evaluated regarding the role of the cultural backgrounds of participants.

i) Space Syntax Analyses: Based on the theories of Bill Hillier (1999) Space Syntax was implemented to investigate spatial development and transformation patterns. By elaborating a comprehensive Space Syntax model of Doha the various levels of spatial integration were analysed with a focus on the general layout of the city as well as the 
locations of business centres. The space syntax method enabled the project team to assess the data gathered during the GIS analyses systematically. Configuration is considered a key quality of space on a local as well as on an urban scale, since it affects movement patterns, public-private delineation and environmental conditions. The two Space Syntax analysis methods of Doha's street network included Integration and Choice. Integration measures how many turns one has to make from a street segment to reach all other street segments in the network, using shortest paths. The street segments that require the least amount of turns to reach all other streets are called 'most integrated' and are usually represented with hotter colours, such as red or yellow. Integration can also be analysed in local scale, instead of the scale of the whole network. Choice measure is easiest to understand by imagining water flowing in the street network. Each time an intersection appears, the remaining value of flow is divided equally amongst the splitting streets, until all the other street segments in the graph are reached. The streets with the highest total values of accumulated flow are said to have the highest choice values. Both Space Syntax methods were applied to investigate the general spatial configuration of Doha and its evolution. Furthermore, the spatial integration of company locations was examined by implementing the Integration technique.

\section{RESEARCH MODULES}

\section{RESEARCH MODULE I: INVESTIGATING THE 'CONCEIVED SPACE'}

\section{The historic evolution of urban governance in Qatar}

In order to understand the complex dynamics of contemporary urbanism in Doha the historic evolution of the city and its various transformations were explored. Many current developments are still heavily affected by the first modernization period, which took place during the 1950 s and 1970s when the oil production began (Wiedmann, Salama and Thierstein, 2012). Based on the evaluation of aerial photography and satellite images from the years 1947, 1959 and 1971 and 1977 and 1988 as well as the time period from 2003 to 2011 the historic urban development was analysed. The main objective of this methodology was the elaboration of comparative maps in order to illustrate the rapid growth of the city between 1947 and 2011. In addition various technical reports as well as publications of previous studies were evaluated with respect to planning policies and spatial urban development in order to gain insights into the various factors impacting urban transformations in Qatar. This included the evaluation of population growth statistics as well as the analysis of immigration patterns.

At first the research team focused on the origin of Doha, which was founded during the 19th century, and the historic social, economic and environment context of its initial settlement. Therefore historic photography from the 1940s was evaluated in order to analyse the built environment and architecture of that time period. This study led to the identification of the first settlement areas regarding their location, size as well as role. As many Gulf cities historic Doha was a small port settlement spread along the coast. In addition fishing and pearl diving was one of the key economic drivers at the beginning of the 20th century (Al Buainain, 1999).

As second step the historic documents from the time period between the 1950s and 1980s, when the oil production commenced and led to rapid urban growth, were evaluated. The main objective was to explore the socio-economic transformation as well as its impact on the urban environment. First infrastructural networks became the key drivers of spatial development, which was not yet guided by a local planning department.

The final step was the investigation of how new development dynamics during the past 20 years were a direct result of new urban development strategies introduced during the 1990s. Therefore various documents were evaluated including official public reports. The main outcome has been a set of comparative maps illustrating the rapid urban growth during the last 70 years. 
The recent mega projects have redefined Doha, which grew to a metropolis covering a region of almost 2 million inhabitants. The continuous urban sprawl and the focus of developments along the shoreline have led to the contemporary urban structure of Doha (Wiedmann and Salama, 2013).

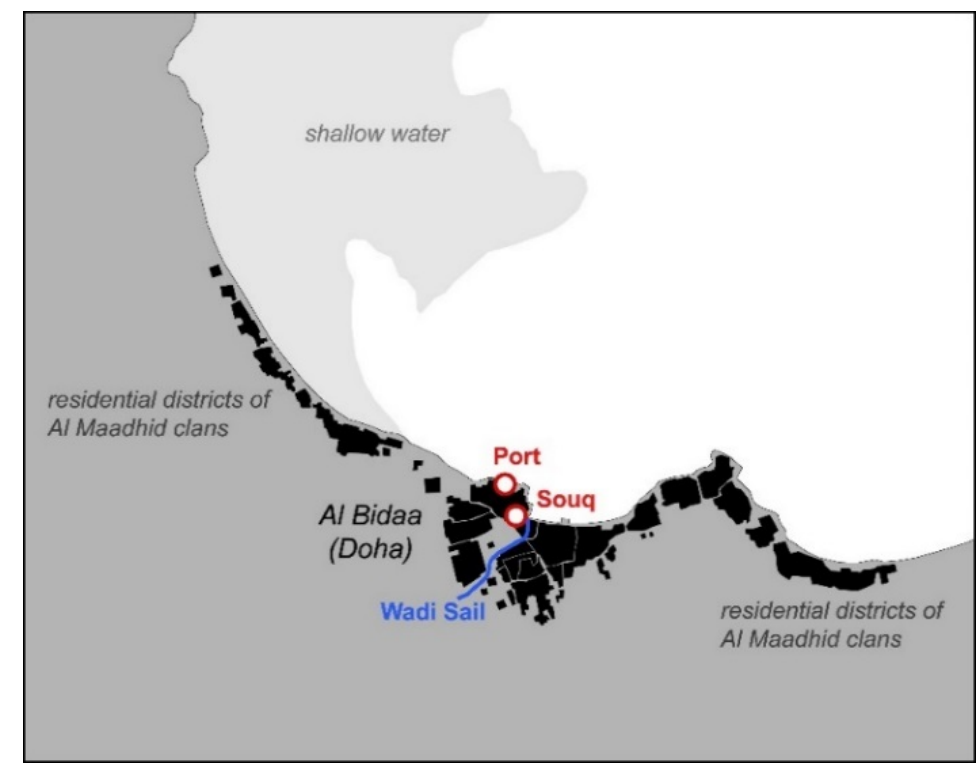

Figure 2. An elaborated map of the historic settlement of Doha in 1947 (Source: Authors, 2012).

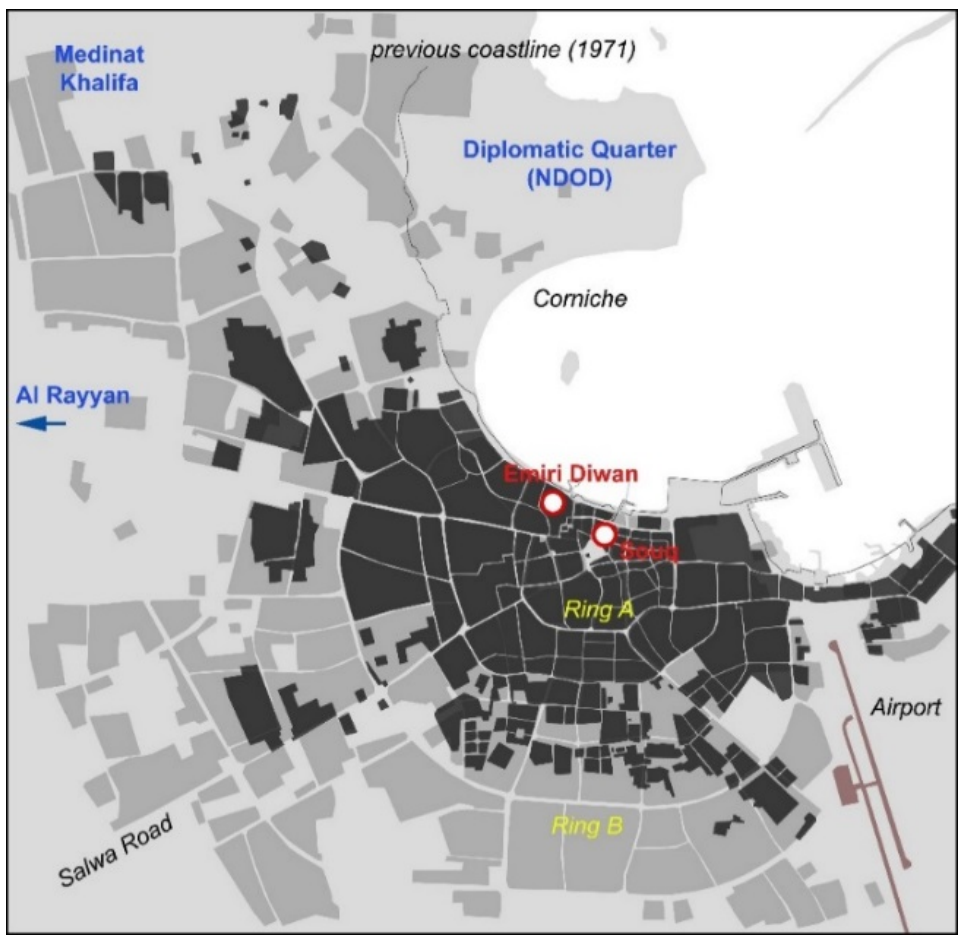

Figure 3. A comparative illustration of urban growth in Doha during the oil boom in 1971 (Source: Authors, 2012). 


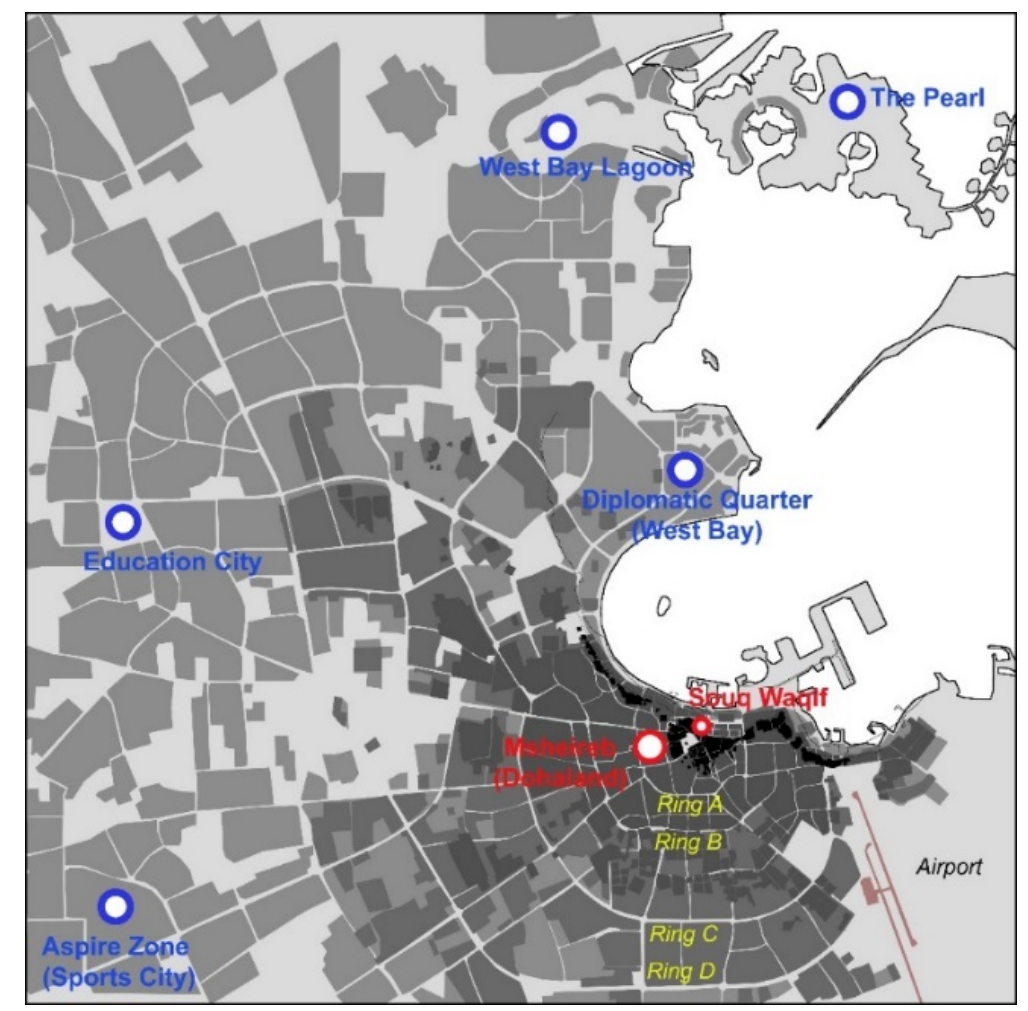

Figure 4. A comparative illustration of the contemporary settlement expansion (Source: Authors, 2012).

\section{Urban planning analyses}

Based on the elaborated research framework public urban planning was analysed in order to understand the impact of decision making on spatial developments as well as interdependent economic developments. Thus, an interview series with senior urban planners at the Ministry of Municipalities and Urban Planning was carried out at the end of 2011. All in all, ten key planning authorities at the Qatar National Master Plan department of the Ministry of Municipalities and Urban Planning (MMUP) were interviewed. The interviews were carried out by following the principles of the Delphi methodology and by using a matrix of a limited number of key questions. The ten interviewees were selected according to their role in developing and implementing new strategies and plans.

All ten interviewees are involved in key positions analysing and evaluating urban developments. The major aim was the investigation of main public development strategies that have been launched as well as the identification of all factors having led to a decentralized form of urban governance and the definition of consequences regarding urban structure and built environment. After the first series of interviews, which was evaluated to identify the most frequent answers, the participants were asked in a second round to respond to a questionnaire built on these assessed interviews in order to identify the most important investments and decentralization factors within governance as well as the most significant consequences for contemporary urban morphologies. They rated the importance in their view of the various items on a scale from 1 (least important) to 5 (most important).

In addition to the series of interviews all recently published documents by government agencies have been examined. The main effort was centred on the evaluation of the Qatar National Vision and the Qatar National Development Strategy (GSDP, 2008, 2009 and 2011). 
Table 1. Summary of key interview questions (Source: Authors, 2012).

\begin{tabular}{|c|}
\hline I. Public Development Strategies \\
\hline 1. What major investments were carried out by the public sector over the last 15 years? \\
\hline 2. Which public organisation is behind these investments? \\
\hline 3. What are the particular projects within each development sector? \\
\hline II. Urban Governance \& Planning \\
\hline 1. How has urban governance changed since the 1990 s? \\
\hline 2. What were the factors for the decentralisation process of urban planning? \\
\hline 3. How is urban governance currently being restructured? \\
\hline III. Urban Morphologies \\
\hline 1. How did urban morphologies change during the last ten years? \\
\hline 2. What was the particular impact of recent strategies on existing urban structures? \\
\hline 3. Which new urban typologies were introduced? \\
\hline
\end{tabular}

Based on the evaluated interview series the ten urban planners from the MMUP identified five main public development strategies to establish Doha as an international and regional service hub: (1) Real Estate, (2) Infrastructure, (3) Cultural Events, (4) Education \& Science and (5) News \& Media. Public engagement and investment in real-estate projects were seen as the main factor impacting recent urban growth and spatial transformations (Table 2). The subsequent construction boom has shaped contemporary Doha not only morphologically but also socioeconomically due to the businesses and foreign workers that have moved there as a result. In addition, the interviewees are convinced that in future, urban developments in Qatar will be primarily driven by public investments in infrastructural projects. This is a clear indicator of an increasing demand in consolidation strategies. Future projects such as the Doha Metro are perceived as new catalysts in reconfiguring general urban morphologies in Doha.

Table 2. The evaluated interviews regarding public strategies (Source: Authors, 2012).

\begin{tabular}{|l|l|}
\hline \multicolumn{1}{|c|}{ I. Public Strategies } & $\begin{array}{l}\text { Which public strategies have } \\
\text { had the biggest impact on } \\
\text { urban developments over the } \\
\text { last 15 years? }\end{array}$ \\
\hline A. Real Estate & $40 / 50$ \\
\hline B. Infrastructure \& Services & $31 / 50$ \\
\hline C. Culture \& Sports & $29 / 50$ \\
\hline D. Education \& Science & $29 / 50$ \\
\hline E. News \& Media & $13 / 50$ \\
\hline
\end{tabular}

\begin{tabular}{|l|l|}
\hline \multicolumn{1}{|c|}{ I. Public Strategies } & $\begin{array}{l}\text { Which public strategies will } \\
\text { have an increasing impact on } \\
\text { urban developments in the } \\
\text { future? }\end{array}$ \\
\hline A. Real Estate & $31 / 50$ \\
\hline B. Infrastructure \& Services & $42 / 50$ \\
\hline C. Culture \& Sports & $33 / 50$ \\
\hline D. Education \& Science & $38 / 50$ \\
\hline E. News \& Media & $13 / 50$ \\
\hline
\end{tabular}

Furthermore, all interviewees encountered a weakened position of public urban planning in recent years when compared to the 1980s and 1990s. Four main factors for the decentralization of urban governance were identified by the interviewees: Insufficient staff capacity, inefficient organizational structures, extensive legal rights of private and semi-public developers and outdated master and zoning plans. Most interviewees shared the opinion that inefficient organizational structures in combination with out-dated existing policies were the main factors for the decentralization of urban planning in Qatar (Figure 5). Additionally, staff capacity deficits exacerbated and accelerated this process, particularly at the beginning of the construction boom. The allocation of legal rights to master developers regarding the design and implementation of 
zoning plans was however seen as the least important factor in spite of its indisputable role in decentralizing urban planning.

Table 3. The evaluated interviews regarding urban governance

(Source: Authors, 2012).

\begin{tabular}{|l|c|}
\hline \multicolumn{1}{|c|}{ II. Urban Governance } & $\begin{array}{l}\text { What were the main factors for } \\
\text { the decentralisation of urban } \\
\text { planning? }\end{array}$ \\
\hline A. Staff capacity & $38 / 50$ \\
\hline $\begin{array}{l}\text { B. Organisational structure - lack of } \\
\text { coordination and monitoring }\end{array}$ & $43 / 50$ \\
\hline C. Legal rights of Master Developers & $29 / 50$ \\
\hline D. Outdated zoning plans and regulations & $42 / 50$ \\
\hline
\end{tabular}

By referring to the urban structure analysis interviewees were asked to identify the most significant morphological consequences of recent urban development resulting in the main challenges for future urban planning. According to the evaluated interviews the fragmented patchwork structures caused by mega-projects are perceived as the main resulting characteristic and challenge of the recent construction boom. Furthermore, the increased sprawl of low rise residential developments and the deficient standards in construction are seen as major consequences. Other challenges have been identified in form of an increasing privatization of urban space and thus limited access for public planning as well as an increasing urban density due to high rise clusters in certain areas, like West Bay, where the main challenge is to integrate sufficient infrastructure.

Table 4. The evaluated interviews regarding urban morphologies

(Source: Authors, 2012).

\begin{tabular}{|l|c|}
\hline \multicolumn{1}{|c|}{ III. Urban Morphologies } & $\begin{array}{l}\text { What are the main } \\
\text { consequences for the current } \\
\text { urban structure and built } \\
\text { environment? }\end{array}$ \\
\hline A. Patchwork structures & $47 / 50$ \\
\hline $\begin{array}{l}\text { B. Expanding peripheries - continuous } \\
\text { urban sprawl }\end{array}$ & $37 / 50$ \\
\hline C. High rise clusters & $25 / 50$ \\
\hline $\begin{array}{l}\text { D. Construction standards - low quality vs. } \\
\text { land mark design }\end{array}$ & $35 / 50$ \\
\hline E. Privatised urban landscapes & $33 / 50$ \\
\hline
\end{tabular}

Based on recent planning documents and separate interviews with the management of the planning department the organizational structure of contemporary urban planning was explored. The result has been an organizational chart of all public bodies involved in urban planning today (Figure 5).

Since 2008 and the official introduction of the Qatar National Vision the General Secretariat of Development Planning (GSDP) has occupied a key role in analysing and defining development goals (GSDP, 2008 and 2009). In 2011 the Qatar National Development Strategy was introduced to define more detailed development goals for the year 2016 (GSDP, 2011). While the GSDP has been in charge of a macro vision for the entire nation and its economic development direction, the Ministry of Municipality and Urban Planning (MMUP) has elaborated the Qatar National Master Plan in parallel by following the general development goals. The Qatar National Master Plan itself is divided into a macro planning framework, known as Qatar National Development Framework, 
defining the key spatial development strategies and Municipal Spatial Development Plans in order to implement new regulations. In addition to the MMUP and its various departments, Ashghal (Ministry of Public Works) has played a key role in redefining development patterns and the general speed of urban growth in Qatar.

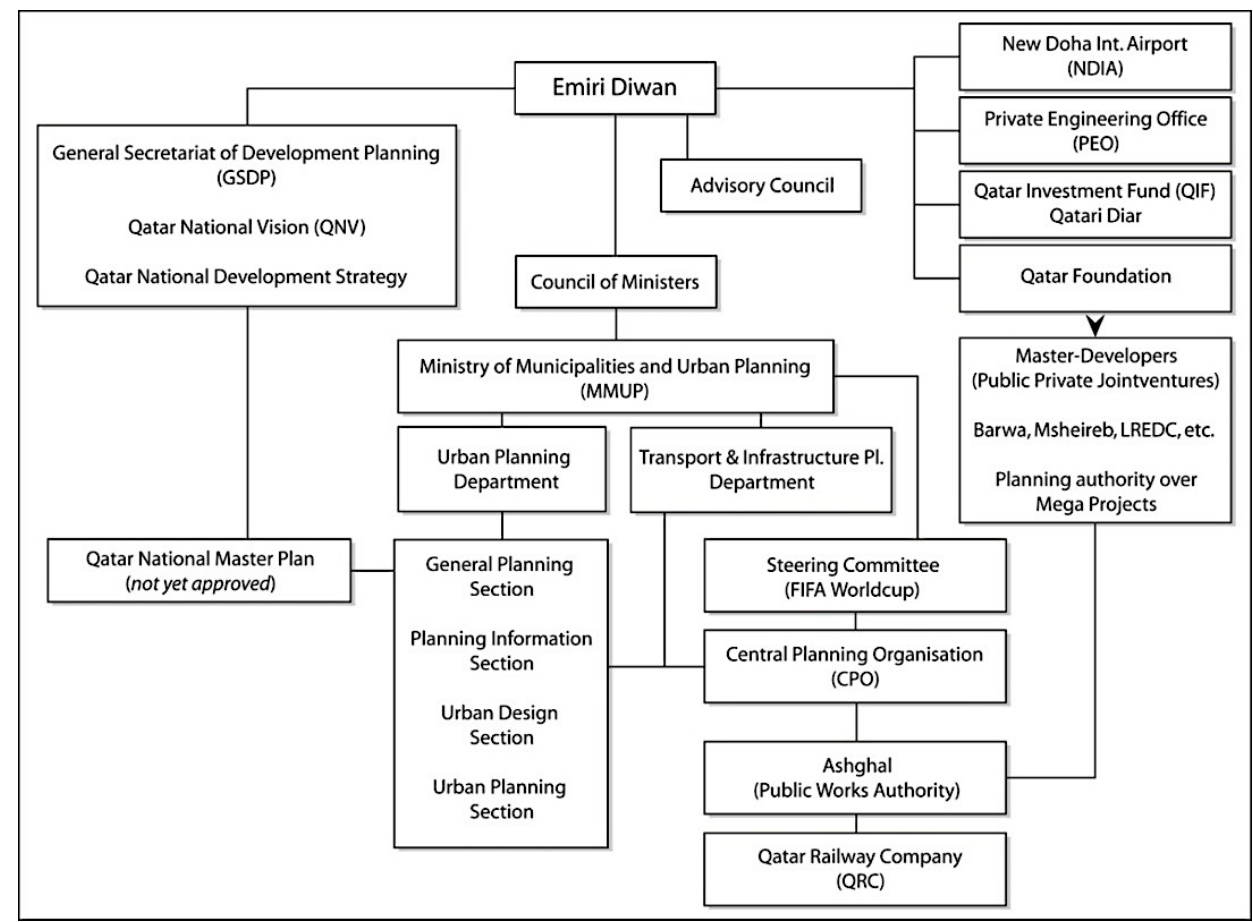

Figure 5. An organizational chart of public urban planning in the case of Qatar (Source: Authors, 2012).

\section{RESEARCH MODULE II: INVESTIGATING THE ‘PERCEIVED SPACE’}

\section{Company Network Analysis}

In order to assess the current state of emerging knowledge economies in the case of Doha a comprehensive company network analysis was implemented. Main objective of this research module was to clarify how international multi-branch companies are connected regionally and globally as well as to investigate how companies are locally connected in the case of their value chains. The in-depth understanding of company networks and their development is an important indicator for economic and subsequently spatial development tendencies (Lüthi et al., 2010). To understand the structure of the current patterns of knowledge-based companies in Qatar's capital city it was necessary to investigate their functional logic and the networks in which the firms interact. The project team analysed the networks of multi-branch firms and measured the flows of information between business partners and their locations on different spatial scales.

The analysis of the intra-firm networks is based on the methodology of the GaWC at Loughborough University. This approach estimates city connectivity from the office networks of multi-location of APS and High-Tech firms. The basic premise of the model is that the more important the office, the greater its flow of information to other office locations. In the first stage of this empirical work, a company database was created. In identifying knowledge-based firms within the emerging city of Doha the Zawya Database was utilised. The firms were allocated to the sectors using its (NACE) codes (Table 5). The following lines of business have been analysed in the present research project: 
Table 5. Operationalization of the knowledge-economy with NACE-codes (GaWC)

(Source: Authors, 2012).

\begin{tabular}{ll}
\hline High-Tech & Advanced Producer Services (APS) \\
\hline Chemistry \& Pharmacy & Banking \& Finance \\
$2330,2413,2414,2416,2417,2420,2441$, & $6511,6512,6521,6522$, \\
$2442,2451,2461,2463,2464,2466,2511$, & $6523,6711,6712,6713$, \\
2513,2615 & 7011,7012 \\
Machinery & Advertising \& Media \\
$2911,2912,2913,2914,2924,2931,2932$, & $7440,2211,2212,2213$, \\
$2941,2942,2943,2952,2953,2954,2955$, & $2214,2215,9211,9220$, \\
2956,2960 & 9240 \\
Electronics & Information and Communication Services \\
$3110,3120,3140,3150,3161$, & $6430,7221,7230$, \\
$3162,3210,3320,3330$ & $7240,7250,7260$ \\
Computer-Hardware & Insurance \\
3001,3002 & $6601,6602,6603$ \\
Telecommunication & Logistics $(3 p$ \& 4p) \\
3220,3230 & $6030,6110,6220,6230,6340$ \\
Medical \& optical instruments & Management-and IT-Consulting \\
3310,3340 & $7210,7222,7413,7414,7415$ \\
Vehicle construction & Design, Architecture \& Engineering \\
$3410,3430,3511,3520,3530$ & 7420,7430 \\
& Law \\
& 7411 \\
& Accounting \\
& 7412 \\
\hline
\end{tabular}

In addition to this, the collected firms were crosschecked and where necessary completed with a company list provided by the GaWC Research Group and by Forbes. All in all, 162 knowledge-intensive companies have been identified and mapped. To carry out an interlocking network analysis requires the construction of the so-called service activity matrix. Each cell in the matrix is a service value that indicates the importance of the location $i$ to firm $j$. The importance is defined by the size of an office location and its function. By analysing the firms' website, all office locations are rated on a scale of zero to five. In a first step, the connectivity between two locations $(a, b)$ of a certain firm (j) is analysed by multiplying their service values $(v)$. In this respect, the following equation respects the so-called elemental interlock between two locations for one firm:

$$
\mathrm{rabj}=\mathrm{vaj}{ }^{*} \mathrm{vbj}
$$

To calculate the total connectivity between two locations, the elemental interlock for all firms located in these two locations has to be summarized. This leads to what is known as the city interlock (rab):

$$
\mathrm{rab}=\sum \mathrm{rabj}
$$

Aggregating the city interlocks for a single location produces the interlock connectivity $(\mathrm{Na})$. This describes the overall importance of a location within the network:

$$
\mathrm{Na}=\sum \text { rai } \quad(\mathrm{a} \neq \mathrm{i})
$$

Finally, if we relate the interlock connectivity for a given city to the city with the highest interlock connectivity, we gain an idea of its relative importance in respect to the other cities that have been analysed. These scores - creating a scale from 0 to 1 - will be used to indicate hierarchical tendencies. 
Table 6. Numerical values of global connectivity of Qatari advanced producer services (Source: Authors, 2012).

\begin{tabular}{|c|c|c|c|c|}
\hline Rank & City & Country & $\begin{array}{c}\text { Gross } \\
\text { Connectivity }\end{array}$ & $\begin{array}{r}\text { Proportio nate } \\
\text { Con nectivity } \\
\text { (1=New York) }\end{array}$ \\
\hline 1 & New York & United States & 60747 & 1,00 \\
\hline 2 & London & United Kingdom & 59431 & 0,98 \\
\hline 3 & Hong Kong & China & 49972 & 0,82 \\
\hline 4 & Tokyo & Japan & 49216 & 0,81 \\
\hline 5 & Paris & France & 48042 & 0,79 \\
\hline 6 & Singapore & Singa pore & 47210 & 0,78 \\
\hline 7 & Sydney & Australia & 47056 & 0,77 \\
\hline 8 & Frankfurt & Germany & 46364 & 0,76 \\
\hline 9 & Milan & Italy & 46124 & 0,76 \\
\hline 10 & Shanghai & China & 45474 & 0,75 \\
\hline 11 & Sao Paulo & Brazil & 44515 & 0,73 \\
\hline 12 & Vienna & Austria & 44171 & 0,73 \\
\hline 13 & Dubai & United Arab Emirates & 43684 & 0,72 \\
\hline 14 & Hamburg & Germany & 42838 & 0,71 \\
\hline 15 & Istanbul & Turkey & 41961 & 0,69 \\
\hline 16 & Moscow & Russia & 41811 & 0,69 \\
\hline 17 & Copenhagen & Denmark & 41772 & 0,69 \\
\hline 18 & Madrid & Spain & 41771 & 0,69 \\
\hline 19 & Mumbai & India & 41302 & 0,68 \\
\hline 20 & Prague & Czech Republic & 41030 & 0,68 \\
\hline
\end{tabular}

Table 6 shows the spatial dimension of intra-firm connectivity for Doha and illustrated the 20 most intensively connected locations on an international scale. New York as the world's most important financial centre shows the highest interlock connectivity value for APS firms based in Doha. This finding indicates that these APS firms most often choose New York as their second most important location. APS firms based in Doha show a strong orientation towards Europe and Asia. Among the top 20 agglomerations two are located in the Americas; six are located in Asia, one in Australia while the majority of 10 cities are situated in Europe. With Moscow, Sao Paulo, Shanghai / Hong Kong and Mumbai four cities of the emerging BRIC-States are represented among the 20 most connected cities. Within the Gulf region the neighbouring city of Dubai, the region's top economic centre, shows the most intensive connectivity patterns with Doha.

Figure 6 shows the spatial patterns of the intra-firm connectivity between APS firms on supra regional scale. The thickness of the lines and the darkness of the colour illustrate the relative connectivity between the different cities on a supra-regional scale. These connectivity values are related to the highest interlock connectivity of the case study, which is the connection between Doha and Dubai. On the supra-regional level connections to the United Arab Emirates' cities of Dubai, Abu Dhabi, Al-Ain and Sharjah seem to play the biggest role. Taken all together, the UAE accounts for $30 \%$ of overall connectivity, followed by Saudi Arabian with $15 \%$ and Lebanon with $10 \%$. A very pronounced degree of linkages can be seen with Riyadh and Jeddah and to the Lebanese cities of Beirut and Tripoli. In contrast to this, Kuwait and Manama account for $8 \%$ each, Jordan cities like Amman come up to $7 \%$, while $6 \%$ of the total connectivity can be ascribes to Omani cities. Weaker connections of approximately $5 \%$ exist with cities Israeli cities like Tel Aviv or Haifa. Damascus and Tehran with $3 \%$, Ramallah and Sana with $2 \%$ each, and Bagdad with $1 \%$ are nearly not integrated within the Qatari regional network. Towards a regional orientation Doha shows the strongest connections with Dubai the regional leader and according to the GaWC Research Network the internationally best-connected City of the Gulf region. The high value is due to the fact that many Advanced Producer Service companies have relatively important and highly rated offices in Dubai and Doha. 


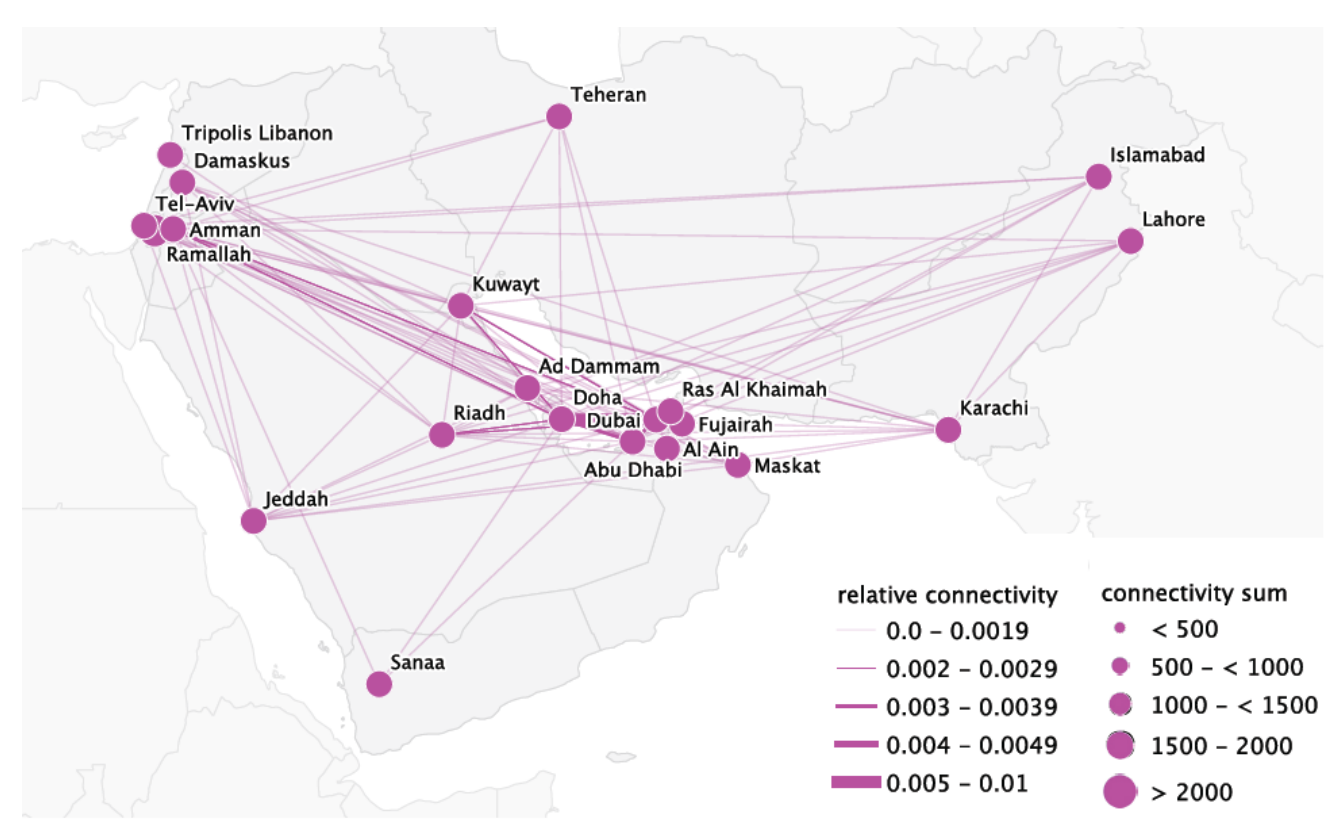

Figure 6: Regional connectivity of Advanced Producer Service companies based in Doha (Source: Authors, 2013).

In contrast to Advanced Producer Service sector, High-Tech seems to be networked much more with Asian locations while North-American locations play no role. Singapore, Moscow, Paris, Sao Paulo and Buenos Aires are the most connected cities. The most important region is still Europe. Interestingly, there are also two Latin American cities among the top ranked cities: Sao Paulo ranked 5th and Buenos Aires ranked 6th. Both cities represent the economic gateway to their respective countries.

Table 7: Numerical values of global connectivity of Qatari High-Tech firms

(Source: Authors, 2012).

\begin{tabular}{|c|c|c|c|c|}
\hline Rank & City & Country & $\begin{array}{c}\text { Gross } \\
\text { Connectivity }\end{array}$ & $\begin{array}{r}\text { Proportionate } \\
\text { Con nectivity } \\
(1=\text { Singapore })\end{array}$ \\
\hline 1 & Singapore & Singapore & 30462 & 1,00 \\
\hline 2 & Moscow & Russia & 28478 & 0,93 \\
\hline 3 & Paris & France & 28034 & 0,92 \\
\hline 4 & Sa o Paulo & Brazil & 27756 & 0,91 \\
\hline 5 & Buenos Aires & Argentina & 27067 & 0,89 \\
\hline 6 & Shanghai & China & 27037 & 0,89 \\
\hline 7 & Brussels & Belgium & 26610 & 0,87 \\
\hline 8 & Vienna & Austria & 26415 & 0,87 \\
\hline 9 & Seoul & South Korea & 25788 & 0,85 \\
\hline 10 & Beijing & China & 25518 & 0,84 \\
\hline 11 & Tokyo & Japan & 25364 & 0,83 \\
\hline 12 & Prague & Czech Republic & 25147 & 0,83 \\
\hline 13 & Milan & Italy & 24764 & 0,81 \\
\hline 14 & Joha nnesburg & South Africa & 24505 & 0,80 \\
\hline 15 & Hong Kong & China & 24367 & 0,80 \\
\hline 16 & Bangkok & Thailand & 23991 & 0,79 \\
\hline 17 & Istanbul & Turkey & 23506 & 0,77 \\
\hline 18 & Budapest & Hungary & 22904 & 0,75 \\
\hline 19 & Madrid & Spain & 22552 & 0,74 \\
\hline 20 & Mexico City & Mexico & 22480 & 0,74 \\
\hline
\end{tabular}

As in case of APS-firms the different ranges, directions and importance of spatial scales can be visualized for High-Tech companies. Figure 7 clearly shows the relevance of the European and Asian spatial scale for Qatari High-Tech companies within their value chain processes. More 
than $46 \%$ of all connectivity is going to Europe. In contrast to this Asia only accounts for $27 \%$, North America for $11 \%$, South America for $7 \%$, Australia and Oceania for $3 \%$ and Africa for $6 \%$ of all connectivity. On a supra-regional spatial scale Doha shows the strongest connection with the United Arab Emirates and Saudi Arabia. While the United Arab Emirates accounts for approximately $20 \%$, Saudi Arabia accounts for around $17 \%$ of all connectivity. In contrast Syria accounts for $5 \%$, Israel, Lebanon and Kuwait for $8 \%$ each, Palestine 1\%, Bahrain and Oman for $6 \%$ each, Iran for $7 \%$ and finally Yemen for $4 \%$ of all connectivity.

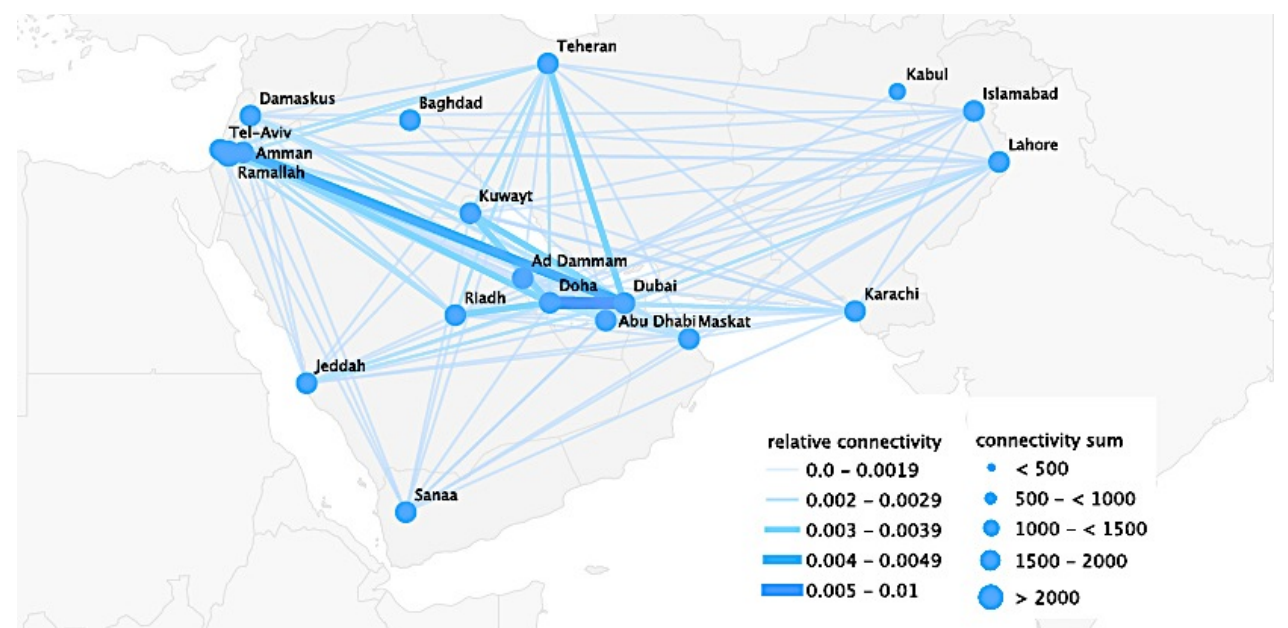

Figure 7: Regional connectivity of High-Tech companies based in Doha

(Source: Authors, 2013).

The Interlocking Network analysis outlines the structural organizations and spatial impacts of intra-firm networks. In order to explore the extra-firm networks of knowledge-intensive firms a value chain analysis has been applied in form of a web-survey and face-to-face interviews. The firms are from various backgrounds like for example accounting and finance, real estate as well as information and communication services. Based on the evaluated data and interviews the most frequent interactions of the participating firms are with other APS firms, in particular insurance, law, advertising \& media companies. This can be seen as clear indicator that APS firms in Doha are highly interdependent as in other cases worldwide. These branches assume an important role as an entrepreneurial support network within the city. On the European scale, a high number of extra-firm relations in banking \& finance, marketing and research can be observed reflecting the fact that many firms in Doha have to attract financial and marketing services as well as research inputs from outside of the State of Qatar. Figure 8 shows quite clearly that geographical proximity to other enterprises appears to be a driving force generating extra-firm networks and interactions.

This finding provides evidence that extra-firm linkages of advanced producer service firms concentrate in Doha and that there is currently very little interaction concerning the extra-firm linkages with companies outside Qatar. These empirical findings correspond with the findings of the qualitative network analysis. The most important finding of the web-survey is that Doha's APS firms organize their external-firm linkage predominately on a local spatial scale or supranational scale that is to say the Gulf region. Spatial scales beyond these scales play nearly no role.

In order to identify the various potentials and challenges for knowledge-intensive firms in Doha from the standpoint of internationally acting business practitioner seven face-to-face interviews were carried out. According to the interviewees Doha offers a unique combination of strengths that will be very helpful to establish and promote the emergence of Doha as an influential city on the regional and global stage. The tremendous wealth on oil and gas makes Archnet-IJAR, Volume 10 - Issue 1 - March 2016 - (xx-xx) - Regular Section

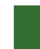


Qatar to one of the richest economies in the world. During the current global economic downturn Doha is still characterized by a prospering economic landscape with economic growth rates that are far above average. The revenues of the oil and gas production permit large-scale infrastructure developments, including the construction of a new port and new international airport. The ability to embark on new projects and far reaching development activities of the urban landscape in times of a global crisis and global instability illustrates the power and potentials of Qatar. The economic potentials of Doha are thus along two key dimensions: One is capital, which permits state-of-the-art infrastructure and the ability to launch various new initiatives, such as Education City. And the second key dimension is the fortunate geopolitical location of Doha within the Gulf region itself between the Kingdom of Bahrain and Kuwait in the north, main urban centres in Saudi Arabia in the west and the UAE and Oman in the south (Conventz et al., 2015).

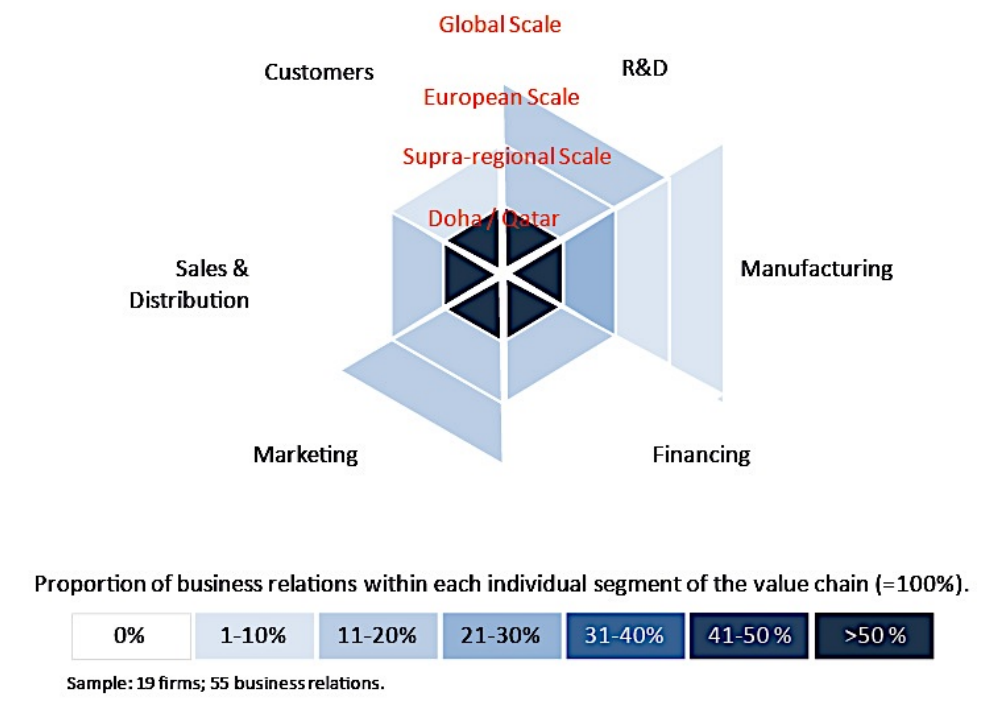

Figure 8: Extra-firm relations of knowledge-intensive companies in Doha (Source: Authors, 2013).

\section{GIS assessment of spatial practice}

In addition to the analysis of company networks and how they connect to their branches and markets globally, regionally and locally, the project team followed the objective to assess the urban development tendencies in recent years, which are a direct consequence of the investment interests of developers. Utilising GIS data to investigate the distances medium to high-income groups have to travel within Doha in order to follow up their weekly activities.

As first step the GIS data, provided by the Ministry of Municipality and Urban Planning, were examined. In order to analyse the rapid change of land use distribution a comparative set of various GIS maps were assessed by using existing data and satellite maps. The key effort in this respect was a comparison of land use development over three periods: a) $2003-2006$, b) 2006 - 2009 and c) 2009 - 2012. All data were evaluated via the GIS software application ArcGIS.

As final step 130 questionnaires, distributed to employees engaged in APS sectors, were assessed regarding the locations of homes, offices, services and leisure spaces. The main objective of this task was to calculate the distances one individual has to travel within the city in order to commute between home and office as well as home and weekly activities, such as shopping. Therefore the locations mentioned in the questionnaires were implemented in a GIS model of Doha and the distances were calculated via ArcGIS. The results were evaluated with 
reference to the three most frequent locations for mid-income homes: Downtown districts between $B$ Ring and D Ring, suburban compounds in the urban periphery and high rise apartment along the waterfront.

Based on the five major public development strategies rapid urban growth was initiated particularly after 2003 , when the population increased from around 744,000 inhabitants to about 1.8 million in 2013. Thus, almost one million people moved to Doha within only nine years. Based on the project teams' GIS survey the recent construction boom increased total settlement area of metropolitan Doha from around 162 square $\mathrm{km}$ in 2003 to around 292 square $\mathrm{km}$ in 2012, which is more than $80 \%$ of its previous size (Figure 9 ).

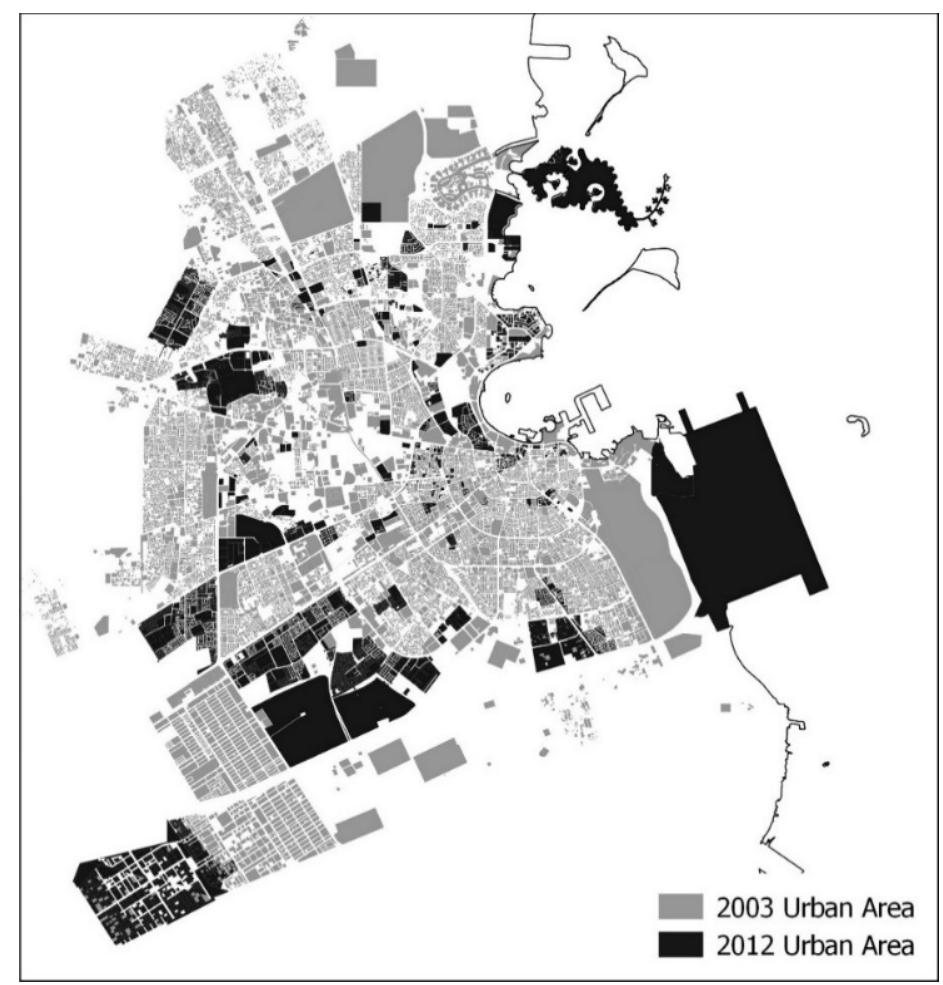

Figure 9: The settlement growth between 2003 (grey areas) and 2012 (black areas)

(Source: Authors, 2013).

Table 8: Evaluated land use statistics based on GIS survey

(Source: Authors, 2013).

\begin{tabular}{|l|r|r|r|r|r|r|r|}
\hline \multirow{2}{*}{ Land Use } & \multicolumn{1}{|c|}{2003} & \multicolumn{2}{|c|}{2006} & \multicolumn{2}{|c|}{2009} & \multicolumn{2}{|c|}{2012} \\
\cline { 2 - 8 } & EXISTING & \multicolumn{1}{c|}{ NEW } & \multicolumn{1}{|c|}{ TOTAL } & NEW & \multicolumn{1}{c|}{ TOTAL } & NEW & \multicolumn{1}{c|}{ TOTAL } \\
\hline Residential & 109.1 & 17.8 & 126.9 & 10.6 & 137.5 & 60 & 197.5 \\
\cline { 2 - 8 } Commercial & 21 & 24.8 & 45.8 & 1.1 & 46.9 & 1.6 & 48.5 \\
\cline { 2 - 8 } Public \& Private Services & 34.1 & 6.6 & 40.7 & 4.9 & 45.6 & 0.6 & 46.2 \\
\hline Total Area (sq km) & 164.2 & $\mathbf{4 9 . 2}$ & $\mathbf{2 1 3 . 4}$ & 16.6 & $\mathbf{2 3 0}$ & $\mathbf{6 2 . 2}$ & $\mathbf{2 9 2 . 2}$ \\
\hline
\end{tabular}

During the first period between 2003 and 2006 developers focused on commercial projects, which had a share of around $50 \%$ of the total built-up area (Table 8 ). These commercial developments were mainly office buildings located in West Bay and along C-Ring Road in addition to several shopping malls. After the first period of rapid growth, which was fuelled by initial investments and the Asian Games in 2006, a total area of almost 50 square $\mathrm{km}$ was added. Due to the international financial crisis in 2008 and an oversupply of commercial projects less 
than 17 square $\mathrm{km}$ of settlement area was built during 2006 and 2009, which meant a decrease of $66 \%$ in the growth rate. However, the growth rate picked up again during 2009 and 2012 when a total area of 62 square $\mathrm{km}$ was developed in addition to the new airport development of approximately 22 square $\mathrm{km}$. In contrast to the first extensive development period between 2003 and 2006 over $95 \%$ of the total development area between 2009 and 2012 is occupied by lowrise residential projects in the periphery of Doha. According to the GIS data and field surveys developers and their investors focused on four distinct development types:

Another focus of particularly smaller developers has been on building residential developments including villas, detached or semi-detached, in Doha's suburban areas. Many of these projects took the form of compounds and were financed by individual Qatari landowners, who rent their developments to companies and their staff. According to the GIS survey, more than $50 \%$ of Doha's entire urban area is currently occupied by low-rise residential developments, initiating a low average density of less than 6,000 people per square kilometre.

In addition to the general GIS survey a questionnaire was used to investigate how higher income groups have to travel in Doha in order to meet all their needs. Most participants live in proximity to the old city centre along B- and C-Ring or in compound developments in Doha's inland periphery. The location analysis conveys that $70 \%$ of these participants are accommodated in apartment blocks along A-, B- and C-Ring, while around $20 \%$ reside in compounds in the periphery and the remaining $10 \%$ are housed in waterfront developments along the northern shore. According to GIS calculations most participants live on average at distances of around 7 kilometres to their working places, 6 kilometres to their favoured grocery stores and 8 kilometres to their favourite leisure spaces. The main leisure spaces include hotel developments in West Bay, the Corniche / Waterfront, the Souq Waqif in the old city centre and shopping mall complexes in the periphery.

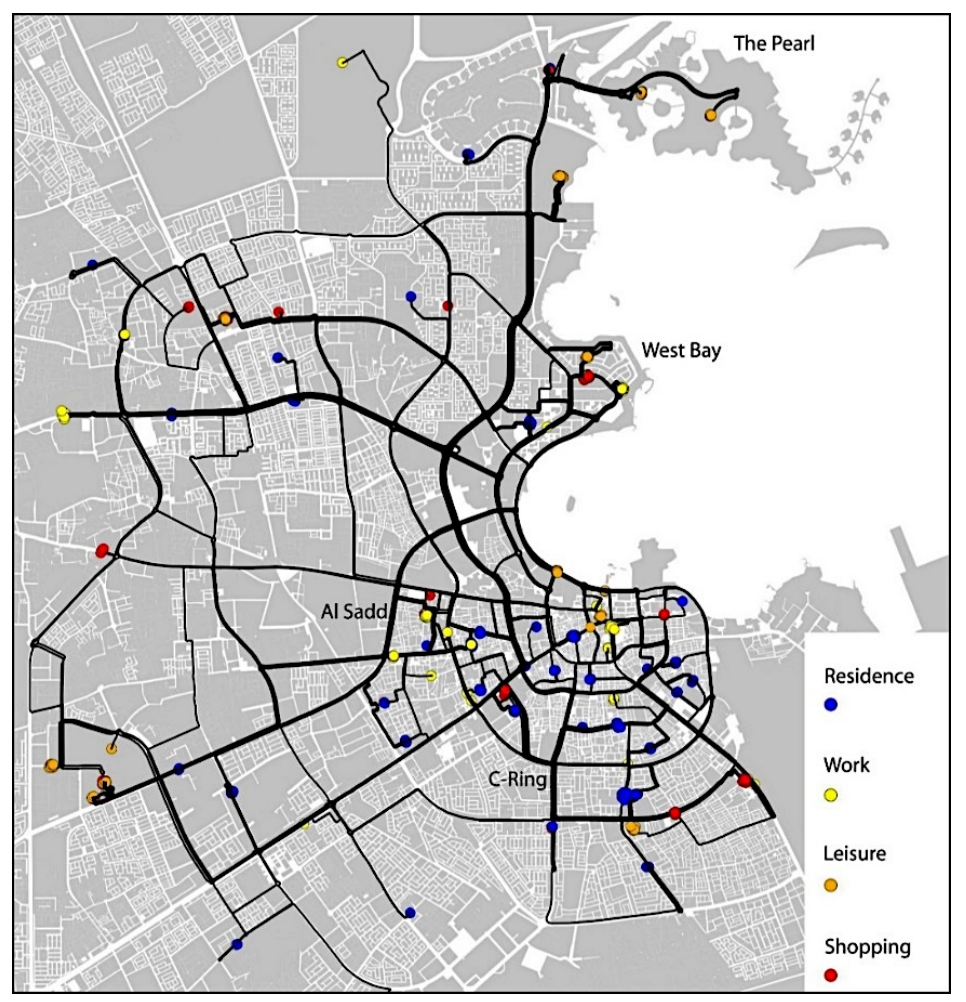

Figure 10: The movement map of 130 inhabitants and their weekly activities. The map clearly indicates a higher level of land use integration in Al Sadd due to shorter travel distances (Source: Authors, 2014). 
The map of inhabitant movements (Figure 10) illustrates the long distances between various locations and the lack of integration of services on district scales. Today, the most integrated urban area is the Al Sadd district due to its high spatial accessibility along C-Ring on a global and local level (Mirincheva et al., 2013). Therefore, it can be argued that in the future the tendency of inhabitants to prefer services at short distances will lead to more integrated and diverse urban districts. The continuous exchange of immigrants however currently still hinders the demands of communities from having a more efficient impact on development patterns.

\section{RESEARCH MODULE III: INVESTIGATING THE LIVED SPACE}

\section{Cognitive Mapping}

Various studies were implemented to explore the impact of the existing built environment on the general public. One of the main objectives of this research project was the investigation of emerging urban qualities during the recent phase of economic diversification. Since urban qualities are to a certain extent dependent on the individual perception of inhabitants, their conscious and subconscious reaction to existing urban environments was examined (Burgess, 1925; Altman, 1975 and Lynch, 1960). The analysis of human behaviour in public spaces has allowed the project team to assess the various factors attracting or resenting the use of urban space. Thus, exploring how the city's inhabitants' experience their surroundings should go beyond interviewing a small group of inhabitants as this may support what is already self-evident.

As a first research step cognitive mapping was utilized, which is composed of a series of psychological transformations by which individuals acquire, code, store, recall, and decode information about the relative locations and attributes in their everyday spatial environment. In essence, cognitive maps are a mental representation of physical locations and movement between them. When reviewing and analysing how the city of Doha is experienced by its residents and users, two critical urban elements appear as predisposing factors governed by the spatial perception of the structure of the city; these are the understanding of geographical locations and urban mobility or movement within the city, and the way in which people relate to both.

In order to examine the experience of the city's inhabitants in terms of movement and their comprehension of the city in terms of where they live, work, entertain, and what travel routes they use, a survey questionnaire was developed with two objectives in mind. The first aim was to gather data for interpretations of how the city is experienced based on the inhabitants' reactions to certain parameters, rather than utilizing the more standard practice of reading and interpreting the city based on analyses of reports by specialized professionals or observers. The second objective was to investigate the way in which inhabitants perceive movement in the city in relation to the geographical locations most important to them such as living areas, work areas, and the public places they frequent.

The questionnaire provided a map of greater Doha and included queries about basic information related to the gender, age, and cultural background of the participants; they were required to name them and indicate the area where they live and work on the map. Participants had to select the three public spaces that they frequented the most, as well as indicate the routes they take from their residence to their workplace, and the routes taken to the most visited public spaces on the map. Relying on cognitive mapping procedure, the questionnaire required participants to mark the home zone and home range on the map. Home zone was defined to the participants as the immediate context around their homes, which reflects a shared or collective hypothetical ownership of communal space or area while home range was delineated as the respondents' mental image, based on their understanding of what defines such an environment and their perception of its boundaries, of the entire residential environment or district around their home. 
Over $50 \%$ of the targeted population responded to the survey with a total of 108 responses received. The profile of the respondents was representative of a wide spectrum of people, from different cultural backgrounds: $65 \%$ of the respondents were Qatari nationals while $35 \%$ were expatriate professionals, mainly from neighbouring Arab countries. Sixty-nine per cent of the respondents were between 20 and 40 years old, the majority of whom (65\%) were female.

Utilizing frequency, cross-tabulation, and cumulative mapping procedures for the total number of respondents and four groups of Qataris and Arab expatriates, results were categorized into three bands that pertained to: (1) living, working, and visiting; (2) home range, home zone, and movement; and (3) ethnic affiliation: Qataris and other Arab expatriates.

Living, working and visiting patterns: The areas where the participants in the survey live vary greatly. However, three areas or districts stand out from the responses; these are Mamoura, Gharrafa, and Khraitiyat: $9 \%$ of the respondents live in Mamoura district, while Gharrafa and Khraitiyat districts each received $8 \%$ of the responses. This result corresponds with the overall profile of the respondents: for example, the Mamoura district is characterized by a mix of Qataris, who reside in privately owned homes, and other Arab nationals. In contrast, the Gharrafa and Khraitiyat districts, located in close proximity to the north-western peripheries of the city, are primarily characterized by Qatari homes thus reflecting their preference for living on the outskirts and periphery of the city. In terms of the areas where survey participants work, four areas are clearly identified from the responses: $32 \%$ of the respondents work in the Tarfa district while $12 \%$ work in the Dafna area. This may be due to the fact that the former is characterized by the presence of the Qatar University campus, while the latter represents the emerging business and financial district in the West Bay area. The AI Sadd and Shaqab districts received $7 \%$ and $6 \%$ as respectively as workplace areas. This suggests that while the Al Sadd area represents a more traditional business district, close to the city centre core, the Dafna or West Bay financial area has already started to attract more businesses and employees. Four public spaces appear to compete for the most frequently visited urban open spaces: Katara Cultural Village received $58 \%$ of the total responses, followed by Souq Waqif, Aspire Zone, and the Corniche waterfront area which received $57 \%, 56 \%$, and $49 \%$ respectively. This suggests a strong interest, by the respondents, in culture and sports, which are specific attributes of these particular spaces. The result could be attributed to the fact that these places offer a wide variety of facilities, functions and activities including cultural events and art exhibitions.

Comprehension of home range, home zone and movement experience: Mapping the respondents' identification of home and work locations, home zones, home ranges, and the routes taken from living areas to work areas reveals interesting findings (Figure 10). Based on the responses, the distribution of homes clearly reflects the fragmented nature of the city where residential areas are located far from the business or commercial districts. The perception of home zone is rather varied as some respondents depict it as an undefined bubble while others portray it with clearly defined perimeters or boundaries. The responses with regard to home locations and home zones reveal three major areas that can be considered home zones for the participants: these are AI Waab, Dahil Al Hamam, and Khraitiyat. Responses to home range also vary with regard to size of representative areas and the demarcation of boundaries. Notably, the cumulative mapping and the intersection of home ranges show specific residential areas as representative of home ranges for the respondents. Areas of significance include Mamoura, Al Waab, Azizya, Dahil Al Hamam, Madinat Khalifa, and Gharrafa. The distant location of certain residential areas could also reflect difficulties with mobility and access across the city. Interestingly, the concentration of private sector residential areas seems to be moving toward the West Bay; the new business and financial district. This trend could eventually initiate better access routes to the residential areas located northwest of the city, in addition to benefiting businesses because of the closer proximity to certain governmental institutions that have recently relocated to the West Bay area. The results of mapping the respondents' indications of roads and 
routes taken to work areas and to the most visited places reveal significant findings. For example, D-Ring Road, as part of the new Doha Expressway which later merges into Al Shamal Road, appears to be the most commonly used route for respondents to reach their workplace (Figure 11). This is likely due to its connectivity as a main artery to the most important areas of the city. Its vehicular capacity and flow of movement makes it an important urban transport spine that links different parts of the city.

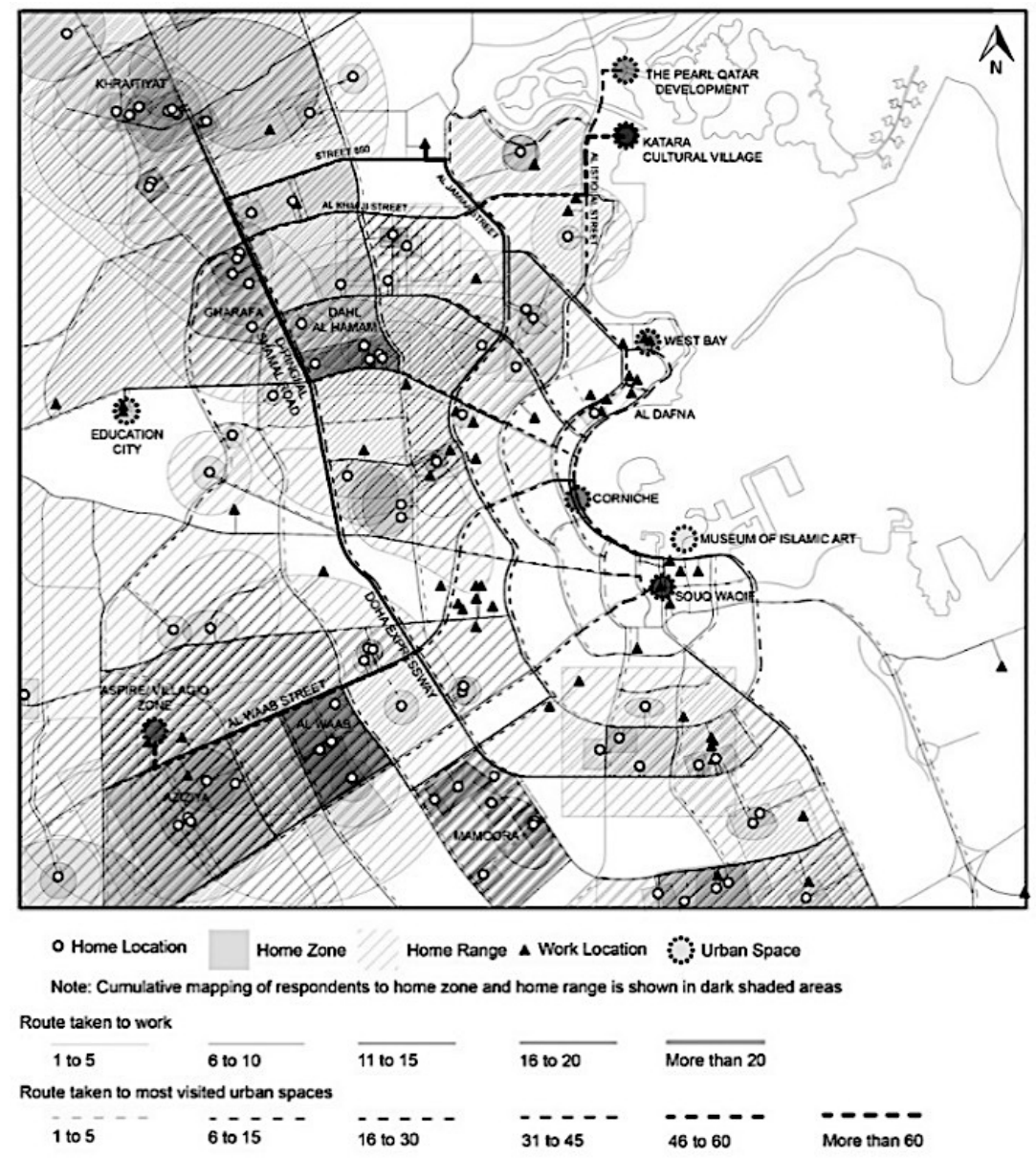

Figure 11: Cumulative mapping of respondents' reactions to geographical location and movement across the city (Source: Authors, 2013).

Ethnic affiliation: Qataris and Arab expatriates: A number of usage and destination differences were found in the responses of Qataris compared to other Arab expatriates, for example, Aspire/Villagio Zone, Katara Cultural Village, and Souq Waqif appear to be the most visited urban spaces for Qatari respondents, receiving $42 \%, 38 \%$, and $34 \%$ respectively. In contrast, Souq Waqif, the Corniche, and Katara Cultural Village were identified as the most visited by Arab expatriate respondents, receiving 23\%, 22\%, and $20 \%$ respectively. Both groups agreed on the least visited urban spaces: Education City and the Museum of Islamic Art Park. In essence, the preceding results reflect the preference of both groups to visiting urban spaces that are closer to their residence. Since the majority of Qatari respondents live in the northwest or southwest part of the city, they usually visit urban spaces like Katara Cultural Village and Aspire Zone that are in close proximity to where they reside. As Arab expatriate respondents tend to live closer to the centre core, their two most visited places, Souq Waqif and the Corniche waterfront 
area, are also closer to the centre; however, Katara Cultural Village rated as the third most visited urban space, is just a few kilometres further north of the centre (Figure 12).

In generic terms, there is no clearly defined area for Qatari respondents of a significant dense concentration representative of their interests with regard to their perception of home zones and home ranges. The Qatari respondents are more distributed and reside further away from the centre core, around the peripheries of the city in areas where their requirements are more easily met with the availability of larger properties, bigger houses and more private space. In contrast, for Arab expatriates, home zones and home ranges are much more clearly defined and are larger in size and area as evidenced in the cumulative responses (Figure 13).

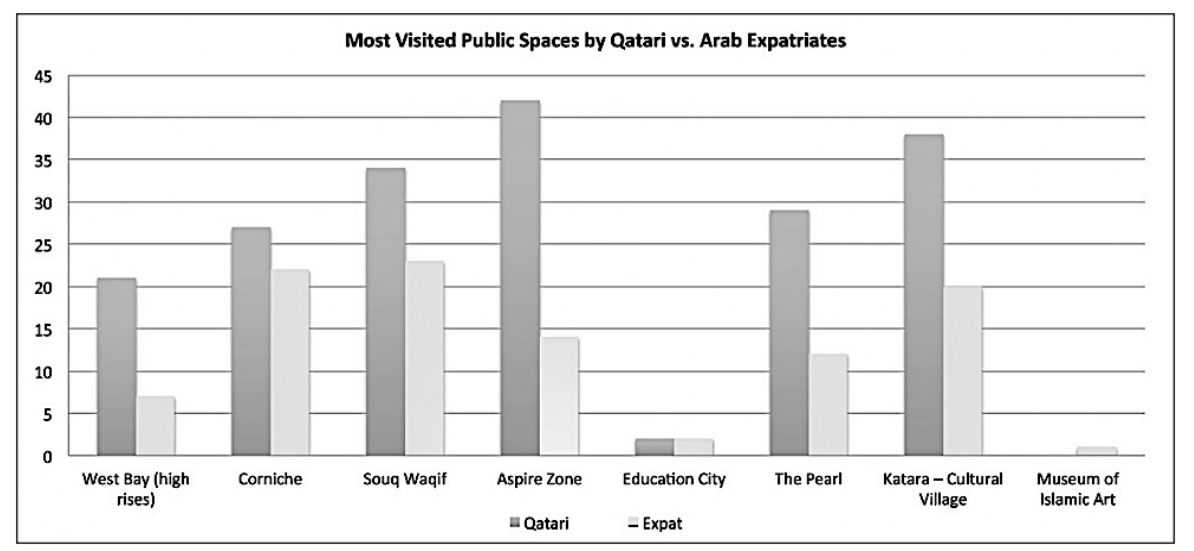

Figure 12: Most visited public spaces by Qatari vs. Arab expatriates respondents (Source: Authors, 2013).

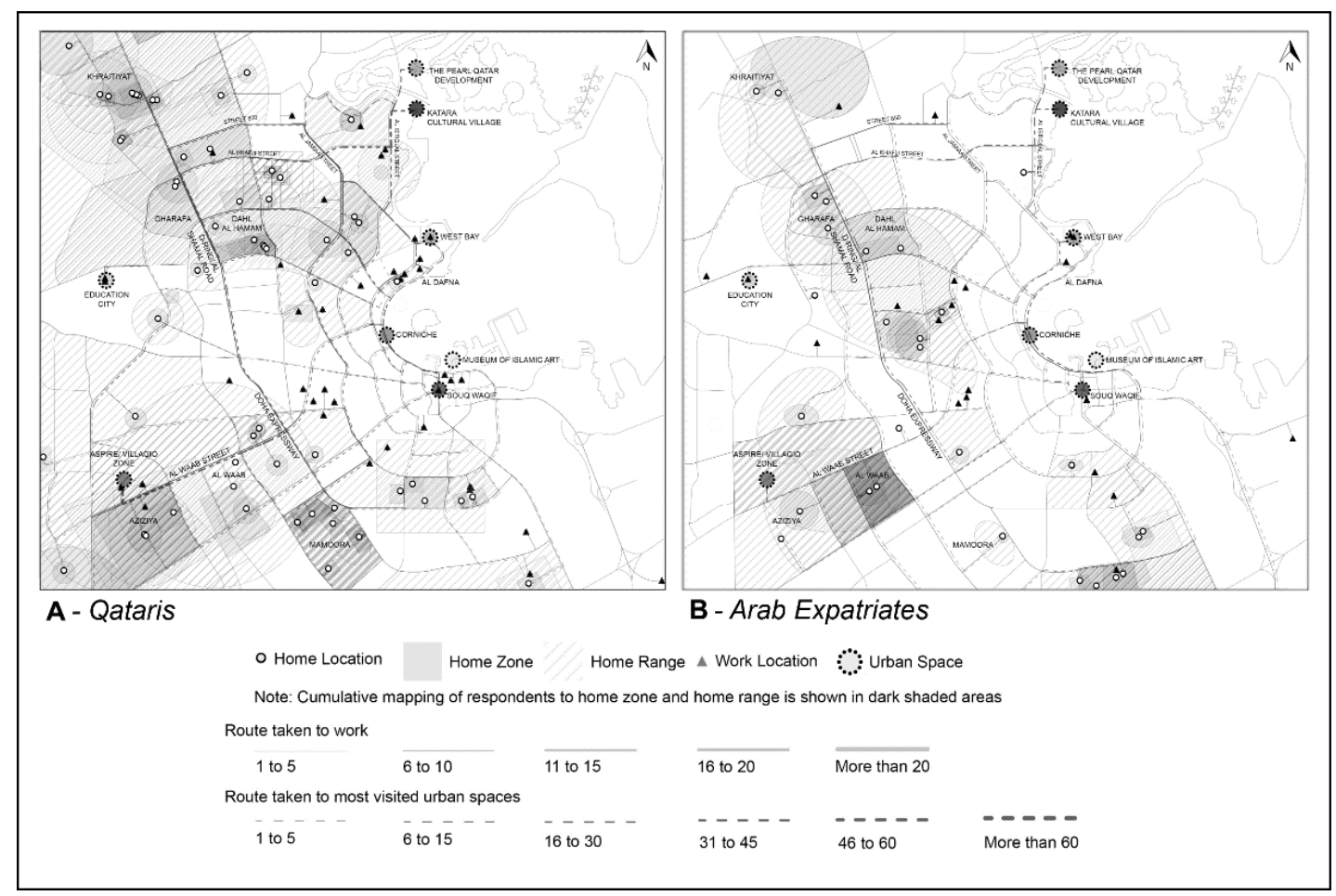

Figure 13: Cumulative mapping of Qataris' and of Arab expatriates' reactions to geographical location and movement across the city (Source: Authors, 2013). 


\section{Behavioural Studies}

In addition to cognitive mapping direct observation and behavioural mapping are systematic methods for describing what visitors and users of a space actually do there. It is a direct approach, unlike the methods that require the indirect involvement of inhabitants in seeking information about the understanding of geographical locations and urban movement. Observation and mapping are additional tools for understanding the dynamics of people and their interaction with the urban environment; it is an alternative approach to data collection that views people as 'objects' by recording their periodic behaviour (Salama and Azzali, 2015). Valuable information can be obtained when behaviour is systematically recorded. Unplanned observation may result in inadequate findings that may reveal only what seems to be already obvious. Systematic observation of behaviour involves four aspects; these are: people, activities, setting or space, and timing (Salama et al., 2013).

In this procedure a combined unobtrusive mapping technique, which integrates 'placecentred' mapping and "individual-centred" mapping, was used. Place-centred mapping aims at observing actions in a particular setting or portion of a public space; these were recorded on floor plans, maps, or diagrams. Individual-centred mapping records the tasks, activities, and movements of people throughout the investigated space: it represents a systematic learning about a particular group of individuals whose activities are distributed throughout a specific period of time.

Based on the results of investigating geographical locations and movement, 12 urban open spaces were identified to conduct direct observation and behavioural mapping studies. These included: Katara Cultural Village, Corniche Waterfront Area A, Souq Waqif Area B, and Aspire Zone. In planning the study, a series of visits to the various spaces was conducted to explore key settings within them; these were selected because of their importance in terms of intensity of visitors and variety of activities. Original maps were obtained and re-drawn and timings were identified: each of the spaces was observed twice during the week and twice at weekends. Times of observation varied on weekdays and at weekends. Observation took place on weekday mornings from 10.00 to 11.00 p.m. and during weekend mornings from 10.30 to 11.30 a.m. For weekday and weekend evenings, observation times were from 6.30 to 7.30 p.m. and from 7.00 to 8.00 p.m., respectively. Users were classified into five groups: children, male visitors, female visitors, female domestic workers or cleaners, and male labourers. Maps were generated for each observation and mapping period and combined maps were then developed to illustrate the overall profile of behaviour and activities in each space.

In order to assess the various ways public spaces are used in Doha a total of 12 urban spaces was selected and observed. After a comparative study of all collected data four urban open spaces were identified as key spaces representing the current conditions in Doha. All four urban spaces reveal significant narratives about the physical and social aspects of the contemporary urban environment:

Katara Cultural Village: In observing the mixed types of users at the selected at Katara Cultural Village space, including children and male and female visitors, the actual use can be clearly discerned. The users represent different socio-economic strata and cultural backgrounds, including a substantial presence of Qataris. Male labourers are represented in the space for restaurant staff and beach helpers. Female labourers are mostly cleaners or maids accompanying Qatari families to keep an eye on children. Cleaners seem to be available at all times, but appear to be moving more within the space in the evenings. Since most of the restaurants open late morning or at noon, the number of users is significantly less at these times than during the evenings. Beach use and activities are not common whether during the week or at weekends; this could be due to the high entrance fees. Even though the spaces, particularly the waterfront esplanade, are dark and poorly illuminated at night, Katara is more crowded in the evenings, both during weekday and weekend evenings. Interestingly, this lack of adequate 
lighting on the esplanade impacts in two contradictory ways; first of all, it enables substantial and most likely desired privacy for users, particularly Qataris, and secondly, it minimizes the feeling of comfort and safety, which even so does not prevent people strolling along the esplanade in the concealing darkness. Overall, it was observed that both adults and children seem to enjoy their time in the space. However, the space lacks adequate outdoor furniture such as benches and chairs in addition to sufficient green spaces and landscaped features that would make it more amenable and attractive for use. The minimal use of green spaces creates a rather stark but not unpleasing leisure environment.

Corniche: The mapping of the Corniche elucidates the reality of this space and how it is actually used by a wide spectrum of people of different age groups and from different ethnic backgrounds. The space caters more to lower and middle-income groups. A strong presence of male visitors is evident on weekday evenings; male labourers working in the space are also represented, these include cafeteria staff and Msheireb Enrichment Centre (MEC) security staff. Both males and females, taking exercise in the form of jogging, or casually strolling, were also recorded as passers-by. Additionally, the children's playground at the far northern end of the site is a major attraction for families. Family groups were also observed gathering in the space around the cafeteria, both in front of and behind it: in fact, the cafeteria appears to be the major attraction to the space, especially in the evenings when people come for refreshments. The space is generally crowded with different types of users on weekdays; at weekends they proliferate in the early morning and early evening. However, fewer users were noted on weekday mornings, probably due to the fact that most people are at work. In contrast, maintenance workers and gardeners were strongly represented in the mornings when they are on duty during hours where they are less likely to disturb visitors. It was also noted that a considerable number of male users visited the space specifically to drink traditional tea (karak) while sitting individually or in groups along the seawall, a protective barrier separating the promenade from the sea, chatting and seemingly enjoying the views of the cityscape or the other side of the bay. Interestingly, motorbike riders (a very small interest group in the Doha population) were frequently noted congregating at the drop-off area, near the car-park.

Souq Waqif: As a rehabilitated traditional market and tourist destination area, the Souq Waqif represents one of the most important and attractive leisure spaces in Doha; it caters to diverse groups including tourists, Qataris, and expatriate residents. Conducting behavioural mapping of the selected setting within the Souq reveals the authentic use of the space. Typically, groups of tourists were observed to visit traditional shops prior to relaxing in cafés or dining at one of the many restaurants. It was also noted that there was a very low representation of children, probably due to the lack of activities and facilities that would cater to them. Asian male workers would sometimes visit the space from nearby residential areas located south of the Souq. However, security police stand in front of and near the station and have been known to hustle certain visitors away, particularly unwelcome labourers or those who have been observed annoying visitors. Mounted policemen also frequently patrol the streets and are one of the attractions, especially for tourists. The mapped space is one of the major arteries of the Souq (Figure 14); it is lined by various restaurants with roof terraces and outdoor cafés. In generic terms, the space is lively and well-frequented both in the morning and evening. However, it is more vibrant at weekends than during the week, and in the evenings rather than the mornings. This is likely due to the restaurant and café opening times. Visitors generally go there for a meal or coffee with friends and family and some may go shopping. It was observed that the space was primarily used in the mornings as a passing-by space en route to the shops or the immigration office while in the evenings it was used for dining in restaurants or cafés, as well as shopping in the adjacent traditional market or handicraft shops. Crowds were bigger in the evenings rather than during the morning since the majority of visitors, other than tourists, were more likely to be at work. The space, as part of a pedestrian passageway to the traditional market area, seemed to be 
functioning very well; however, the complete lack of children-oriented activities and venues was also noted.
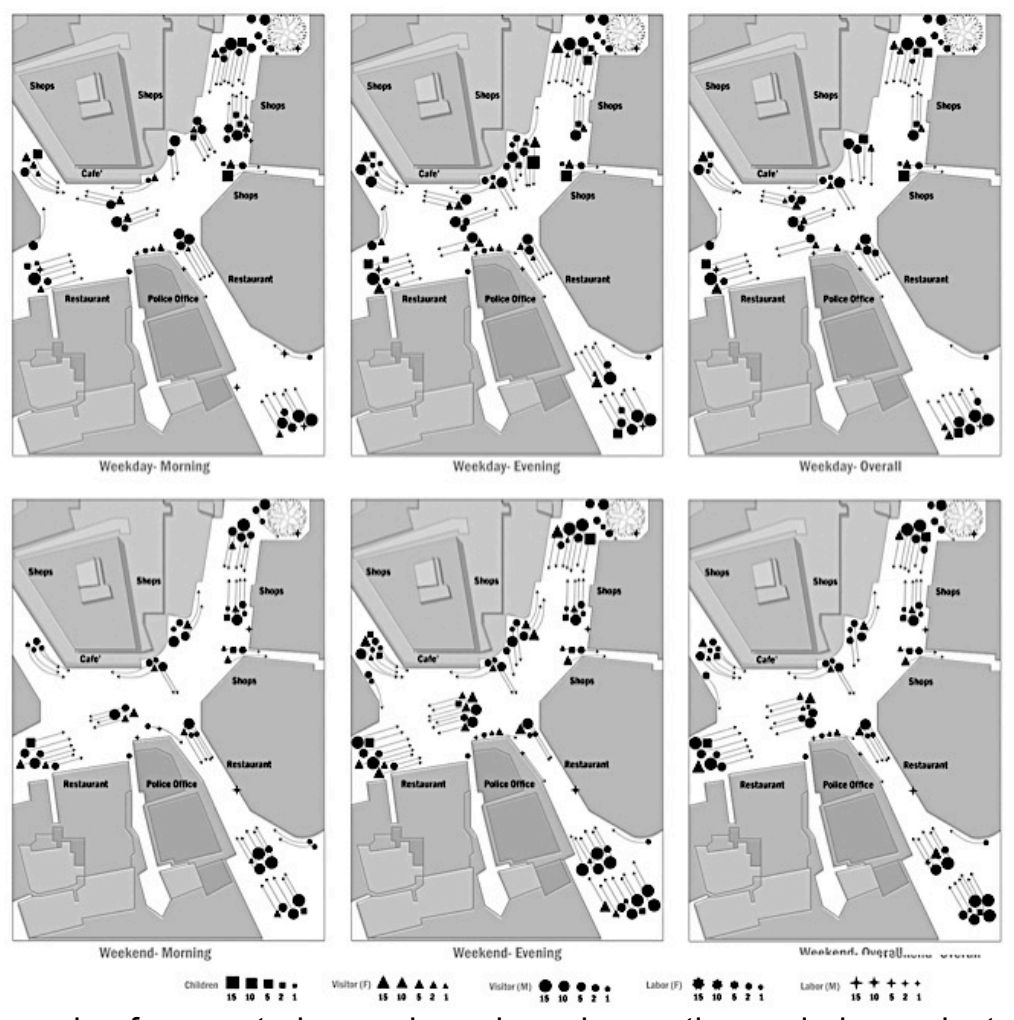

Figure 14: An example of generated maps based on observation periods conducted at Souq Waqif

(Source: Authors, 2013).

Aspire Park-Zone: Mapping behaviour in the Aspire Zone and Aspire Park uncovered some important aspects related to its activities and the users engaged in those activities. People of different backgrounds, gender, and ages were observed to use the space for various purposes. It was noted, however, that most visitors were either Qataris or Arab expatriates; very few Europeans, Americans or people from other western backgrounds were represented during observation times. Typically, users visited the space in groups, as friends or with families; children were well represented in the space since it has extensive landscaped green areas, in addition to a well-appointed children's playground. The space was rarely used during the morning when only a few individuals could be seen in the designated sports area. Strikingly, the number of visitors was higher during the weekdays than at weekends, presumably most visitors came from nearby residential areas. Casual, unscheduled observation revealed that space-use was quite flexible, for example, it was observed being used for special, booked events, such as children's birthday parties, national day celebrations, or sports competitions. Most visitors used the space primarily to enjoy the outdoors prior to or after shopping in two popular nearby malls located east and south of the park. Morning users tended to visit the area for fitness purposes such as walking, jogging, or taking exercise. Evening visitors, however, appeared to use the space for relaxation purposes such as eating, sitting and chatting, etc. The overall experience of users seemed to be a pleasant one. It was further noted, however, that the lack of adequate shaded areas with trees, parasols or other forms of shade, could be an important factor for the minimal use during weekend mornings. 


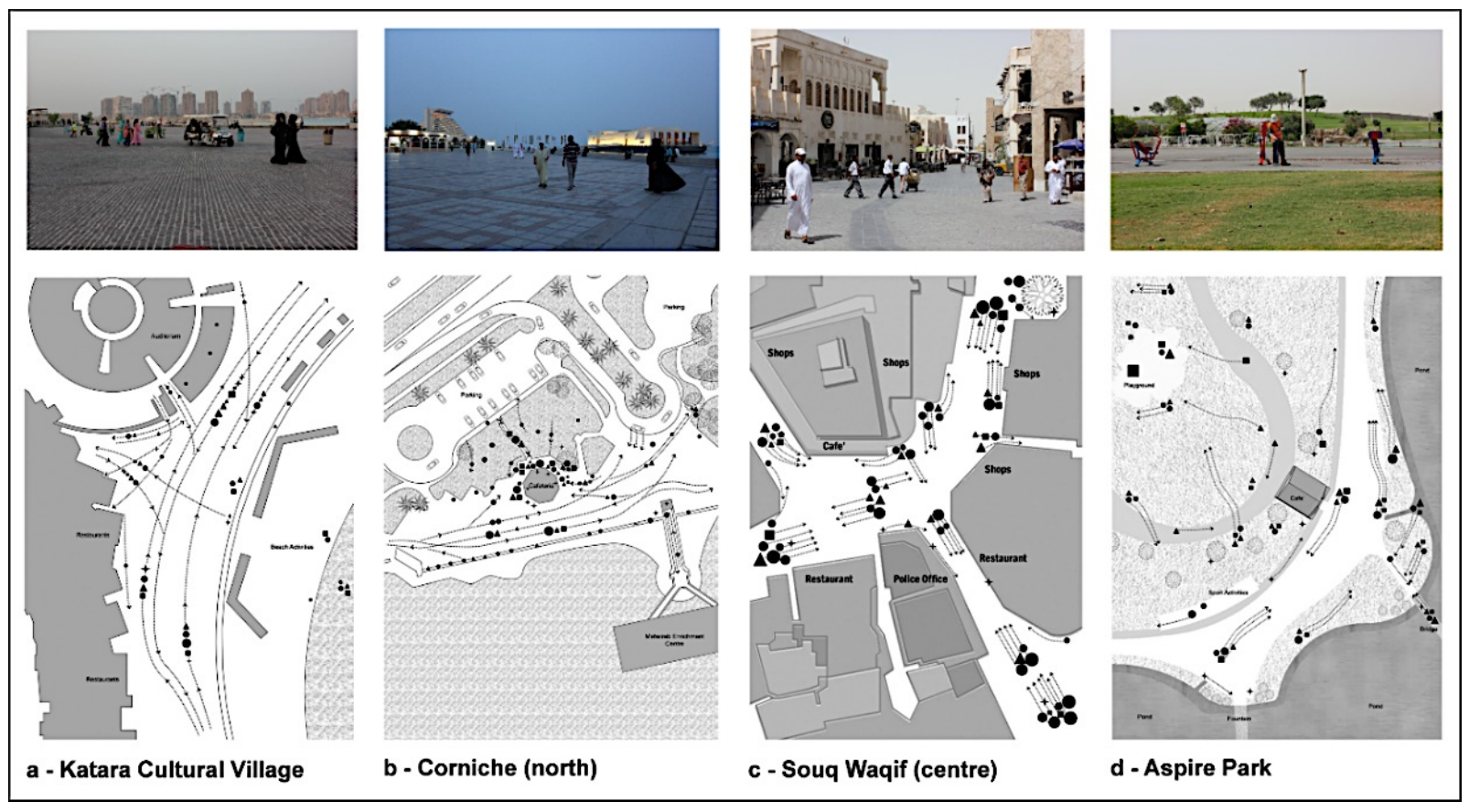

Figure 15: Combined behavioural maps for the four spaces selected for investigation

(Source: Authors, 2013).

The overall experience of users in the four spaces examined demonstrates that people experience and interact with urban open spaces differently and as such their needs vary according to the purpose for which they visit the space. The mapping studies of urban open spaces delineate the fact that there is an absence of landscape features and a dearth of green spaces and of appropriate outdoor furniture, such as benches and seating, in Katara Cultural Village; similarly, there is an absence of adequate shaded areas and shading devices in both Corniche Area A and Aspire Zone. In addition, a lack of children's facilities or a specially designated area for children was noted in Souq Waqif. These observed lacks and absences could be viewed as deficiencies that hinder the maximum efficient and effective utilization and use of such spaces. Addressing the lack of features that enhance people's activities and use of the space, or those that would cater to a specific type of user would make the space more conducive for use by different types of users and at different days and times. In sum, pertinent recommendations can be made with the aim of instigating improvement of existing urban open spaces in Doha or offering guidance for designing new spaces (Salama and Wiedmann, 2013c).

\section{Media Survey}

A media survey was carried in order to investigate the various images of Doha. The business category includes articles and advertisements that promote Qatar's interest in establishing partnerships in the fields of information technology, oil and gas petrochemical industries, sustainable technologies, energy production and conservation, and construction industries. Images associated with this category showcase views of factories, advanced industries, industrial plants, banking, or scenes from the business districts. The category of sports includes materials that represent the role of Doha throughout the past decade in developing its resources to enable it to become key tourist destination and an effective host of regional and international sporting events, championships, and league matches. Images in this category include existing facilities and proposals for new stadiums, while emphasising the technologies and sophistication involved in such structures. The culture and tourism category has materials that depict the recent role the 
country has played in investing in cultural projects and museums, promoting conservation of the arts, and the protection of architectural heritage. They represent Qatar as a centre for diverse cultures, a cultural hub that hosts art exhibitions, high profile cultural events, and international concerts and festivals. Images in this category include artwork, existing museum buildings and proposals for new cultural projects. The fourth category is education and knowledge, which includes materials that showcase Qatar as a centre of excellence in education and research and the role of Doha as an emerging knowledge-based economy city. Images associated with this category include laboratories, conference halls, and educational institutions. The fifth category is real estate; this includes materials that picture Doha as an interesting and liveable environment with many new career options and lifestyles that support business and attract a highly qualified and talented workforce. Images in this category include scenes of recently completed residential projects, projects in progress, or future proposals that exhibit vibrant, upscale work and residential environments.

With regard to both articles and advertisements, it should be noted that a single article could cover more than one of the preceding categories while one advertisement might provide messages or images that could relate to one or more categories. For the articles examined in Oryx magazine, a total of 272 responses to the categories were recorded while 388 responses to the same set of categories were noted in the articles examined in Edge magazine (Table 9). In Oryx, culture and tourism received the highest number of responses with over two-thirds of the total responses (66.00 per cent), while business was ranked as the second category, receiving 14.33 per cent of the total responses. The categories of sports and real estate received equal responses and were ranked as the third with 9.19 per cent of the responses. A surprising result emerged from the education and knowledge category in that it received the lowest responses (1.1 per cent) despite the fact that Qatar Foundation, Qatar University, and the Supreme Education Council are making a considerable investment in the architecture of educational facilities, as for example those at Education City which are designed by famous international architects. The results with regard to the articles published in Edge magazine were anticipated: since the magazine's focus is on business, the business category received the highest number of responses (64.94 per cent), followed by real estate (13.91 per cent), and culture and tourism (9.2 per cent). The category of education and knowledge is ranked as fourth (6.18 per cent) while the sports category received the lowest number of responses (5.92 per cent).

Table 9: Analyses of articles published in Oryx and Edge magazines (Source: Authors, 2013).

\begin{tabular}{|l|c|c|c|c|}
\hline Oryx Articles & Dec 09-Dec 10 & Jan 11-Dec 12 & Jan 12-Jul 12 & Total \% \\
\hline Business & 6 & 22 & 11 & (39) $14.33 \%$ \\
\hline Sports & 20 & 4 & 1 & $(25) 09.19 \%$ \\
\hline Culture/Tourism & 32 & 105 & 43 & (180) $66.0 \%$ \\
\hline Education/Knowledge & 1 & 1 & 1 & (03) $01.10 \%$ \\
\hline Real Estate & 6 & 14 & 5 & (25) $09.19 \%$ \\
\hline Total & 66 & 146 & 61 & (272) $100 \%$ \\
\hline Edge Articles & April 10-Dec 10 & Jan 11-Dec 12 & Jan 12-Jun 12 & Total \% \\
\hline Business & 79 & 110 & 63 & (252) $64.94 \%$ \\
\hline Sports & 6 & 11 & 6 & (23) $05.92 \%$ \\
\hline Culture/Tourism & 13 & 17 & 5 & (35) $09.02 \%$ \\
\hline Education/Knowledge & 7 & 11 & 6 & (24) $06.18 \%$ \\
\hline Real Estate & 18 & 25 & 11 & (54) $13.91 \%$ \\
\hline Total & 123 & 174 & 91 & (388) $100 \%$ \\
\hline
\end{tabular}


Advertisements examined in Oryx magazine received a total of 692 responses to five categories while a total of 244 responses were recorded for Edge magazine (Table 10). In Oryx, with regard to advertisements, the category of business received the highest number of responses (42.19 per cent), while culture and tourism ranked second with 27.31 per cent of the total responses. This was followed by real estate (19.50 per cent), education and knowledge (7.94 per cent), and sports (3.0 per cent). Comparing these results to the results obtained from analysing the articles, the categories of business and culture and tourism exchange positions in the ranking; however, they occupy the first and second ranks in both articles and advertisements. The category of education and knowledge ranked fourth- higher in the responses to the advertisements, and slightly higher than the same category in articles. The sport category does not appear to be of much interest since it received the lowest number of responses. The results of examining the advertisements published in the Edge magazine were similar those of the articles where the business category received the highest responses (63.11 per cent), followed by real estate (21.72 per cent), and culture and tourism (8.19 per cent). Education and knowledge is ranked fourth (3.68 per cent) while the sports category received the lowest number of responses (3.27 per cent).

Table 10: Results of analysing advertisements published in Oryx and Edge magazines (Source: Authors, 2013).

\begin{tabular}{|c|c|c|c|c|}
\hline Oryx Adverts & Dec 09-Dec 10 & Jan 11-Dec 12 & Jan 12-Jul 12 & Total \% \\
\hline Business & 121 & 116 & 55 & (292) $42.19 \%$ \\
\hline Sports & 17 & 2 & 2 & (21) $03.0 \%$ \\
\hline Culture/Tourism & 56 & 71 & 62 & (189) $27.31 \%$ \\
\hline Education/Knowledge & 22 & 20 & 13 & (55) $07.94 \%$ \\
\hline Real Estate & 60 & 50 & 25 & (135) $19.50 \%$ \\
\hline Total & 276 & 259 & 157 & (692) 100\% \\
\hline Edge Articles & April 10-Dec 10 & Jan 11-Dec 12 & Jan 12-Jun 12 & Total \% \\
\hline Business & 65 & 65 & 24 & (154) $63.11 \%$ \\
\hline Sports & 6 & 2 & 00 & (08) $3.27 \%$ \\
\hline Culture/Tourism & 9 & 5 & 6 & (20) $8.19 \%$ \\
\hline Education/Knowledge & 6 & 3 & 00 & (09) $3.68 \%$ \\
\hline Real Estate & 18 & 24 & 11 & (53) $21.72 \%$ \\
\hline Total & 104 & 99 & 41 & (244) $100 \%$ \\
\hline
\end{tabular}

These results corroborate the commitment toward image-making: they unequivocally portray an image of Doha as an emerging international hub in different fields to the global community. The three categories examined in the print media that emphasise such a vision are business, culture and tourism and real estate. On the one hand, business images represent Doha as an investment and transit hub thanks to its key geopolitical position and enormous wealth. Images of business districts, bank headquarters, and industrial plants in the magazine are designed to promote businesses and encourage partnerships. The category of culture and tourism is tasked with creating an image of Doha as an international cultural hub with vast potential for attracting tourists to fascinating cultural facilities as well as exotic desert destinations. However, while Qatar is busy promoting its capital city as an international knowledge and tourism hub through major capital investment in the architecture of educational and sport facilities, the images in the articles 
and advertisements examined do not convey such a vision due to their limited frequencies in the two magazines.

\section{Attitude Survey}

In addition to the surveys of inhabitants and their perception, the research team analysed medium to high-income groups by conducting an attitude survey study. These groups are of particular importance for the emerging knowledge economies in Doha. Therefore around 30 companies were approached and 350 employees participated in this survey about the quality of urban life in Doha. The most important objective of this research task was to clarify if the current urban environment suites the needs of a large number of higher income groups and thus to identify the main challenges for urban planners and decision makers.

After the distribution of all questionnaires in 2012 all 350 responses were collected and subsequently evaluated. All participants were from medium to high-income background. Due to their positions as employees within the emerging private sector, all of the participants were expatriates, who immigrated to Qatar during the last fifteen years. The questionnaires contained six sections:

- General Information: In this section the research team asked for age, gender and professional background as well as how many years participants have already worked in Doha.

- Mobility: In the case of mobility the questions focused on car use as well as liveability concerns such as traffic congestions and missing parking spaces.

- Housing: First participants were asked in which area and in which housing typology they live. Further questions focused on the quality of housing and how it can be improved from the participants' perspective.

- Work Place: After participants were asked where they work. The office environment and the urban surroundings were investigated.

- Services: In order to assess the quality of services such as schools and leisure facilities the participants were asked to mention general concerns. The participants furthermore were asked which leisure spaces they prefer to visit.

- City Image: Finally participants were asked to share their general impressions regarding Doha as place for long term settling and their particular subjective perception on certain images created by recent urban developments.

The first evaluation focused on a general quantitative assessment of questionnaire answers in order to gain general insights who the participants are and how they perceive their working and living experience in Qatar. 


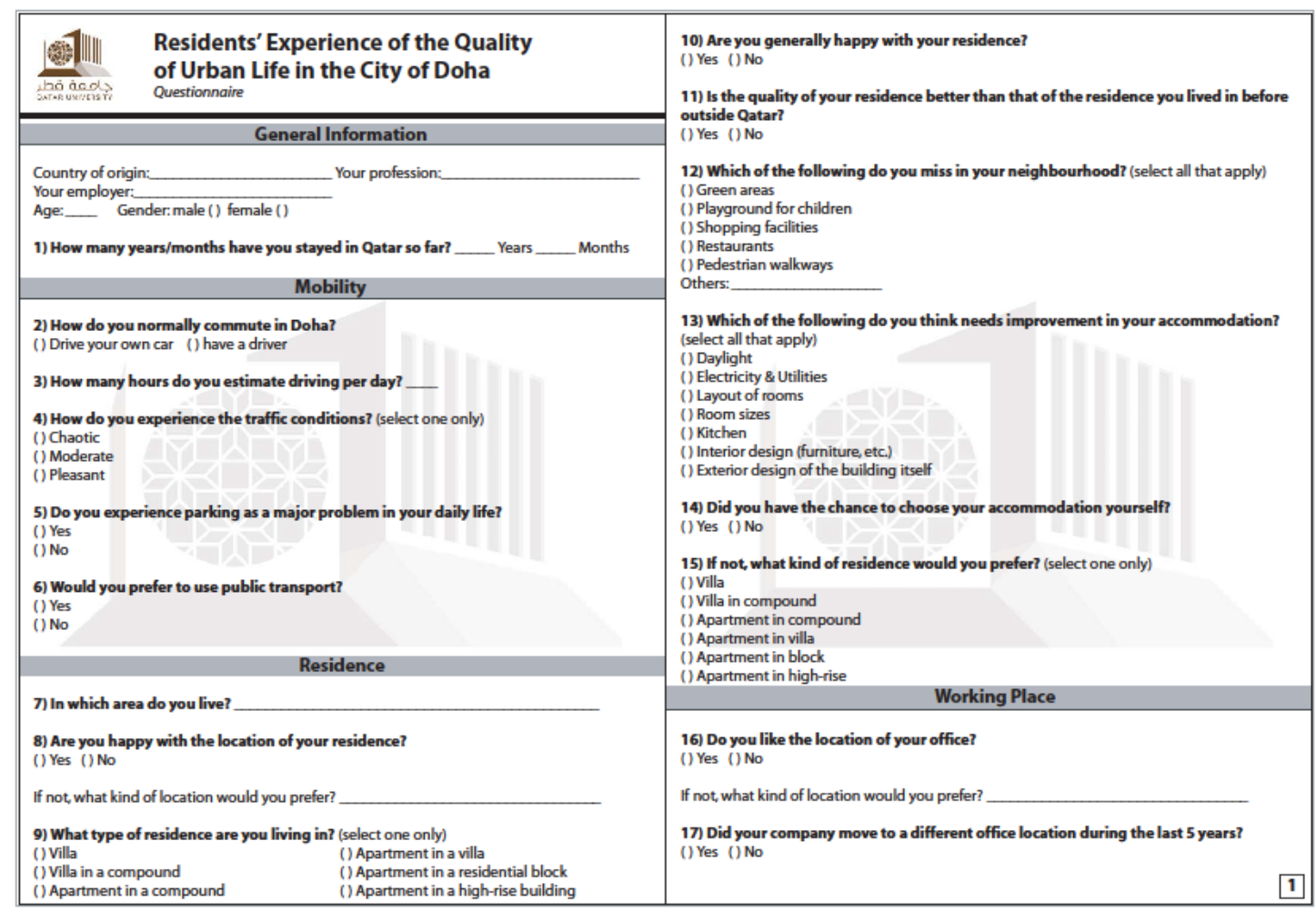

Figure 16: Sample page of the distributed attitude survey/ questionnaire (Source: Authors, 2013).

General Liveability Concerns: Based on the evaluated questionnaires the main factors that impact the employees' perception of liveability in Doha are mobility concerns related to traffic congestions, driving distances and a lack of parking spaces and insufficient services. Another factor is the low standard of construction quality in the case of their residences and offices.

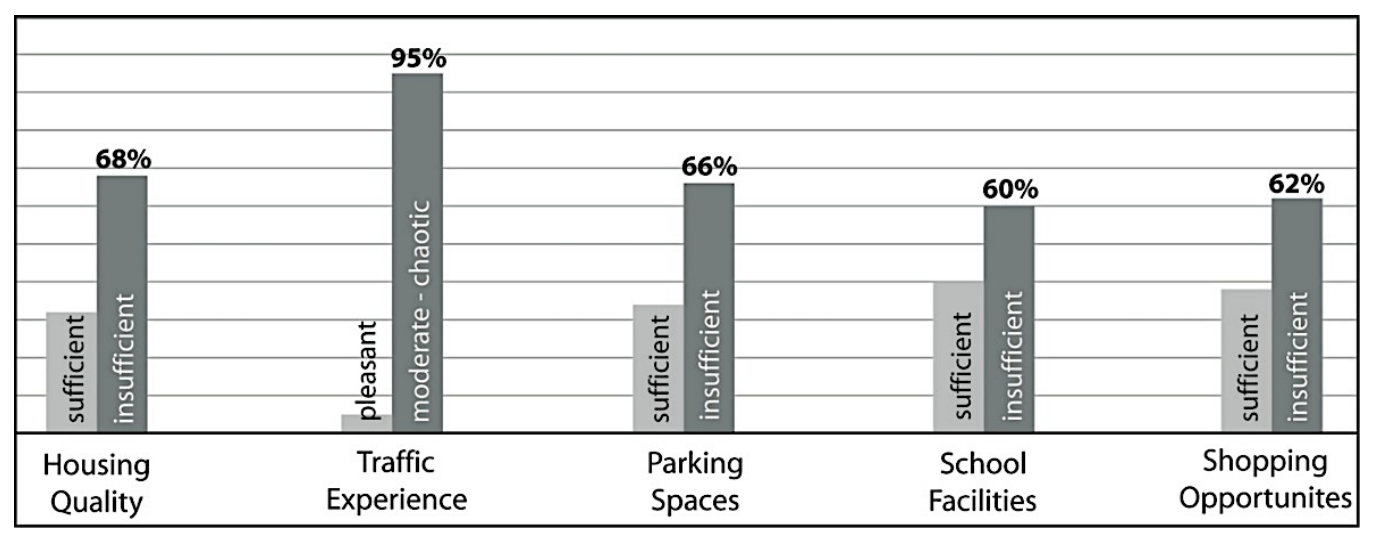

Figure 17: Frequency of employees' responses to issues related to liveability factors in Doha (based on 344 responses). (Source: Authors, 2013).

Career Perspectives: While the perceived liveability of a city is the immediate result of how people feel about Doha regarding their current needs, the individual perspectives to settle longterm in Doha are dependent on future economic aspects as well as legal rights for immigrants. Today, Qatar's service economy is to a large extent dependent on foreign guest workers, which make up 93\% of the private sector (Qatar Statistics Authority, 2012). While public incentives to Archnet-IJAR, Volume 10 - Issue 1 - March 2016 - (xx-xx) - Regular Section 
integrate the local population in developments is necessary for implementing the end of welfare mechanisms, these strategies also imply reduced long-term perspectives for guest workers in certain areas. Based on the evaluated questionnaires $66 \%$ of the participants perceive Doha as a potential place to settle due to career opportunities and high salaries, among other factors.

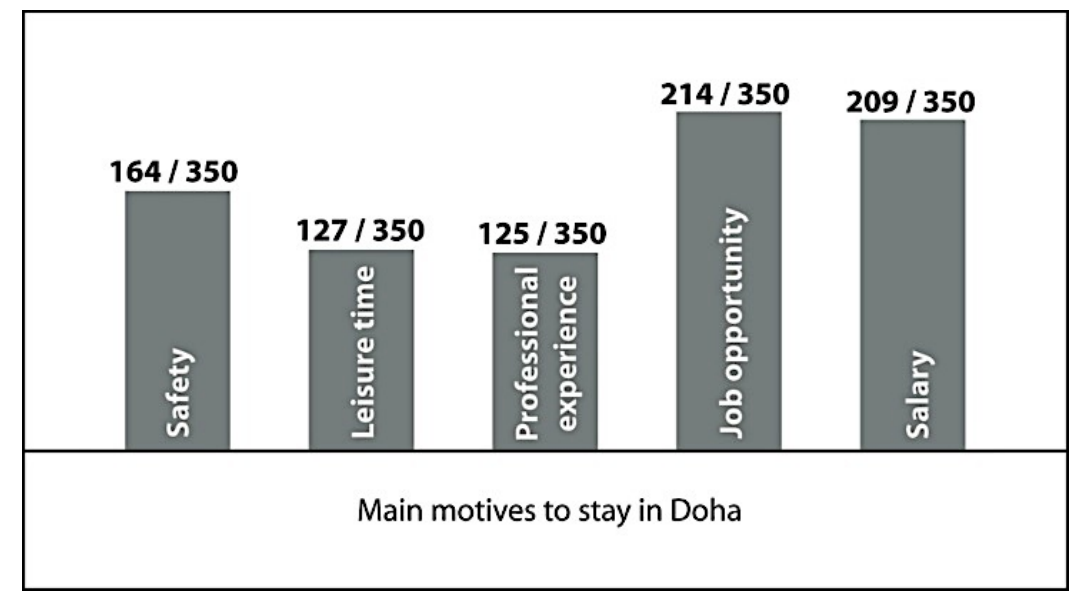

Figure 18: Frequency of employees' responses related to their long-term individual perspectives (based on 350 responses). (Source: Authors, 2013).

Aesthetics of the Urban Environment: The third factor in producing an identification process is based on the image of a city and its aesthetics from an inner cultural perspective. Only $13 \%$ of participants identify the Souq Waqif as the most prominent landmark in Doha. However, a majority of $65 \%$ of participants perceive it as a highly attractive leisure space. In addition to landmark projects, general urban design, particularly in the case of public spaces, can have a large impact on how space is aesthetically experienced. Due to its low built density Doha is dominated by low-rise housing and because privacy is usually manifested by walls, large urban areas are experienced as rather rejecting and unwelcoming by most participants.

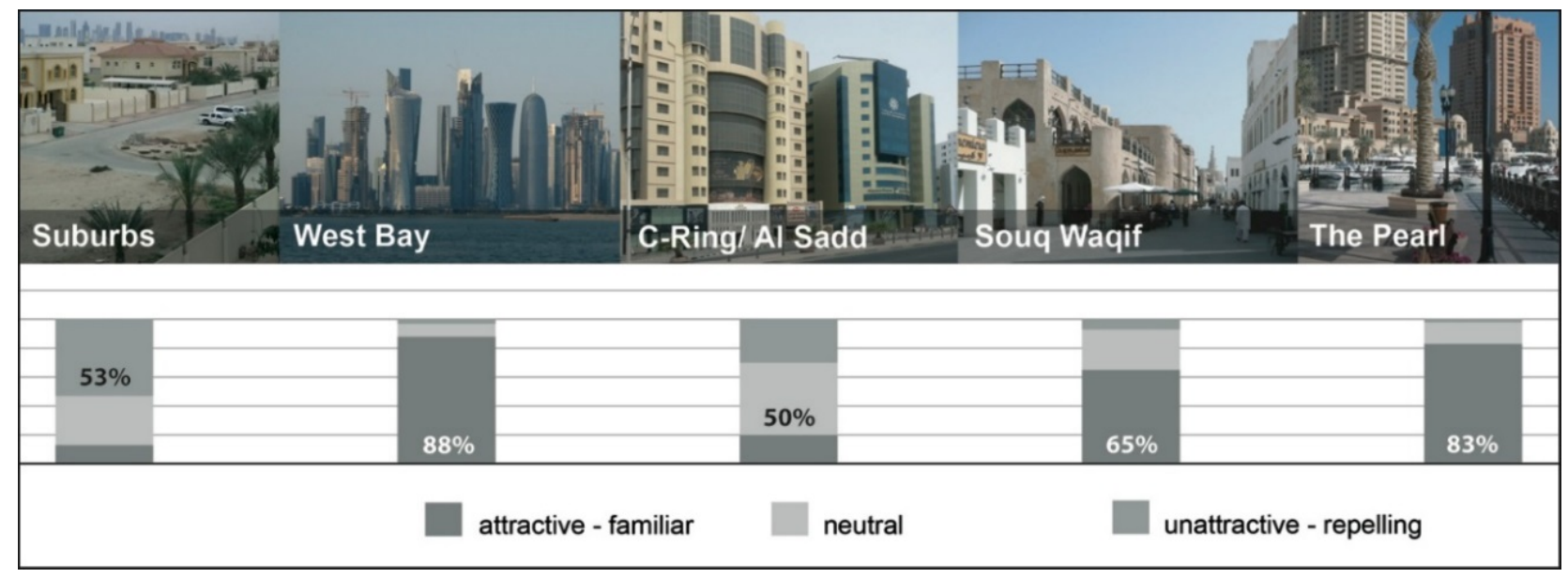

Figure 19: Employees' perception of urban spaces in Doha (based on 350 responses). (Source: Authors, 2013).

In addition to the general assessment of how the majority of participants perceive the quality of urban life, the project team focused on the role of the country of origin and the various cultural 
backgrounds. Therefore the questionnaires were evaluated by distinguishing three main groups: South Asians, Arabs and Westerners. A large majority of the 350 participants were from South Asia (India and Pakistan), while the Westerners and Arabs were similarly represented. This result is in coherence to general immigration statistics (Figure 20).

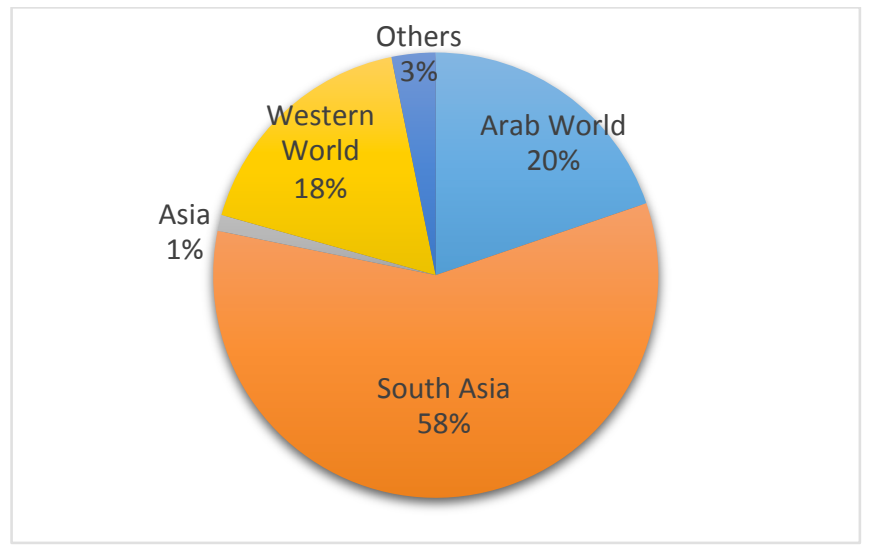

Figure 20: The distribution of percentages regarding the origin of participants (Source: Authors, 2014).

Traffic conditions: Due to the various backgrounds and the past experience of respondents traffic conditions are perceived rather differently. While a majority of South Asians experience traffic as moderate, a majority of Westerners perceive it as chaotic. The group of Arab origin is divided, although a slight majority would interpret traffic moderate rather than chaotic (Figure 21).

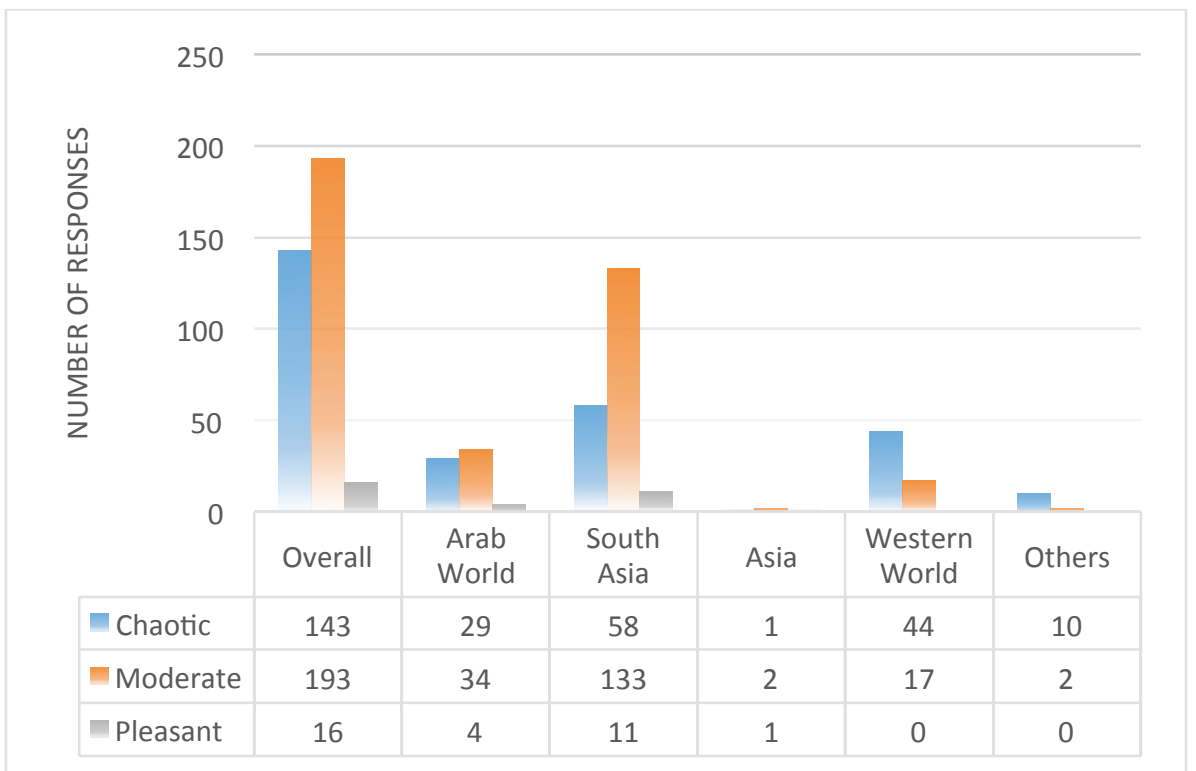

Figure 21: The perception of current traffic conditions (Source: Authors, 2014).

Preferred residence types: The South Asian group mainly lives in apartments within multistory blocks or high rises, while the Arab group equally prefers to live in villas. In the case of the Westerners a clear majority is housed in villas within compounds followed by apartments in serviced high-rise buildings (Figure 22). 


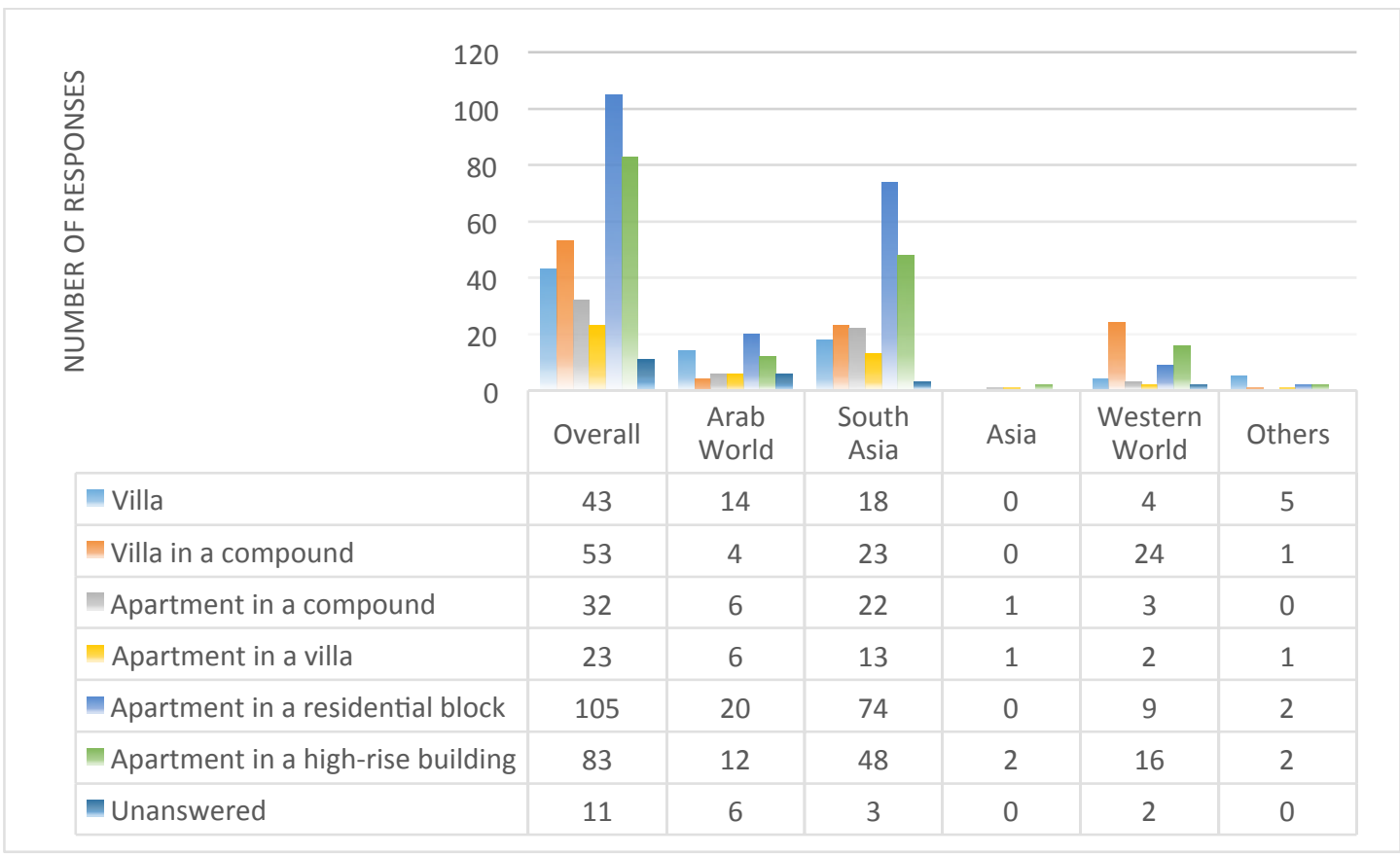

Figure 22: Residence types according to the origin of participants (Source: Authors, 2014).

Preferred leisure spaces: In the case of the preferred leisure space all three groups mainly prefer shopping malls due to the climatic conditions in Doha. But in contrast to Westerners a large percentage of South Asia identify the Corniche as their favourite leisure space in Doha. While a significant percentage of Arabs prefer the Souq Waqif as their leisure destination, a large amount of Westerners prefer to spend their leisure time in hotels, where restaurants are permitted to serve alcohol (Figure 23).

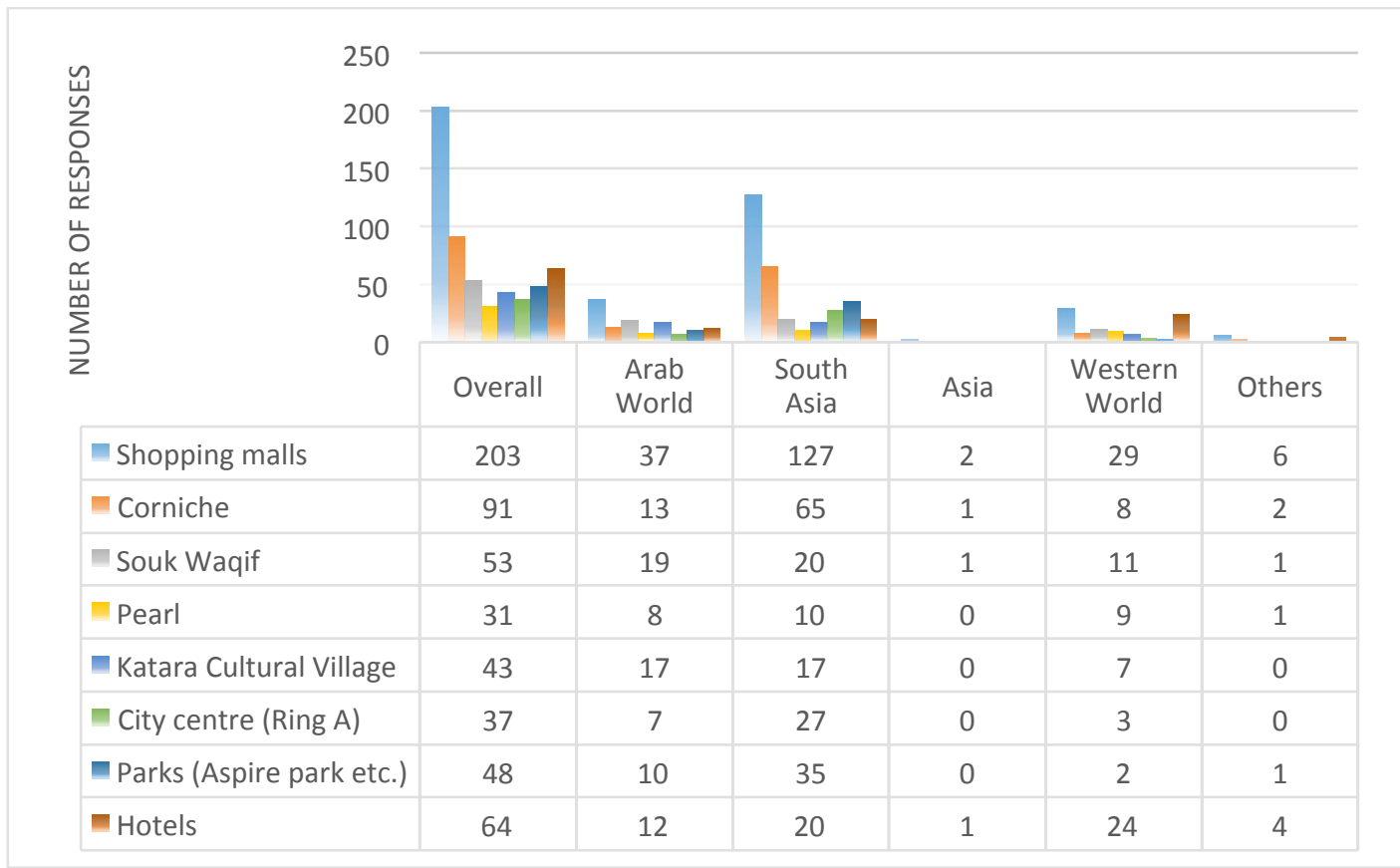

Figure 23: Preferred leisure spaces in Doha according to the origin of participants (Source: Authors, 2014) 
Frequency of visits to the historic city core: One particular interest of the research team was to explore the significance of the historic core of the city. In recent years the historic centre has witnessed a major transformation process due to the development of various mega projects (Wiedmann et al., 2013). Therefore participants were asked: how often they visit the old downtown area including Souq Waqif. While a large percentage of Arabs visit the area on a monthly basis, South Asians and Westerners have rather limited interest to spend their time in the historic parts of the city. This is a clear indication that the Souq Waqif area mainly attracts tourists and Arabs, who feel culturally attracted to the vernacular urban environment as well as to ethnic restaurants and crafts shops.

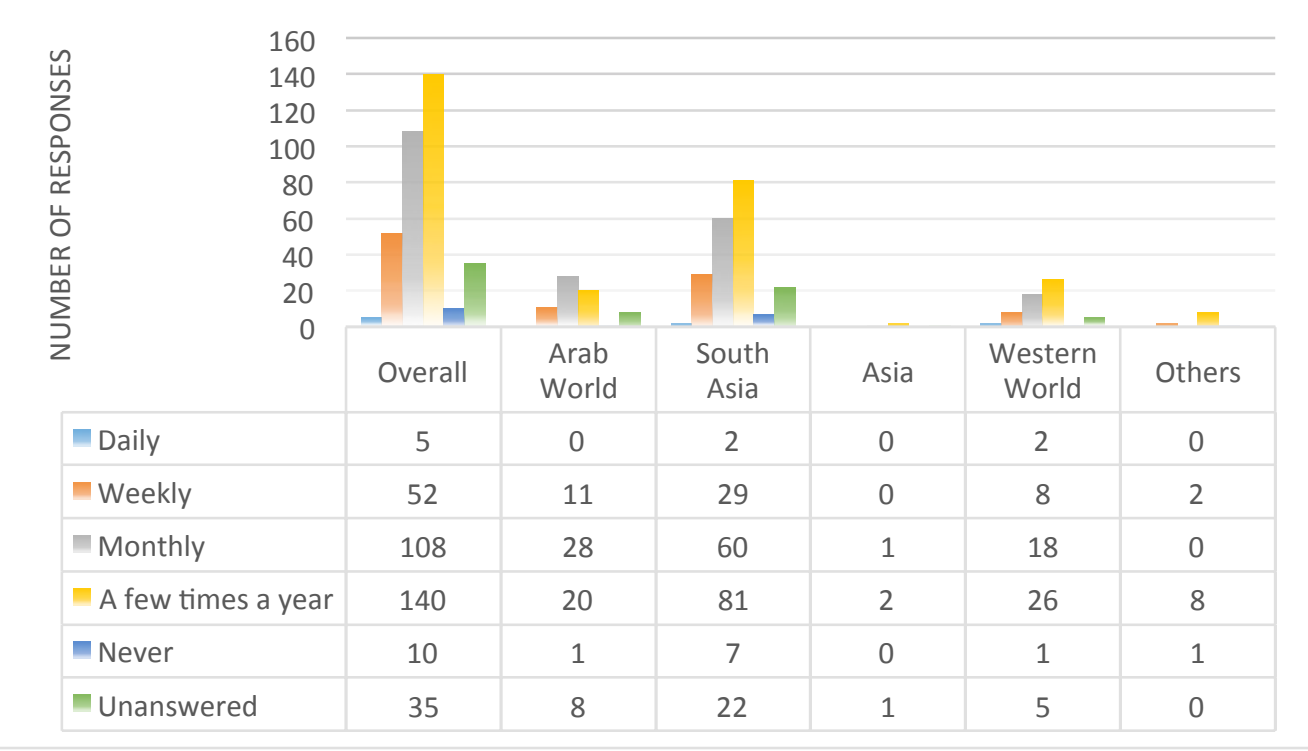

Figure 24: The frequency of visits to the historic centre of Doha (Source: Authors, 2014).

Main motives to visit the historic city core: In the case of the reasons of visiting the historic centre of Doha, a majority of Arabs and Westerners identified dining out as the main reason, while South Asians mainly visit the old centre to go shopping (Figure 25).

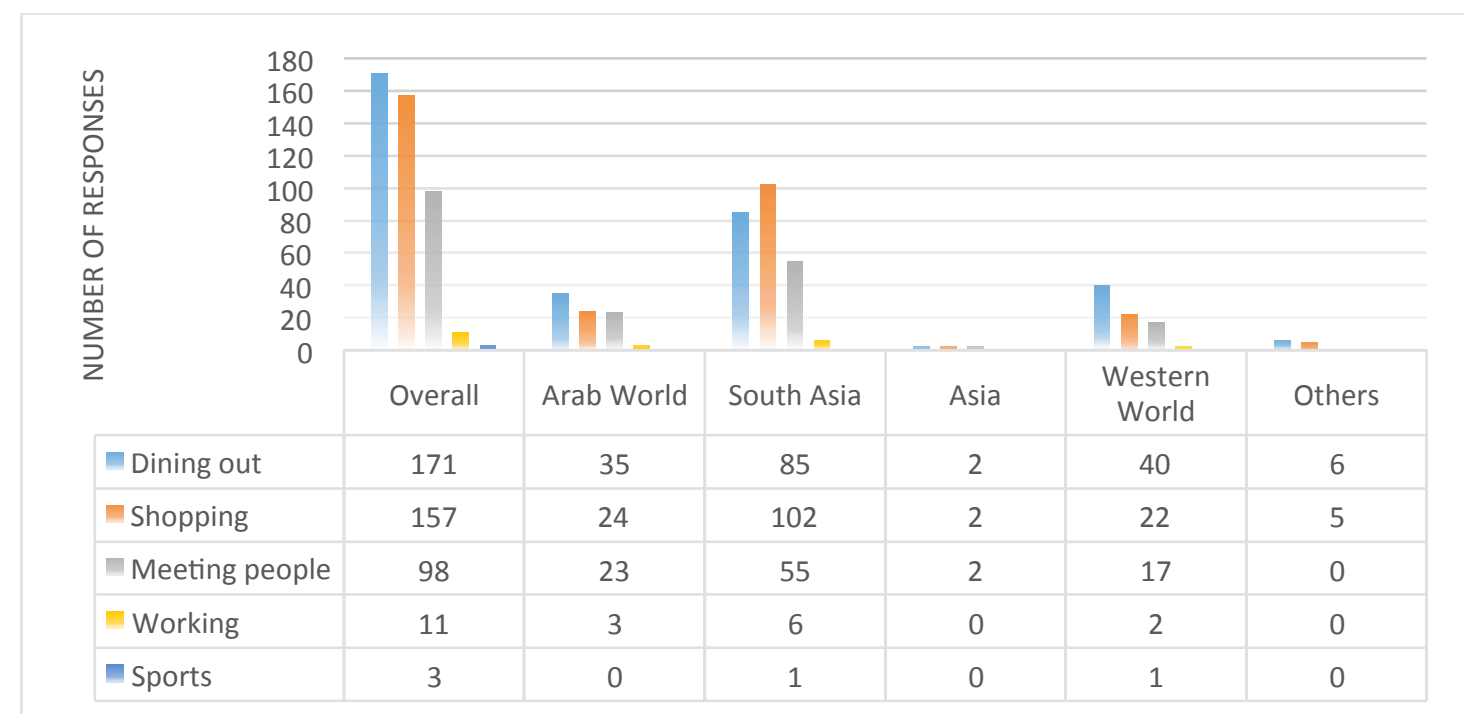

Figure 25: The reasons for visiting the historic centre of Doha (Source: Authors, 2014).

Archnet-IJAR, Volume 10 - Issue 1 - March 2016 - (xx-xx) - Regular Section 
The most frequently associated images with Doha: Last but not least the research team focused on understanding the main images associated with Doha by participants of various cultural background. While Arabs and South Asians perceive the Corniche as the key feature of Doha's urban environment, Westerners identify the cluster of high-rise building as the most significant image representing Doha. This can be interpreted as a clear indication of a rather short-term stay of many Westerners and thus a lack of historic or cultural awareness (Figure 26).

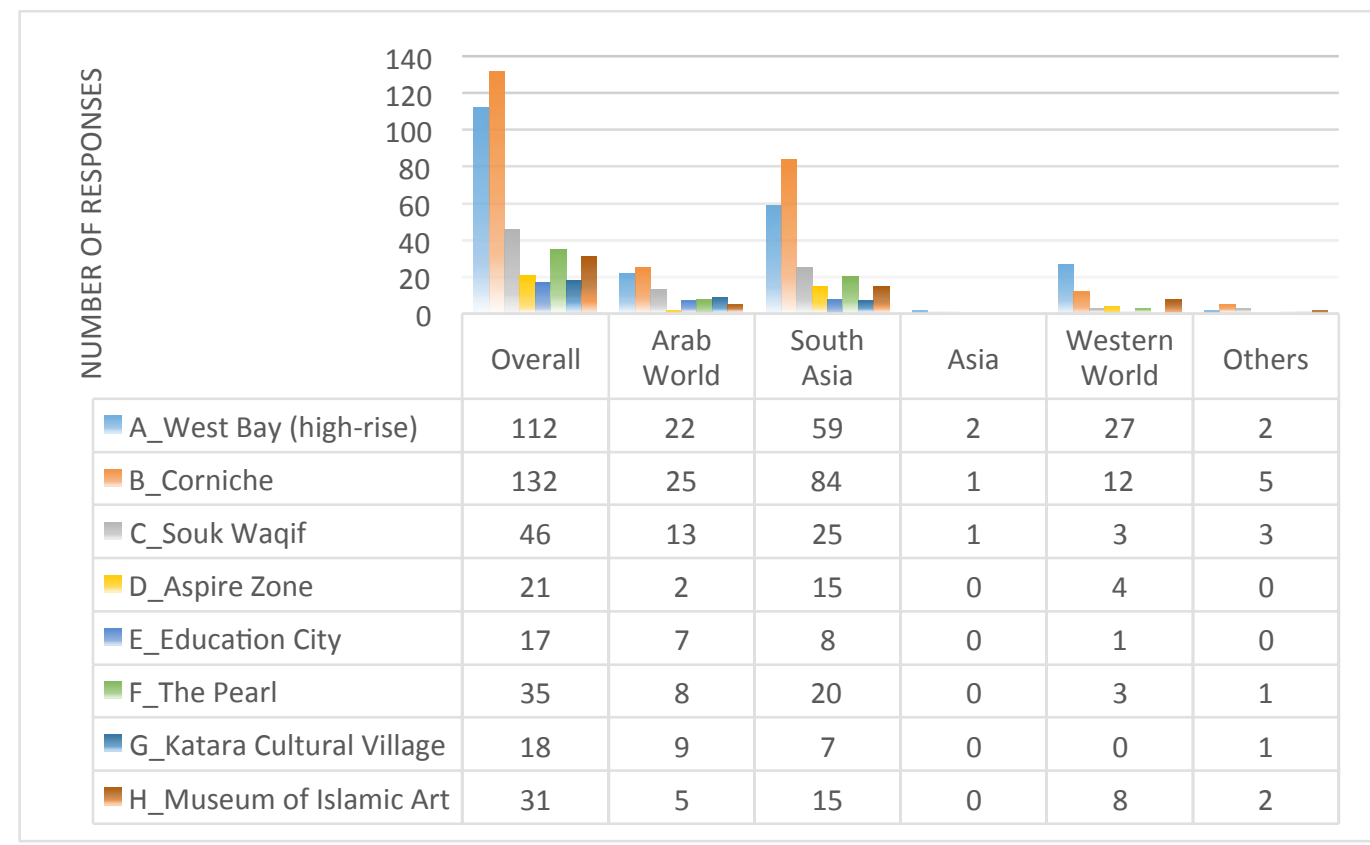

Figure 26: The most frequently associated images with Doha (Source: Authors, 2014).

Notably, medium to high-income groups in emerging service sectors play an important role in securing economic growth in Qatar. Thus, their identification with Doha as a highly attractive place for living and working is decisive for a successful economic diversification and the longterm establishment of knowledge economies. The outcomes of the survey reveal that South Asians, who form a significant majority in the private service sector, are generally attracted to Doha. Main reasons are the high levels of security and safety and the perceived living standards in comparison to their countries of origin. The results furthermore indicate aspects urban planners find as main challenges for creating a liveable urban environment in Doha: Traffic conditions, insufficient social infrastructure, insufficient services such as schools, and the architectural and construction quality of residences.

\section{RESEARCH MODULE V: SPATIAL IMPACT ANALYSES}

\section{Urban Structure Assessment}

The final research module focused on the spatial consequences of the recent economic diversification and the emergence of knowledge economies in Doha. This module is of high importance for the overall objective of this research project and helps to clarify how emerging service sectors have transformed the urban environment during a rather short period of rapid growth. Therefore the spatial transformation of Doha was investigated between 2003 and 2012 .

At first the spatial configuration of the existing street network was analysed. Preliminary analyses showed that the syntactic variables were most effective in discovering systematic relationships. The analysis led to the recognition that the highest level of integration at a global radius $\mathrm{Rn}$ (in red) can be found along most ring roads with an existing high density of commercial 
activities. On the contrary, at a local radius (R500) the highest level of movement integration can be found in local areas within the old core of Doha.

Global Accessibility: After measuring the degree of global accessibility of each segment of streets in the whole system (city-wide scale) the study led to following results:

- The most accessible streets (in red) are located mostly in urban roadways, such as main roads, ring roads and highways. Some of these roadways start from the centre and extend to reach the city edge in a different direction. Others cross from the north to the south of Qatar extending to other towns near Doha.

- The shoreline of Doha city (Corniche) is picked out in yellow and orange, which reflects a generally accessible space at the global radius.

- A number of local areas, such as suburban areas, and new urban developments, such as Lusail, visibly disappear from the global accessibility, being the least accessible (in blue), and thus almost disconnected from the global urban network of Doha.

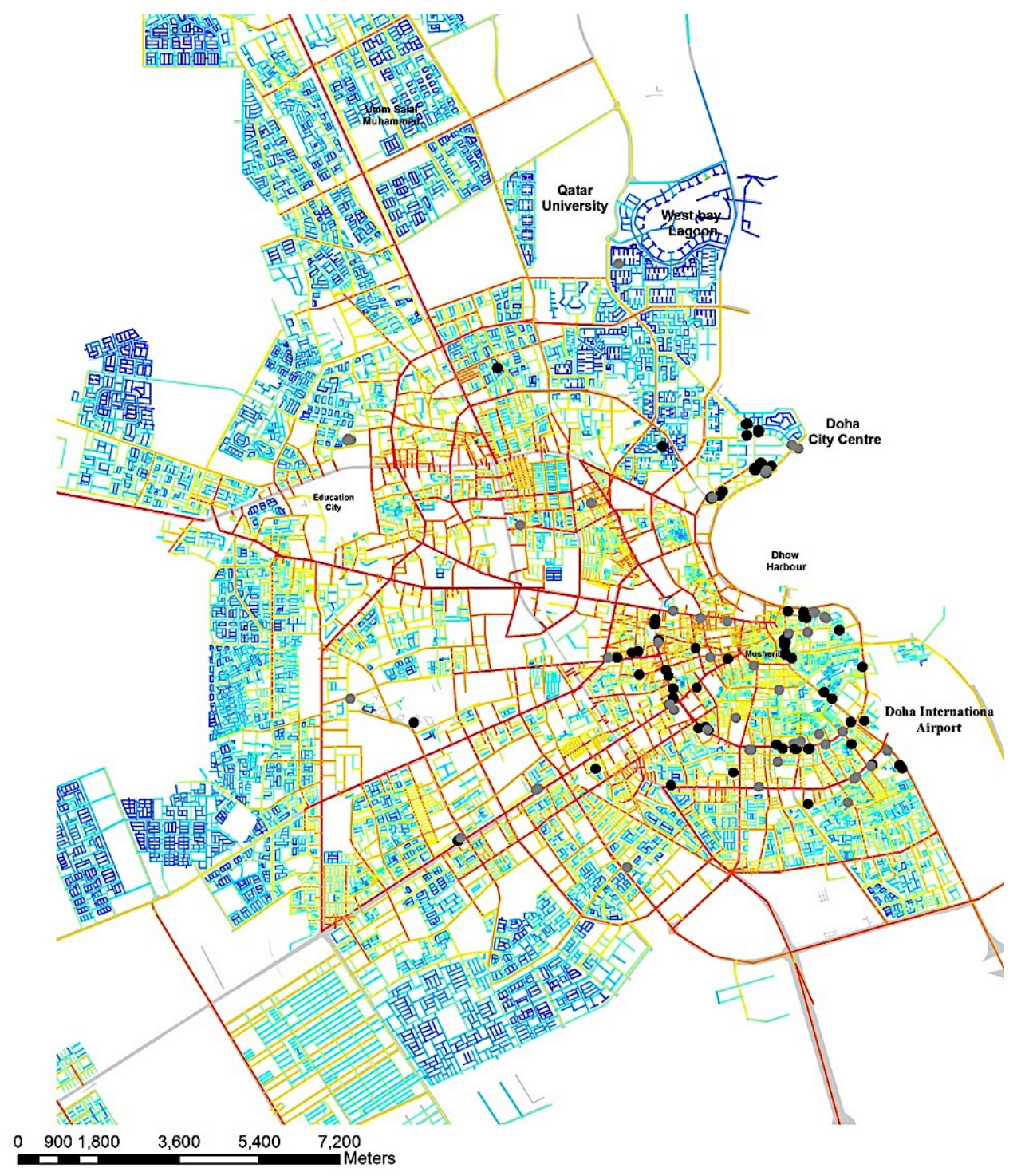

Figure 27: Doha street network - segment integration at global radius Rn (Source: Authors, 2013). 


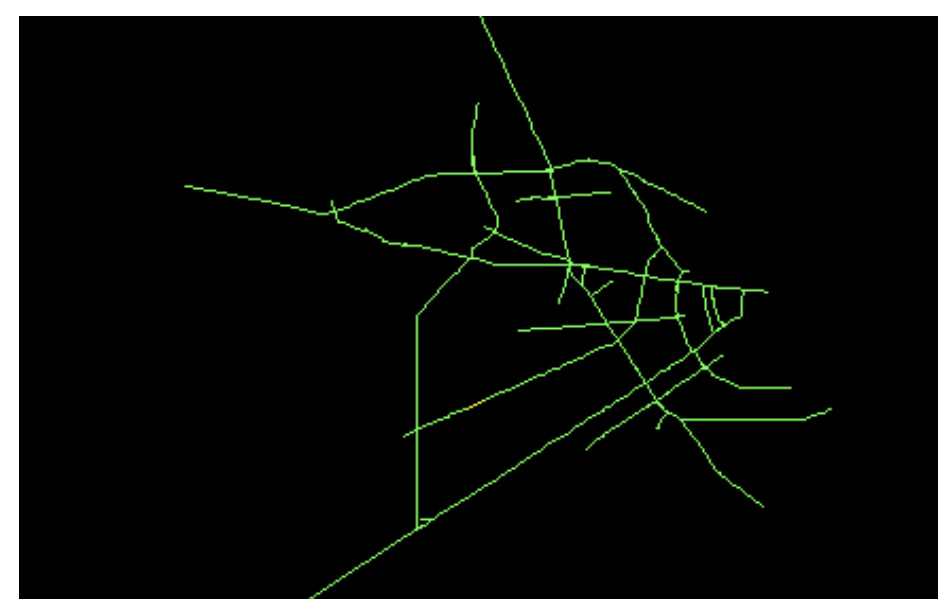

Figure 28: High potential movement space of normalized integration at global radius (Source: Authors, 2013).

Local Accessibility: The following results were found based on the analysis of Doha's spatial network at local radius R500 measuring the degree of local accessibility of each segment of the local street network (at a local scale of 5 minutes' walk away from all streets):

- Most of the local centres disappear in the case of the global accessibility analysis; this could indicate an imbalance within the spatial fabric.

- The shoreline of Doha city (Corniche) is highly accessible in the case of both local and global scale.

- The industrial area is highly accessible at the local scale, while it is least accessible (in blue) in the case of the global scale.

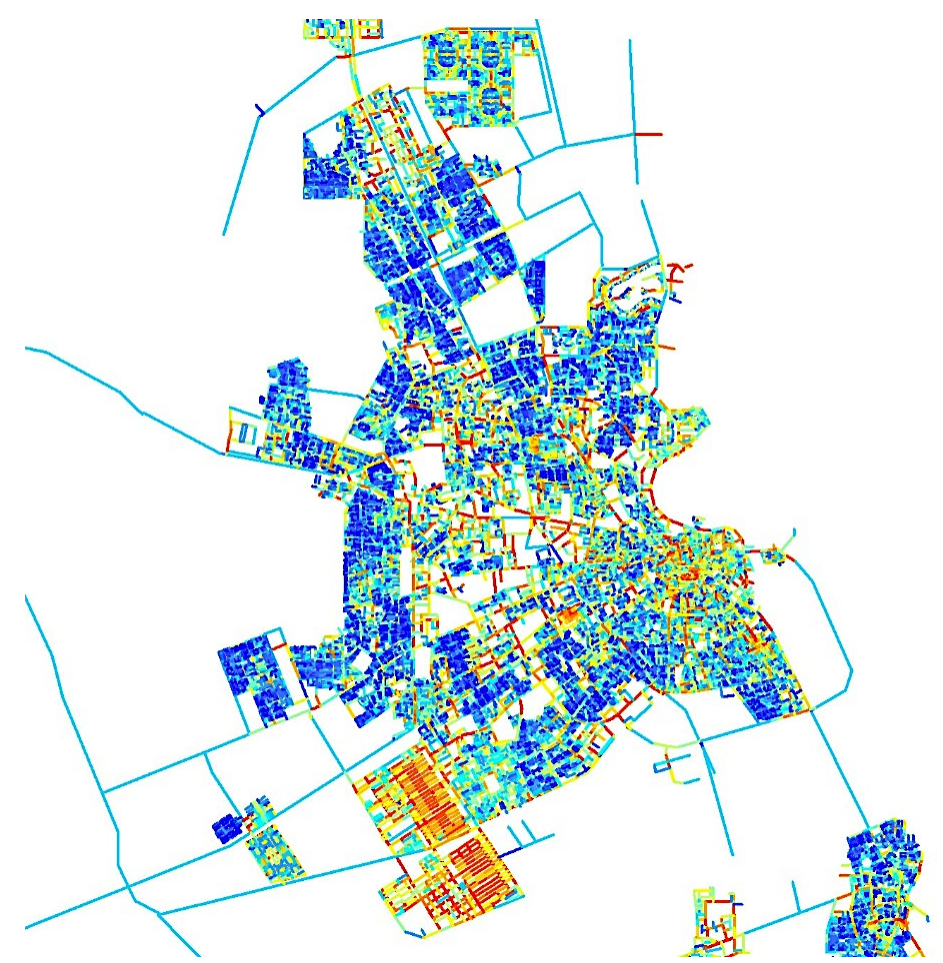

Figure 29: Doha street network - segment integration at Local radius R500 (5 minutes' walking distance) (Source: Authors, 2013). 


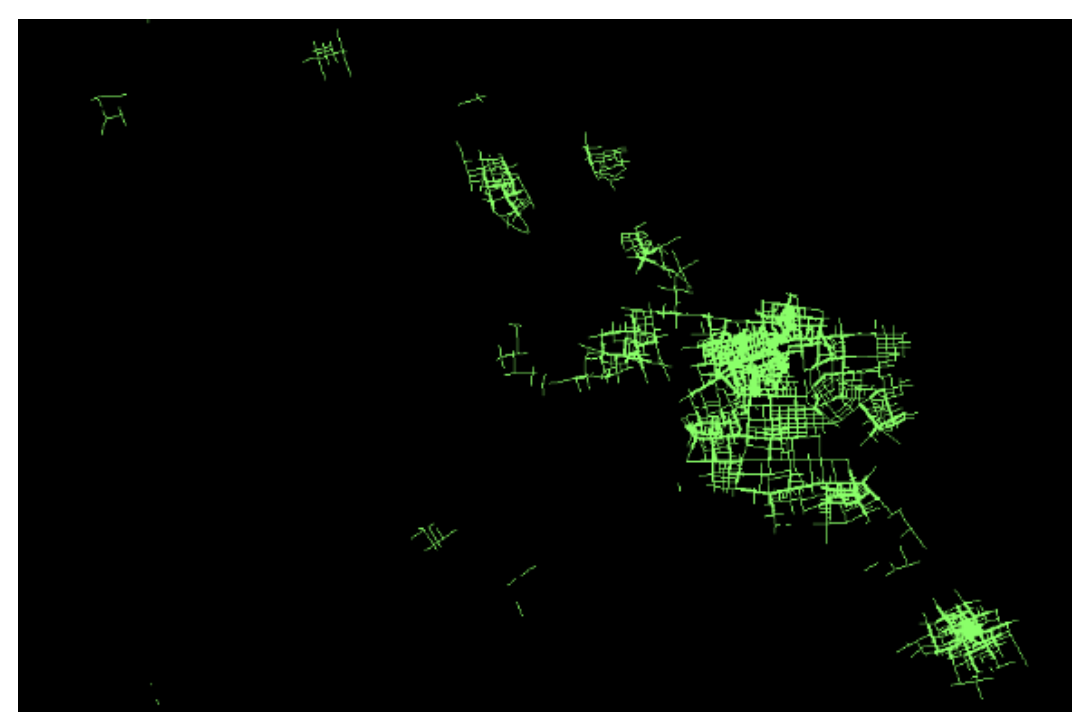

Figure 30: High potential movement space of Integration $\mathrm{T}$. Local radius Integration R500 meters (Source: Authors, 2013).

General spatial layout: Figure 31 shows the normalized integration of the urban fabrics from local to global scale. The red segment represents the most accessible space at multi-scales of distance. At the radius of 250 meters, the most accessible and integrated space is located on an intensified local grid within the old city centre. By increasing the radius to 500 meters the segment moves to the local structure of a deformed wheel shape within the old core of Doha. In the case of a radius of 1000 meters it shifts to the boundaries of the old centre. And in the case of the intermediate radius of 2000 meters the centre shifts to the first ring roads $A$ and $B$. At a global level the highest level of spatial integration can be found along the main highway axis (ring roads $C$ and $D$ ) of the city. Thus the level of spatial integration shifts from the old city centre to the urban motorways in the outskirts if the radius is increased from local to global scale. There is almost no overlap between the locally and globally highly accessible spaces. This research outcome mirrors the high level of accessibility in the case of the C Ring Road from most housing areas in Doha as well as the still existing grid of small side roads within the historic centre, which enables accessible areas for pedestrians and thus a high level of land use integration.

At the global integration level, the most integrated roads are Al Sadd Street and Salwa road, the $C$ ring-road and a section of $D$ ring-road, where the main retails and commercial activities take place. This indicates that the fast urban growth of Doha in recent years has led to an insufficient integration of a main urban centre on a metro scale. In the case of the local integration (500 meters), another pattern emerges for the highest integration level. The most integrated districts are found in the old core of the city and its proximity. This leads to the implication that Souq Waqif is still considered as a strong centre but for the local level and not on a metro scale. Further local centres are found rather isolated within the urban fabric. This isolation was further increased by the extension of the main road grid during the last years. Subsequently the local urban fabric of districts is disconnected from the main urban structure. 


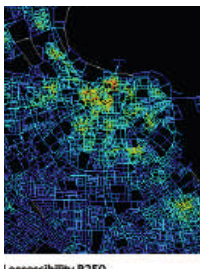
accessibibity R250
on intensity local grid of of
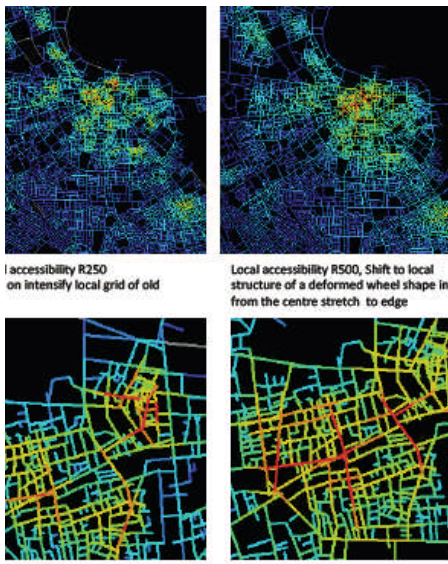
structure of a detormed whee shap
trom the centre stretch to edge
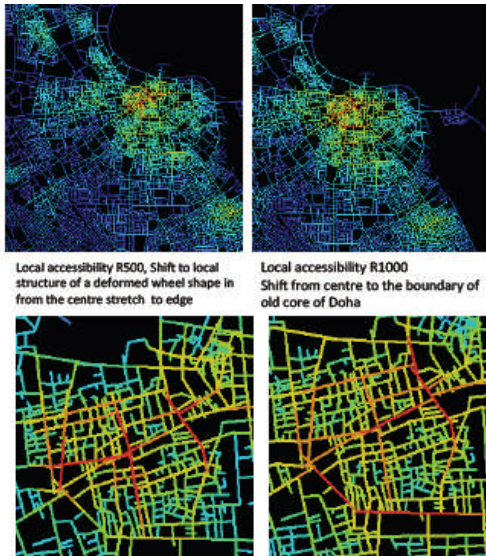

Local accessibility R1000 Shitt from centre
odd core of Doha

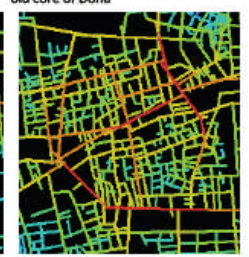

Doha centrality shift :

High local integration R250 picked out the old Doha centre

High local integration R500 picked out a deformed wheel structure at old city centre
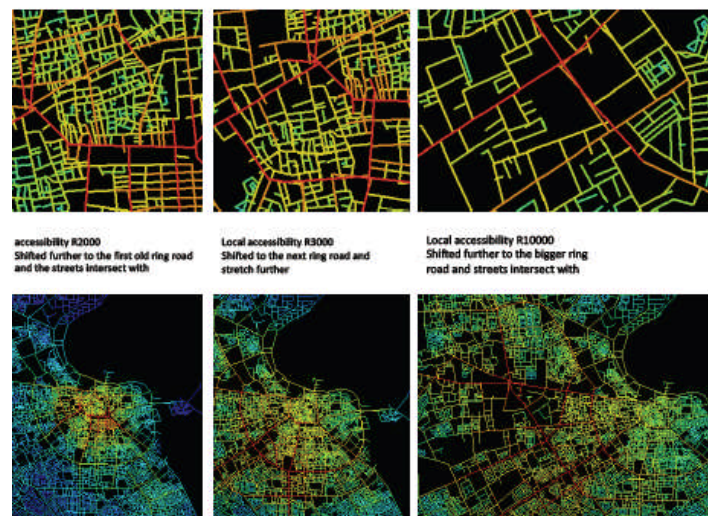

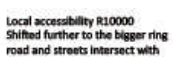

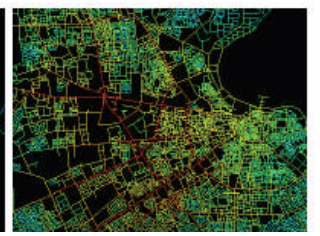
global from old city centre at local scale to urban motorway and ringroads at global scale.

The city is not for congestion, but should be a transaction between social, economic an environment, with a Multi-mode between public and private, Multi-Scale between Macro, Meso and Micro scales, and Multi-active to , through and within space.

Figure 31: Doha's varying levels of accessibility from local to global radius (Source: Authors, 2013).

The syntactic analysis aimed to investigate the spatial structure of Doha in the case of both local and global scale. The resulting patterns of recent urban developments were examined regarding accessibility potentials such as:

- To-movement (integration measure)

- Through-movement (choice measure)

Angular Step Depth analysis (ASD): This research task was needed to test the degree of accessibility and deviation of different areas within the urban grid of Doha. By using the angular step depth (ASD) from a selected segment in different areas it was possible to maintain the direction that facilitates the minimum depth calculation. First, the measure of the angular step depth begins from the inner space of central urban areas. The path length in the selected segment showed significant networks within the urban context of Doha. In some areas there is a strong linear space extended horizontally; this gives an indication of a well-integrated system, which is easy to reach from surrounding areas. Others have a very limited graph, showing a deep system, which means that they are hard to be reached from the main structure of the city and almost segregated from the surrounding context (Figure 32).

Most residential areas within the urban layout of Doha, such as the diplomatic area, the AlDuhail residential area and Madinat Khalifa, have well integrated urban fabrics. The most segregated urban patterns can be found in the case of the West Bay Lagoon project (ASD mean $=9.3$ ). This indicates that new urban development areas in the north are rather fragmented and detached from the main urban network. Furthermore, main urban centres such as the old city centre or the Aspire Zone are better integrated than areas for mono-typological residential use (ASD mean $=6.6$ ), while the ring-roads and highways are most accessible.

Archnet-IJAR, Volume 10 - Issue 1 - March 2016 - (xx-xx) - Regular Section 


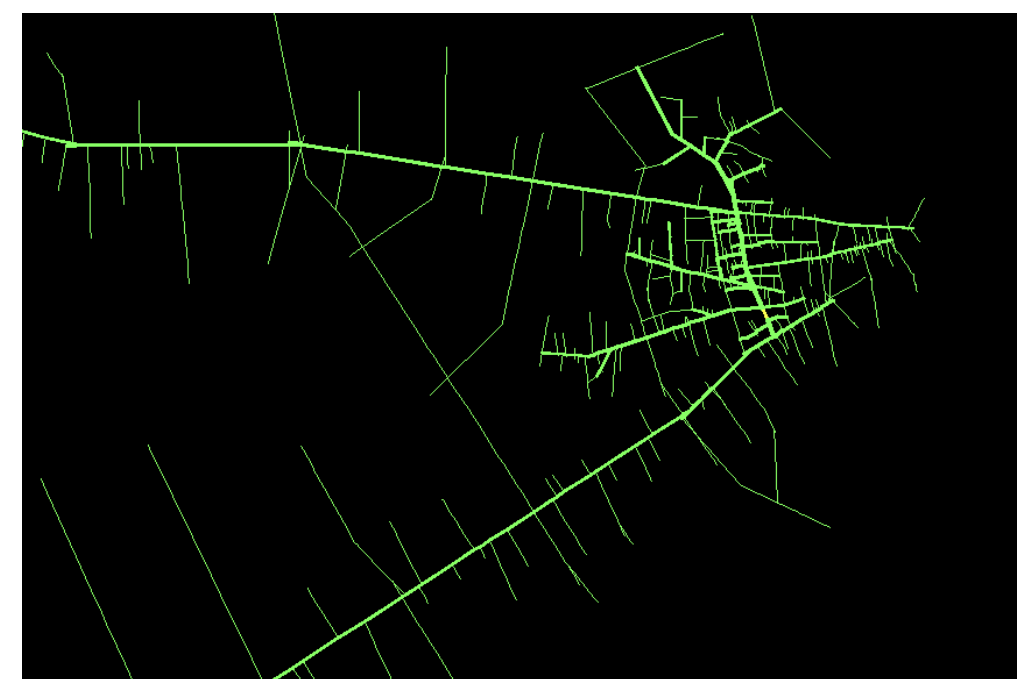

Figure 32: Angular segment depth analysis in the case of the first B Ring-road closer to old core (Source: Authors, 2013).

Land Use Integration Analysis: The analysis of the spatial integration level of certain land uses is an important tool to understand the overall spatial configuration of a city. The main research focus of this task included three steps:

- Global and local assessment of commercial areas used by businesses.

- The location of business clusters.

- Syntactic differences between the different degrees of urban grid geometry (intensify/ disperse) of these centres.

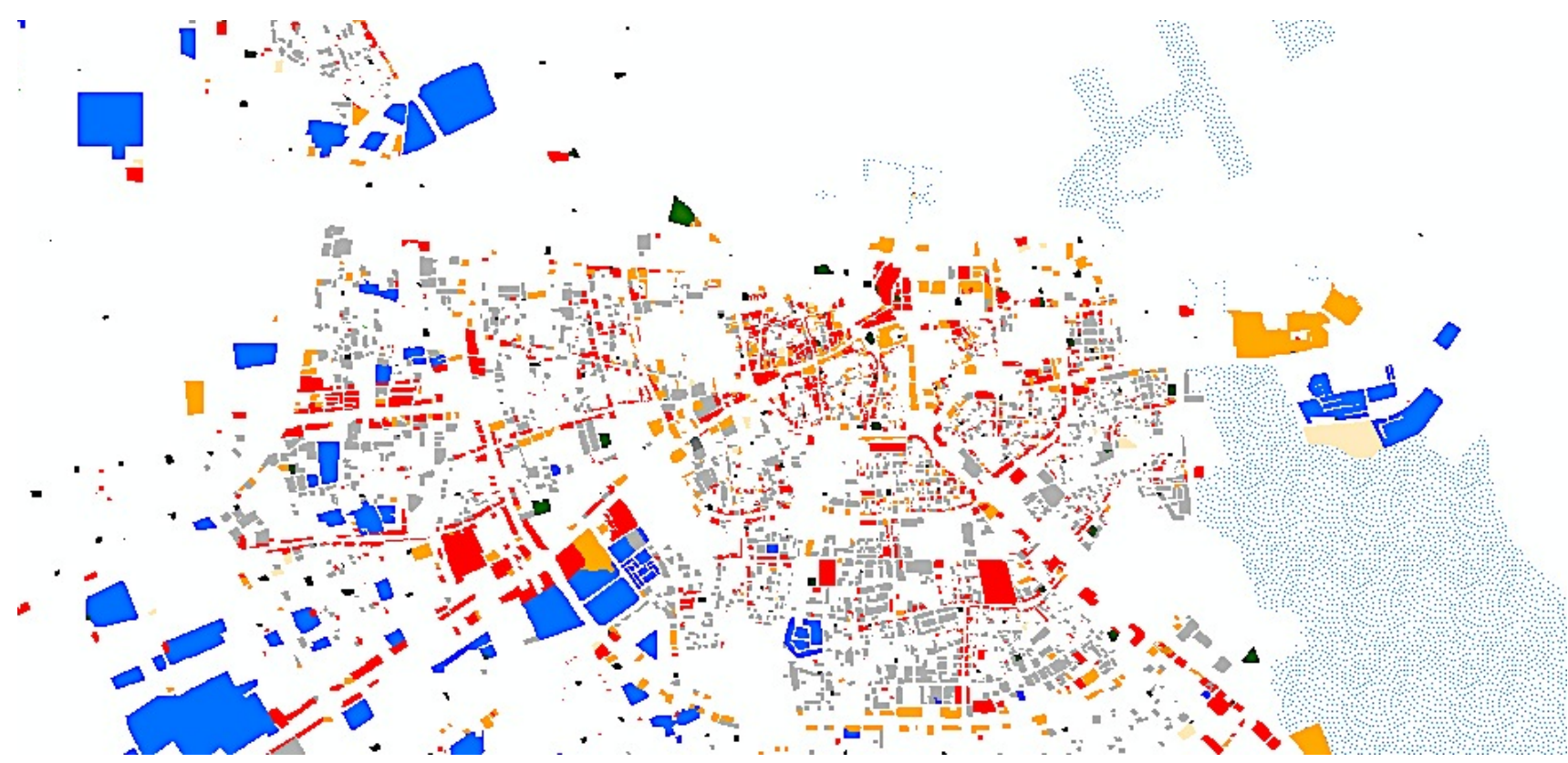

Figure 33: Retail (red), compound residences (blue) and apartment buildings (grey) and offices (orange) (Source: Authors, 2013). 

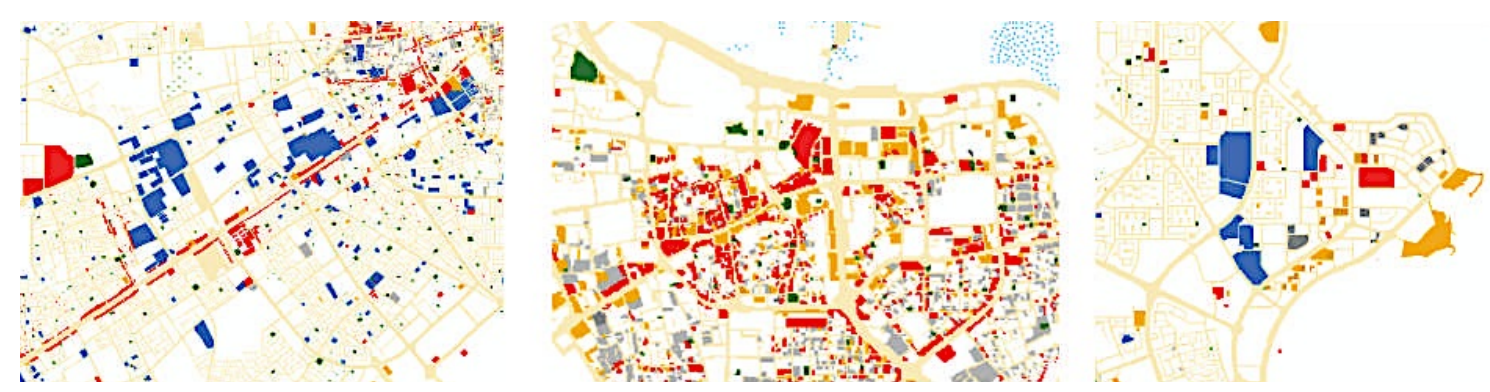

Figure 34: The three main commercial hubs:

Salwa Road (left), Ring Roads (middle) and West Bay (right) (Source: Authors, 2013).

There are three types of commercial activities in Doha:

- Economic activities found within local districts.

- Economic activities found along high streets.

- Shopping malls scattered in different locations in the city.

These commercial activities have certain spatial characteristics. Some commercial activities are distributed following a linear form and others with high density follow a convex form and some are segregated surrounded by very low densities.

A segmental angular analysis of the city of Doha at global scale between 2003 and 2013 illustrates how the old core and local districts developed to isolated urban areas within an emerging super-grid structure. The graph representation of the syntactic models at 2003 and 2013 mirrors quite accurately the development (Figure 35). The shopping streets located along highways and ring roads are the most integrated entities. The residential areas have witnessed an increasing segregation process during recent years. Due to missing land use integration on local level districts have become more and more dependent on the supra-district network of services, such as large shopping mall complexes.

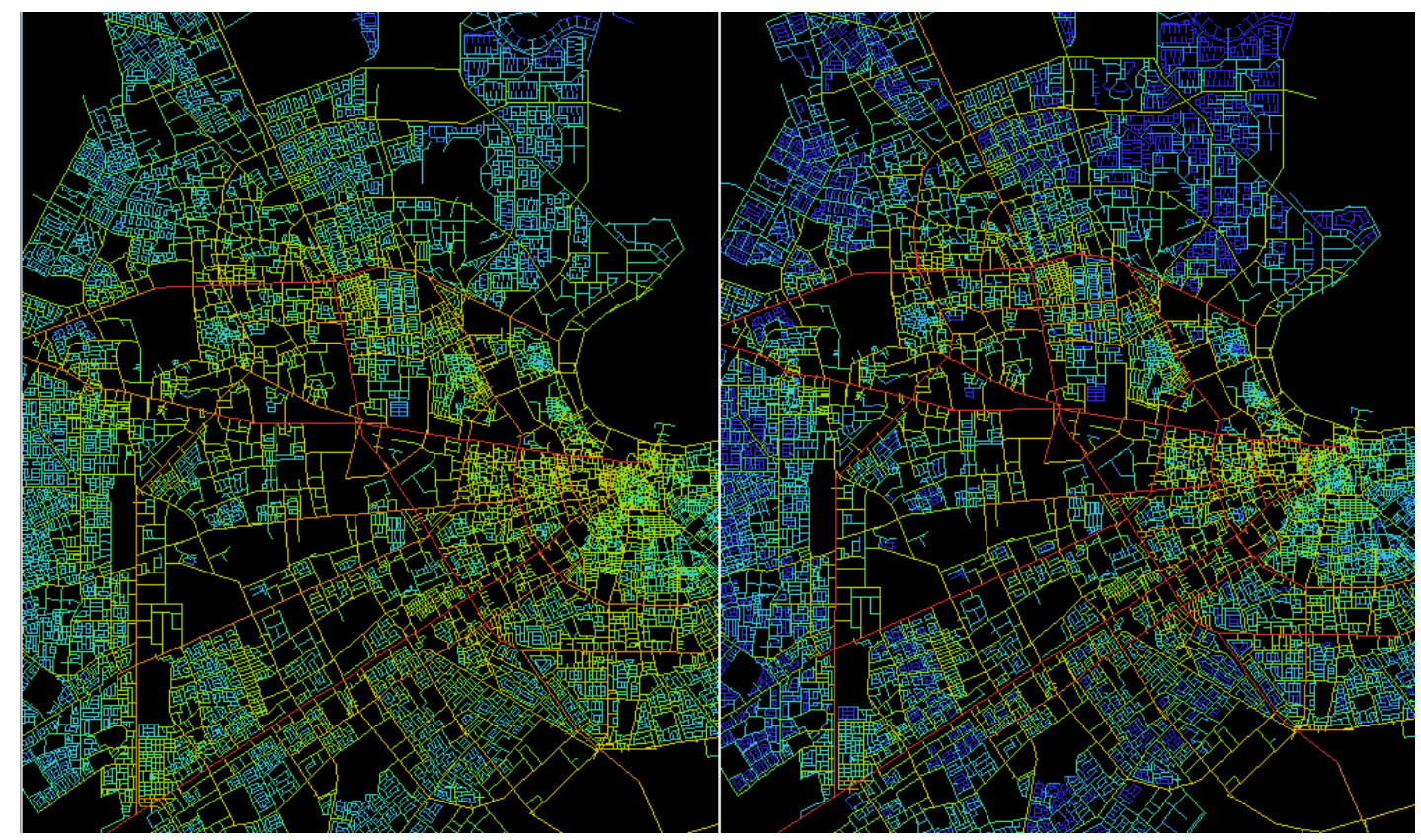

Figure 35: The Space Syntax model of Doha in 2003 (left) and in 2013 (right) (Source: Authors, 2013). 


\section{THE ROLE OF KNOWLEDGE ECONOMIES IN REDEFINING SPATIAL CONFIGURATIONS}

In addition to a general survey of the contemporary spatial configuration of Doha, the project team focused on urban areas, which are of major importance for emerging knowledge economies. Therefore the locations of 160 companies engaged in various service sectors were identified and Space Syntax was implemented to investigate the level of spatial integration depending on business branch and the global connectivity level of companies.

- The first step of this procedure was the identification of all 160-company locations by using official data. All company locations were marked within an ArcGIS file.

- The second step was to investigate if the office locations of companies can be seen as an indicator for certain spatial preferences within knowledge economies. Therefore spatial integration, choice measure and whole-part relationship between local and global distance were analysed. For each company location a 100-meter buffer was created in order to enable a more precise measuring of the spatial variables (Figure 36 ).

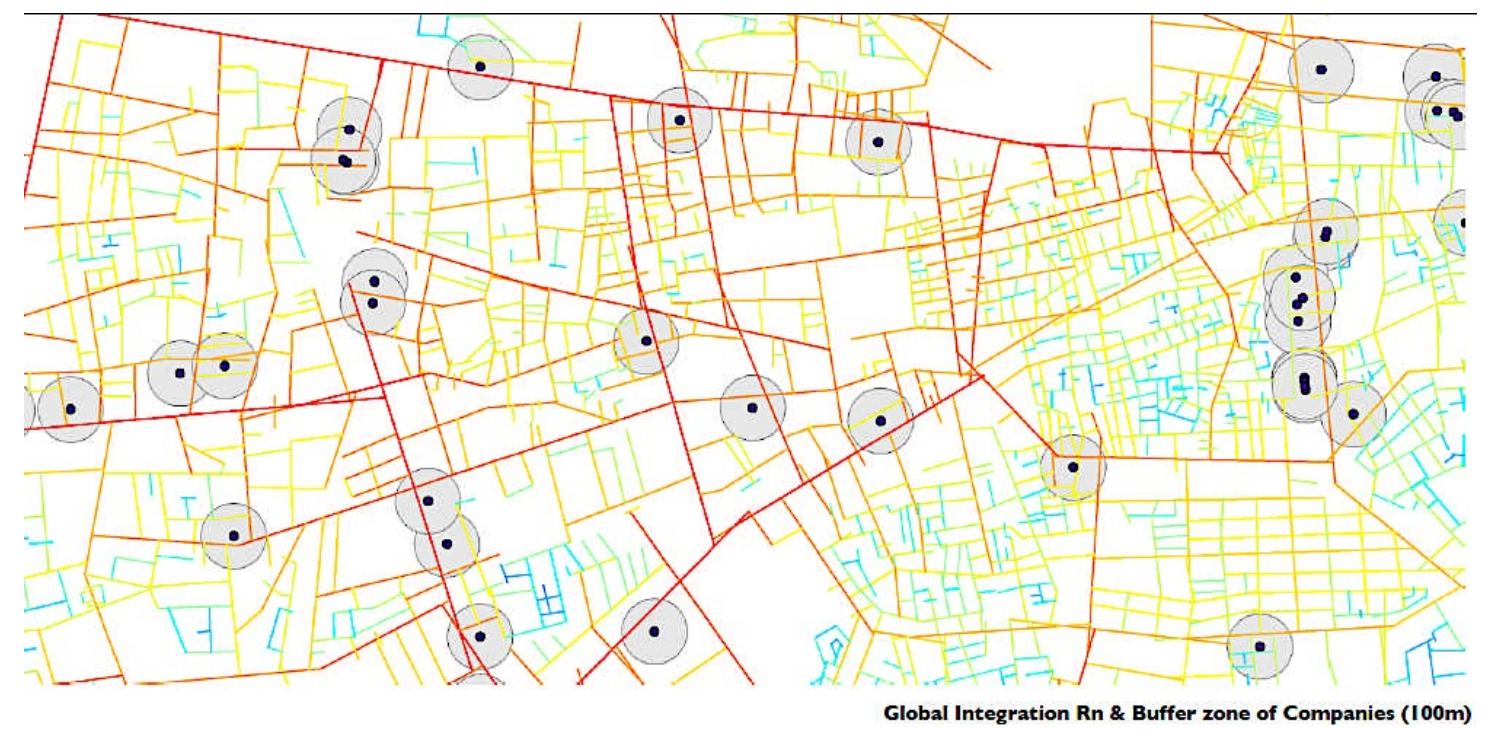

Figure 36: The buffer zone of the companies (100 m) to combine the companies' data with the Space Syntax model (Source: Authors, 2013).

Each company location was analysed with respect to the level of accessibility within the urban fabric. This resulted in clear evidence that most companies preferred highly accessible office locations along the C-Ring Road (Figure 37).

After the general assessment of the spatial integration, each company type was analysed in order to detect, which service sector is dependent on a higher accessibility within the urban structure. In spite of the fact that each sector has a similar need for highly integrated offices, telecommunication and advertising companies appear to be the most integrated at the current stage of development. Insurance, Electronic and Management companies are least integrated in the urban system in the case of this comparison (Table 11). 


\section{ArchNet}

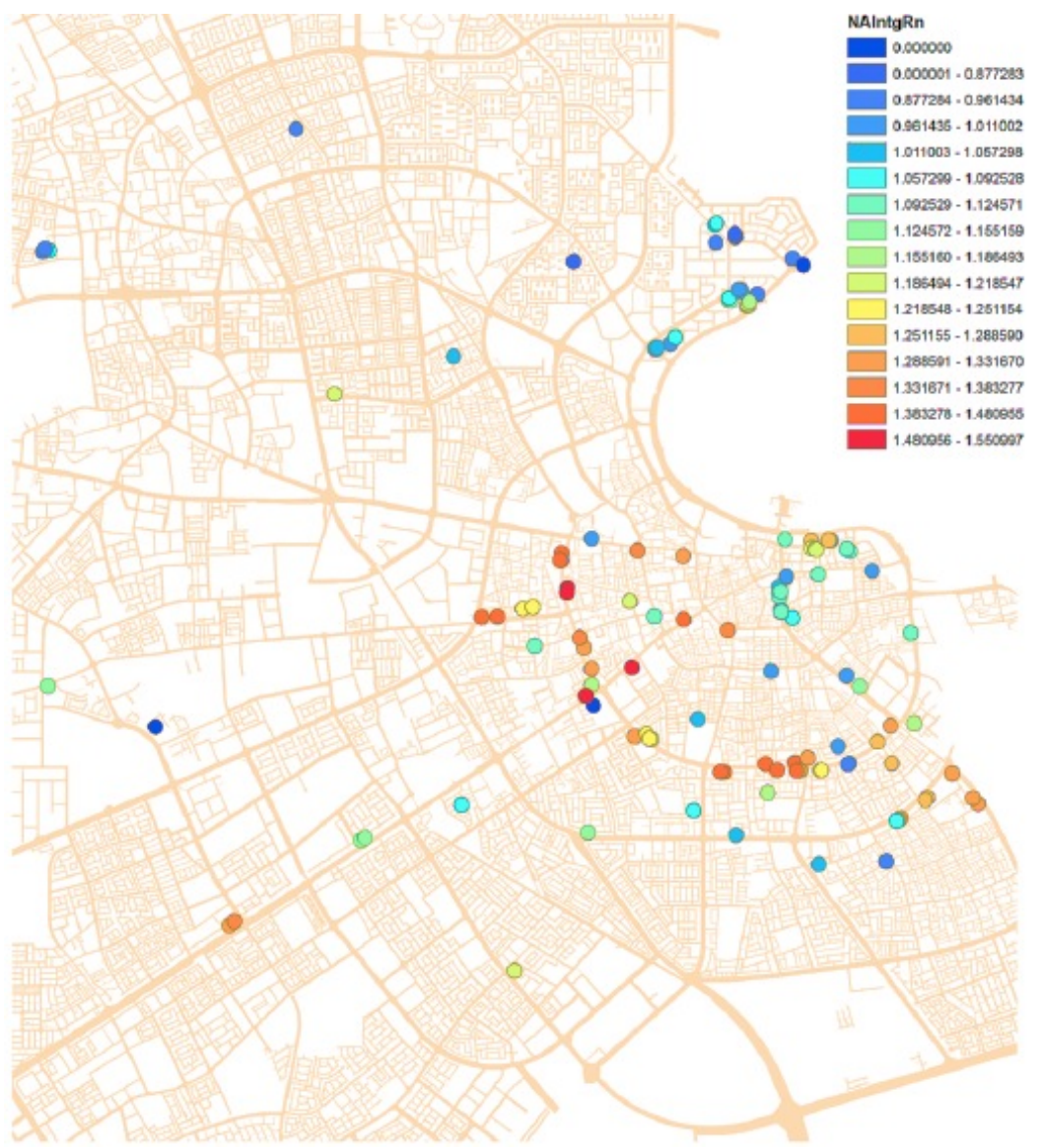

Figure 37: The spatial integration of company locations.

Highly integrated (red) to highly isolated (blue) within the urban fabric (Source: Authors, 2013).

Table 11: The companies syntactic mean values of integration at different scales (Source: Authors, 2013).

\begin{tabular}{|c|c|c|c|c|c|}
\hline Company Type & $\begin{array}{c}\text { Mean NA } \\
\text { Integration } \\
\text { R500 }\end{array}$ & $\begin{array}{c}\text { Mean NA } \\
\text { Integration } \\
\text { R2000 }\end{array}$ & $\begin{array}{c}\text { Mean NA } \\
\text { Integration } \\
\text { Rn }\end{array}$ & $\begin{array}{c}\text { Mean NA } \\
\text { Choice R500 }\end{array}$ & $\begin{array}{l}\text { Mean NA } \\
\text { Choice Rn }\end{array}$ \\
\hline Insurance & 1.167 & 0.969 & 1.027 & 0.883 & 0.832 \\
\hline Management/IT Consulting & 1.159 & 0.896 & 1.069 & 0.851 & 0.762 \\
\hline Electronics & 1.279 & 1.150 & 1.074 & 0.929 & 0.767 \\
\hline Logistics & 1.237 & 1.108 & 1.119 & 0.904 & 0.880 \\
\hline Law & 1.402 & 0.865 & 1.124 & 0.932 & 0.959 \\
\hline Medical \& Optical & 1.127 & 1.132 & 1.125 & 0.838 & 0.829 \\
\hline Banking/Financial & 1.240 & 1.235 & 1.157 & 0.904 & 0.915 \\
\hline Ітс & 1.259 & 1.260 & 1.167 & 0.965 & 0.962 \\
\hline Computer Hardware & 1.309 & 1.252 & 1.169 & 1.005 & 0.983 \\
\hline Machinery & 1.342 & 1.217 & 1.182 & 0.890 & 0.919 \\
\hline Architecture\&\&ngineering & 1.200 & 1.082 & 1.184 & 0.904 & 0.869 \\
\hline Vehicle Construction & 1.314 & 1.192 & 1.209 & 0.917 & 1.011 \\
\hline Chemistry\&Pharmacy & 1.291 & 1.250 & 1.210 & 0.979 & 0.941 \\
\hline Accounting & 1.193 & 1.147 & 1.222 & 0.916 & 0.950 \\
\hline Advertising\&Media & 1.178 & 1.145 & 1.233 & 0.948 & 0.886 \\
\hline Telecommunications & 1.312 & 1.352 & 1.308 & 0.877 & 1.035 \\
\hline
\end{tabular}


The main result of this study has been the recognition of a general tendency of companies to prefer the C Ring Road and Al Sadd area for their office locations. In addition to the high level of accessibility the $C$ Ring Road benefits from a public zoning regulation, which permits high-density residential and commercial developments. The former business district in Al Salata at the old city core has therefore lost its previously predominant role for the service sector. The emerging West Bay CBD cannot yet challenge the C-Ring area as main business hub due to missing infrastructure and a lower rate of accessibility.

\section{POTENTIAL BENEFICIARIES}

\section{The Public Sector in Gulf Cities}

This project is of high significance for the public sector and its urban planning authorities in the Gulf region. The appraised data will enable clear insights into how certain economic developments will reconfigure urban structures as well as how the existing urban environment is playing an important role in attracting or inhibiting the growth of knowledge economies. Thus, the advantage of an interdisciplinary project based on a holistic framework can come into play allowing planners to gain various insights and explore their own role in reconfiguring urban development paths. The main project results that are of particular interest for the public sector include:

- The needs of multi-branch companies for highly accessible and integrated business districts, which provide sufficient residences for their employees as well as amenities and services in order to attract skilled international workforce long term.

- The fragile nature of economic diversification processes in the Gulf and the high dependency on local growth.

- The long travel distances of high-income groups in order to follow up weekly activities due to a lack of land use integration.

- The perception of high-income groups regarding missing urban qualities, such as sufficient modes of transportation, lack of services and low construction quality standards of housing typologies.

- The limitations within existing public spaces, which usually do not offer diverse activities to attract various cultural groups leading to fragmentation and segregation.

- The spatial transformation of a rapidly growing city with respect to the shift of global and local accessibilities.

- The emergence of extensive linear business spines instead of main or clustered business districts.

- The missing definition of urban centres on a macro scale which is leading to continuous urban fragmentation and to the dissolution of neighbourhood centres.

As the focus of this study is on Doha, the project is of particular interest for the planning authorities in Qatar. The project was therefore developed in close cooperation with the Ministry of Municipality and Urban Panning (MMUP), particularly the Qatar National Master Plan Department. The QNMP team provided the research project with GIS data and recent planning documents. The project team presented and discussed research results at the QNMP department in West Bay.

\section{Private Sector in Doha}

The private sector can benefit from the outcomes of this research. In this respect, such a sector includes developers, architects and urban planners. Due to the rapid urban growth in recent years most experts engaged within the urban development process have recently moved to Doha in order to be engaged in large-scale projects. The rather short term stay of many 
consultants and the lack of publications regarding the city and its specific roots have led to a lack of awareness of development backgrounds and urban dynamics. Various publications and newspaper interviews were therefore disseminated during the entire research process in order to close this knowledge gap and to support a proactive discussion of how to shape the future urban environment of Doha. The main project results that are of interest for the private sector include:

- Key data and information regarding the historic evolution of Doha from a small fishing village to an emerging city.

- The analysis of public urban planning and its organization.

- An overview regarding the current cooperation between public, semi-public and private sector in the case of mega projects.

- The demands of companies regarding suitable urban environments and office space: The evaluation of interviews has led to the recognition that most advanced producer service companies prefer medium scale buildings in highly accessible locations.

- The demands of high income groups regarding housing units: Based on the questionnaires a large percentage of participants prefer to live in well serviced and well located apartment buildings instead of compounds.

- The general interest of many social groups to use outdoor spaces rather than being limited on shopping malls.

- The high need for innovative and integrated urban design.

\section{Academia Worldwide}

The academic world will benefit from this interdisciplinary research project by its attempt to comprehensively analyse complex interdependencies between fast urban growth, emerging knowledge economies and the qualities of the urban environment. The newly developed framework can be discussed on various international and regional platforms with respect to its suitability for implementation in other cities in the Gulf and worldwide. The particular approach to integrate analyses of current planning, demand-driven aspects within company networks and the various perceptions on urban spaces of a multicultural society make this project unique. Furthermore, a city is investigated, which has hardly been discussed by the international research community. Doha is one of the rare examples, where extensive urban growth is mainly driven by public investment strategies. Therefore the results of the project will be of high interest for the general international research on cities. The main project results that are of high interest for international and regional academia include:

- A newly tested framework to assess urbanism in the case of emerging cities based on Lefebvre's triadic theory of space production in order to integrate all factors defining spatial development.

- A new perspective regarding the establishment of sustainable urban structures.

- A comprehensive analysis of economic factors triggering urban transformation processes throughout the history of Doha.

- The scientific prove of how multi-branch companies use an emerging city, like Doha, to develop their business, which is primarily focused on local markets.

- The dependency of Doha on Dubai as main service hub in the region.

- The limited number of high tech companies in Doha.

- The main share of construction related businesses within the medium and high service sectors.

- The decisive role of cultural backgrounds regarding the perception of urban qualities in Doha.

- The South Asian dominance of employees within international multi-branch companies. 
- The lack of public spaces and their limited response to the needs of a multicultural society.

- The rapid spatial modification of an urban structure due to extensive urban sprawl.

- The dissolution of integrated urban centres and their replacement by fragmented clusters as well as the resulting lack of efficient urban structures (far travel distances).

- The disintegration of local neighbourhoods and the high level of spatial isolation in the case of a newly initiated Central Business District due to the lack of sufficient infrastructural networks.

- The emergence of an improvised business spine along a main urban growth corridor.

\section{CONCLUSION}

Due to the interdisciplinary nature of the project various recommendations can be made for future research attempts in analysing emerging cities and their complex situation between fast growth, economic diversification and urban qualities. In order to understand the interdependencies between rapid urban growth, economic transformation and urban qualities a research framework was implemented following the theory of space production. Thus, the project did not focus on visible spatial developments only but also the various factors impacting urban structures. While functional qualities can be assessed by analysing data, such as land use integration, urban qualities are mainly defined by the way inhabitants perceive their surroundings. The particular dynamics in emerging cities and their vast migration patterns have led to an urgent need in understanding missing urban qualities in order to initiate consolidated growth within established networks.

The case study Doha has proven to be a valid choice due to its emerging significance in the region and its rather unique development conditions. The recent evolution of Doha has been mainly affected by a new public development vision and parallel public investment strategies in key economic sectors, such as trade, education and tourism (sports events). Subsequently, the city has entered a new and rather distinguished stage of urban development during the beginning of the new millennium. Capacity deficits within planning departments in combination with the unexpected exponential urban growth have led to uncoordinated and fragmented development patterns, mainly defined by mega projects.

The initiated construction boom has attracted a large quantity of international companies. Thus, a large percentage of the present service sector in Qatar is depending on an expanding market within construction related sectors. Furthermore, many companies have only relocated project offices to Doha, while headquarters still operate from other locations, particularly from the Emirate of Dubai due to its proximity and already established free zones. Companies within these newly emerging advanced producer service sectors need a high diversity of accessible office locations in Doha. Due to the extensive urban sprawl in the West of the city, the most integrated and accessible urban area has shifted from Al Salata and A- Ring Road to Al Sadd and C- Ring Road. The newly built West Bay business centre lacks accessibility as well as infrastructure and therefore lacks attractiveness for most companies. Consequently, he C- Ring Road has recently emerged as the main central business spine of Doha.

In general, the urban area of Doha has doubled since 2003. This exponential growth of the overall urban area was mainly caused by urban sprawl. The fast increase of urban sprawl was mainly fuelled by extensive low rise compound developments for international workforce. Subsequently, most residential districts for high income groups within Doha's urban periphery are currently undersupplied regarding services and facilities. This has resulted in long travel distances (such as an average of $7 \mathrm{~km}$ from residences to grocery stores). Moreover, favoured public spaces are limited to a rather small number considering the size of the city and number of inhabitants (less than 2 square meters of green space per inhabitant). Based on various 
observation studies there is a general lack of integrating the various cultural needs of local and migrant communities.

Traffic congestion, diverse housing options, lack of construction standards and missing social services have been identified as the key challenges to establish liveability in Doha. Fast urban growth has led to the need for the extension of highway networks, which has led to the disintegration of local districts and their urban centres. The missing development of integrated urban centres has thus led to a high dependency on shopping malls and thus the experience of Doha as a highly replaceable city by a majority of migrants. Place making and the creation of functioning neighbourhoods are thus further key challenges to attract the creative class to settle in Doha long term and to establish a diversified economy.

\section{ACKNOWLEDGEMENTS}

The material in this paper is part of a longitudinal 3-year research project funded by Qatar National Research Fund (QNRF/NPRP 09-1083-6-023). Thanks are due to Fatma Khalfani, Ahood Al-Maimani, Velina Mirincheva and Arwa Mamlouk for their contribution to various surveys and research activities.

\section{REFERENCES}

Adham, K. (2008). Rediscovering the Island: Doha`s Urbanity from Pearls to Spectacle. In: Y. Elsheshtawy, (ed.), The Evolving Arab City, London: Routledge.

Al Buainain, F. (1999). Urbanisation in Qatar: a Study of the Residential and Commercial Land Development in Doha City, 1970 - 1997. Salford: University of Salford.

Alderson, A. and Beckfield, J. (2007). Globalisation and the World City System: Preliminary Results from Longitudinal Data Set. In: P. Taylor, B. Derudder, P. Saey and F. Witlox, (eds.), Cities in Globalization, London: Routledge. 21-35.

Altman, I. (1975). The Environment and Social Behavior. Monterey, CA: Brookes/Cole.

Beaverstock, J., Smith, R. and Taylor, P. (2000). World City Network: A New Metageography?. Annals of the Association of American Geographers, 90 (1), 123-134.

Burgess, E. W. (1925). The Growth of the City. In: The City: R.E. Park, E. W. Burgess, and R. D. McKenzie, (eds.), Suggestions of Investigation of Human Behavior in the Urban Environment, IL: University of Chicago Press, 47-62.

Castells, E. (2004). The Relationship between Globalization and Cultural Identity in the Early 21st Century. Barcelona: Forum 2004.

Castells, M. (1989). The Informational City: Information Technology, Economic Restructuring and the Urban Regional Process. Oxford: Basil Blackwell.

Cohen, R. (1981). The New International Division of Labor, Multinational Corporations and Urban Hierarchy. In: M. Dear, A. Scott, (eds.), Urbanization and Urban Planning in Capitalist Society, London: Methuen, 287-317.

Conventz, S., Thierstein, A., Wiedmann, F. and Salama, A. M. (2015). When the Oryx takes off: Doha a new rising knowledge hub in the Gulf-region?. International Journal of Knowledge-Based Development , 6(1), 65-82.

Florida, R. (2002). The Rise of the Creative Class: And how it's transforming work, leisure, community and everyday life. New York: Perseus Book Group.

Fox, J. W., Mourtada-Sabbah, N., and Al-Mutawa, M. (2006). Globalization and the Gulf. New York: Routledge.

Friedmann, J. (1986). The World City Hypothesis. Development and Change, 17 (1), 69-83. 
Friedmann, J. and Wolff, G. (1982). World City Formation: an Agenda for Research and Action. International Journal of Urban and Regional Research, 6(1), 309-344.

GSDP - General Secretariat of Development Planning (2008). Qatar National Vision 2030. Doha: Gulf Publishing and Printing Company.

GSDP - General Secretariat of Development Planning (2009). Advancing Sustainable Development, Qatar's Second Human Development Report. Doha: Gulf Publishing and Printing Company.

GSDP - Qatar General Secretariat of Development Planning (2011). National Development Strategy 2011 - 2016. Doha: Gulf Publishing and Printing Company.

Hillier, B. (1999). Space is the Machine: A Configurational Theory of Architecture. Cambridge: Cambridge University Press.

Lefebvre, H. (1991). The Production of Space. Oxford: Blackwell.

Lüthi, S., Thierstein, A., Goebel, V. (2010): Intra-firm and extra-firm linkages in the knowledge economy: the case of the emerging mega-city region of Munich, Global Networks, 10 (2010) 114-137.

Lynch, K. (1960). The Image of the City. Cambridge, MA: MIT Press.

Malecki, E. (2000). Creating and Sustaining Competitiveness: Local Knowledge and Economic Geography. In: J.R. Bryson, P.W. Daniels, N. Henry, J. Pollard, (eds.), Knowledge, Space, Economy. London, 103-119.

Mirincheva, V., Wiedmann, F. and Salama, A. M. (2013). The spatial development potentials of business districts in Doha: the case of the West Bay. Open House International, 38(4), 16-26.

Rapoport, A. (1990). The Meaning of the Built Environment: A Non-verbal Communication Approach. Tucson: The University of Arizona Press.

Rapoport, A. (2005). Culture, Architecture, and Design. Chicago, IL: Locke Science Publishing.

Salama, A. M. (2011). Identity flows, the Arabian Peninsula, emerging metropolises. In: Atlas Architectures of the 21st Century - Africa and Middle East. Madrid: Fundacion BBVA, 170-221.

Salama, A. M. (2012). Architectural identity demystified: visual voices from the Arab world. In: p. Emmons, J. Lomholdt and J. Hendrix, (eds.), The Cultural Role of Architecture. London: Routledge.

Salama, A. M. (2013). Manufacturing the image of Doha: from the public face of architecture to the printed media. Open House International, 38(4), 6-15.

Salama, A. M. (2014a). Media coverage and users' reactions: Al Azhar Park in Cairo re-examined. In: W. F. E. Preiser, A. T. Davis, A. M. Salama and A. Hardy, (eds.), Architecture Beyond Criticism. 91-103. London: Routledge.

Salama, A. M. (2014b). Interrogating the practice of image making in a budding context. Archnet-IJAR: International Journal of Architectural Research. 8(3),74-94.

Salama, A. M. and Azzali, S. (2015). Examining attributes of urban open spaces in Doha. Proceedings of the ICE - Urban Design and Planning, 168(2), 75-87.

Salama, A. M. and Wiedmann, F. (2013a). Demystifying Doha: On Architecture and Urbanism in an Emerging City. Surrey: Ashgate Publishing Limited.

Salama, A. M. and Wiedmann, F. (2013b). The production of urban qualities in the emerging city of Doha: urban space diversity as a case for investigating the 'lived space'. Archnet-IJAR: International Journal of Architectural Research 7(2), 160-172.

Salama, A. M. and Wiedmann, F. (Eds.) (2013c). Unveiling urban transformations in the Arabian Peninsula: dynamics of global flows, multiple modernities, and people-environment interactions. Special issue, Open House International, 38(4), 1-114.

Salama, A. M. and Wiedmann, F. (2013d). Evolving urbanism of cities on the Arabian Peninsula. Special issue, Open House International, 38 (4). pp. 4-5.

Salama, A. M., Al-Maimani, A. and Khalfani, F. (2013). Understanding inhabitants' spatial experience of the city of Doha through cognitive mapping. Open House International, 38(4), 37-46. 
Salama, A. M., Wiedmann, F. and Thierstein, A. (2013). The impact of economic diversification on urban morphologies in Doha: an interdisciplinary assessment. Qatar Foundation Annual Research Forum Proceedings 2013, SSHP-017.

Sanderock, L. (1998). Towards Cosmopolis: Planning for Multicultural Cities. Chichester: John Wiley \& Sons.

Sassen, S. (1991). The Global City. New York, London, Tokyo. Princeton: Princeton University Press.

Savitch, H. (2002). Cities in the International Marketplace, New Jersey.

Simon, D. (1995). The World City Hypothesis: Reflections from the Periphery. In: P. Knox and P. Taylor, (eds.) World Cities in a World-system, Cambridge: Cambridge University Press. 132-155.

Stillerman, J. (2006). The politics of space and culture. Qualitative Sociology, 29, 507-530

Taylor, P. J. (2003). World City Network: A Global Urban Analysis. London, Routledge.

Wiedmann, F. (2012). Post-oil Urbanism in the Gulf: New Evolutions in Governance and the Impact on Urban Morphologies. Stuttgart: SVH Verlag.

Wiedmann, F., Mirincheva, V. and Salama, A. M. (2013). Urban reconfiguration and revitalisation: public mega projects in Doha's historic centre. Open House International, 38(4), 27-36.

Wiedmann, F. and Salama, A. M. (2013). From pre-oil settlement to post-oil hub: the urban transformation of Doha. Archnet-IJAR: International Journal of Architectural Research, 7(2), 146-159.

Wiedmann, F., Salama, A. M. and Thierstein, A. (2012). Urban Evolution of the City of Doha: The Impact of Economic Transformations on Urban Structures. METU-JFA, Journal of the Faculty of ArchitectureMiddle East Technical University, 29(2), 35-61.

Wiedmann, F. and Salama, A. M. and Mirincheva, V. (2014). Sustainable Urban Qualities in the Emerging City of Doha. Journal of Urbanism, 7(1). 62-84.

Witlox, F. and Derudder, B. (2007). Airline Passenger Flows through Cities - Some New Evidence. In: P. Taylor, B. Derudder, P. Saey and F. Witlox, (eds.), Cities in Globalization, London: Routledge. 21-35.

\title{
AUTHORS
}

\section{Ashraf M. Salama}

Professor, Dr.

University of Strathclyde, Department of Architecture

ashraf.salama@strath.ac.uk

Florian Wiedmann

Post-doc, Dr.

University of Strathclyde, Department of Architecture

florian.wiedmann@strath.ac.uk

\author{
Alain Thierstein \\ Professor, Dr. \\ Technische Universität München, Department of Architecture \\ thierstein@tum.de
}

\section{Sven Conventz}

Research Associate, Dr.

Technische Universität München, Department of Architecture

conventz@tum.de

\section{Wafa Al Ghatam}

Research Assistant, MSc

Technische Universität München, Department of Architecture

ucftwal@ucl.ac.uk 